Aus dem Institut für Neuro- und Sinnesphysiologie

(Prof. Dr. rer. nat. S.O. Rizzoli)

im Zentrum Physiologie und Pathophysiologie

der Medizinischen Fakultät der Universität Göttingen

\title{
Analyse funktioneller und struktureller Mitochondrienveränderungen in einem Maus-Modell für das Rett-Syndrom mittels 2-Photonen-Mikroskopie
}

\author{
INAUGURAL-DISSERTATION \\ zur Erlangung des Doktorgrades \\ der Medizinischen Fakultät der \\ Georg-August-Universität zu Göttingen
}

vorgelegt von

Dörthe Friederike Bebensee

aus

Hameln 
Dekan:

Referent:

Korreferent:
Prof. Dr. rer. nat. H. K. Kroemer

Prof. Dr. rer. nat. M. Müller

Prof. Dr. rer. nat. S. Jakobs

Datum der mündlichen Prüfung: 25.01.2017 
Hiermit erkläre ich, die Dissertation mit dem Titel "Analyse funktioneller und struktureller Mitochondrienveränderungen in einem Maus-Modell für das RettSyndrom mittels 2-Photonen-Mikroskopie" eigenständig angefertigt und keine anderen als die von mir angegebenen Quellen und Hilfsmittel verwendet zu haben.

Göttingen, den 05.08.2016 


\section{Inhaltsverzeichnis}

$1 \quad$ Einleitung ....................................................................................................................................... 1

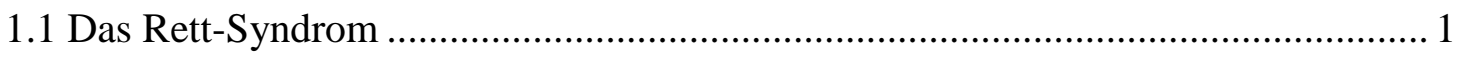

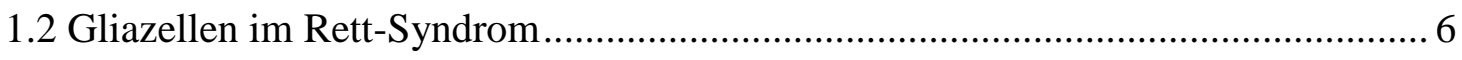

1.3 Mitochondrien-Veränderungen im Rett-Syndrom ............................................ 8

1.4 Optische Darstellung und Analyse der Mitochondrien mithilfe von JC-1 ............. 12

1.5 Ziele der Arbeit................................................................................................ 14

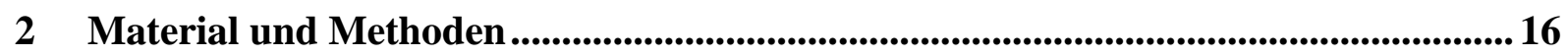

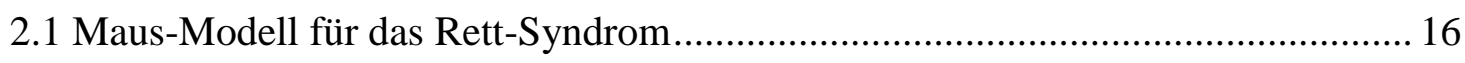

2.2 Präparation und Herstellung der Zellkultur ...................................................... 17

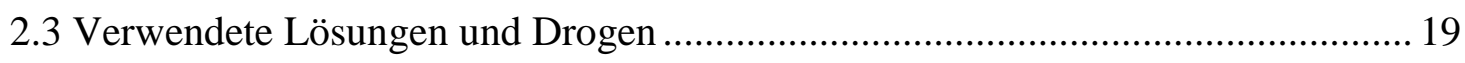

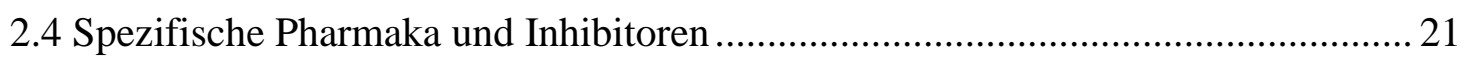

2.5 Aufbau des Messgerätes: 2-Photonen-Laserscanning-Mikroskop (TPLSM)......... 23

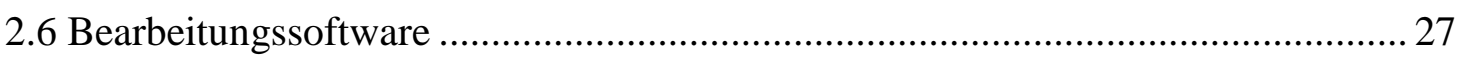

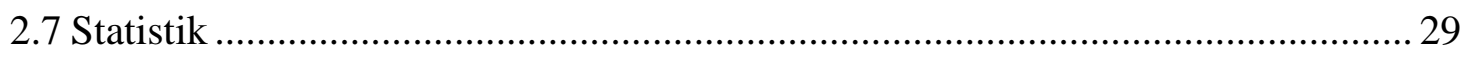

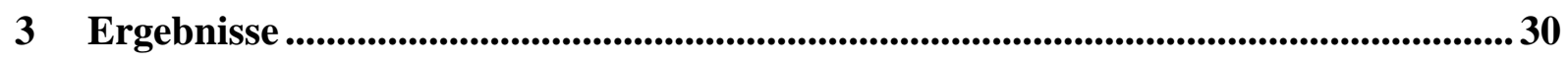

3.1 Kalibrierung des 2-Photonen-Laser-Scanning-Mikroskops ................................. 30

3.2 Veränderungen von Morphologie, Masse und Membranpotential der Mitochondrien von MeCP2-defizienten Mäusen .................................................... 36

3.3 Modulation der mitochondrialen Eigenschaften durch Radikalfängerbehandlung 43

3.4 Einfluss verschiedener mitochondrialer Inhibitoren.......................................... 44

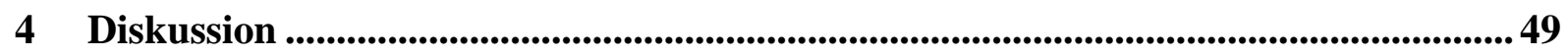

5 Zusammenfassung und Ausblick ..............................................................................56

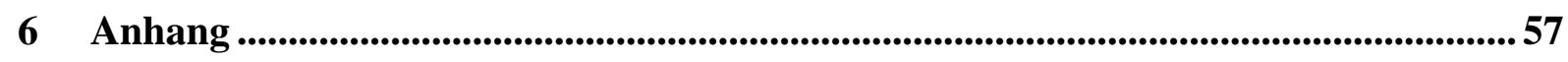

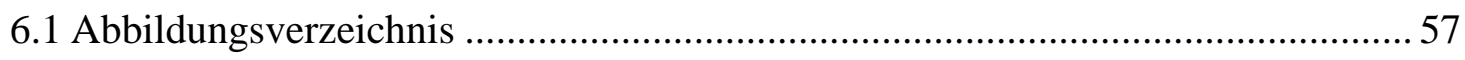

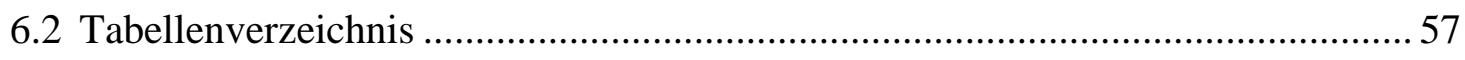

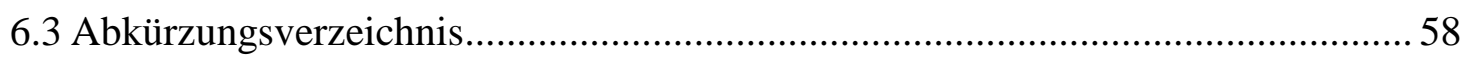

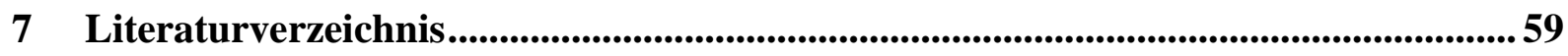




\section{$1 \quad$ Einleitung}

\subsection{Das Rett-Syndrom}

Das Rett-Syndrom ist eine $\mathrm{X}$-chromosomal dominant vererbte Erkrankung aus dem neurologischen Fachgebiet, die zu einer Entwicklungsstörung von Psyche und Motorik der Betroffenen führt. Charakteristisch für diese Erkrankung sind autistische Züge und Demenz, Apraxie vom bereits Erlernten, der Verlust der Gesichtsmimik, stereotype Handbewegungen, schwere Atemstörungen sowie Epilepsie. In der Regel betrifft die Erkrankung nur Mädchen (Hagberg et al. 1983; Rett 1966).

Die Krankheitshäufigkeit liegt bei 1:10.000 bis 1:15.000 weiblichen Geburten (Hagberg 1985). Für männliche Patienten ist die Mutation letal oder es kommt zu schwerer neonataler Enzephalopathie und infolgedessen meist zum Tod innerhalb des ersten Jahres (Villard 2007). Auch wenn das Rett-Syndrom eine seltene Erkrankung ist, bleibt es nach dem Down-Syndrom die zweithäufigste genetische Ursache für geistige Behinderung bei Mädchen. Dies trifft auf 25-30 \% der Fälle genetisch bedingter mentaler Retardierung zu (Hagberg 1985). Das familiäre Wiederauftreten der Erkrankung ist selten. Im Falle von Rett-Patientinnen mit einer MECP2-Mutation, die Schwestern mit Entwicklungsschwierigkeiten haben, ist meist eine andere Ursache zu finden (Gill et al. 2003).

Im Jahr 1966 beobachtete der österreichische Kinderarzt Andreas Rett $(* 1924, \dagger 1997)$ die ersten Fälle der Erkrankung, die er als ,eigenartiges hirnatrophisches Syndrom bei Hyperammonämie“ beschrieb (Rett 1966). Dieses Krankheitsbild wurde später als Rett-Syndrom bekannt. Zwei Jahrzehnte später wurden weitere Fälle des RettSyndroms von dem schwedischen Neurologen Bengt Hagberg beschrieben. Er beobachtete 35 Mädchen in Schweden, Portugal und Frankreich mit den klassischen von Rett beschriebenen phänotypischen Symptomen (Hagberg et al. 1983). Die Ursache der Erkrankung war bis zu diesem Zeitpunkt unbekannt. Im Jahr 1999 kam es dann zu einem Durchbruch in der Rett-Syndrom-Forschung. Es wurde eine spontane Mutation des MECP2-Gens (X-linked methyl-CpG-binding protein 2-Gen) auf dem langen Arm des X-Chromosoms (Lokus Xq28) nachgewiesen (Amir et al. 1999). Zu 
99,5\% handelt es sich dabei um eine spontane de-novo-Mutation des zumeist paternalen X-Chromosoms (Trappe et al. 2001). Bei den Mutationen kann es sich um non-sense, missense oder frameshift-Mutationen handeln (Dragich et al. 2000). MeCP2 ist ein transkriptionaler Repressor, der durch Bindung an methylierte CytosinGuanin(CG)-Dinukleotide in einigen Promotor-Genen eine Chromatinverdichtung verursacht und letztendlich zum Ausschalten des Gens führt (Sanmann et al. 2012). MeCP2 agiert aber auch als transkriptionaler Aktivator (Chahrour et al. 2008).

Die MECP2-Mutation ist die klassische Entstehungsvariante des Rett-Syndroms. Es gibt jedoch auch klinische Rett-Syndrom-Fälle, in denen keine Mutation von MECP2 nachgewiesen werden konnte, so dass davon auszugehen war, dass weitere genetische Varianten vorliegen könnten (Weaving et al. 2004). Eine weitere bekannte Variante beruht auf einer Mutation im CDKL5-Gen (cyclin-dependent kinase-like 5-Gen). Die Mutation befindet sich auf dem kurzen Arm des X-Chromosoms (Lokus Xp22). Die Symptome entsprechen dem der häufigen oben erstbeschriebenen Rett-SyndromVariante. Allerdings treten bei CDKL5-Mutationen die ersten Symptome früher auf, und die Mädchen entwickeln eine starke Prävalenz zum Auftreten von Epilepsie. In molekularbiologischen Versuchen hat sich gezeigt, dass dabei kein Zusammenhang zwischen der MECP2-Expression und der CDKL5-Gen-Expression existiert (Mari et al. 2005). Im Rahmen dieser Arbeit gehe ich nur auf die deutlich häufigere Variante des Rett-Syndroms ein, die auf der MECP2-Mutation beruht.

Das Rett-Syndrom gilt als eine postnatal progrediente neurologische Entwicklungsstörung, die sich in der frühen Kindheit der erkrankten Mädchen präsentiert. Es existiert ein weites Spektrum an klinischen Manifestationen. Der Zeitpunkt des erstmaligen Auftretens von Symptomen und die Schwere der Erkrankung können sehr unterschiedlich sein. Daher sollte die Feststellung einer MECP2-Mutation als unterstützende Diagnostik betrachtet werden, um atypische Fälle zu diagnostizieren. Als grundlegende Diagnosestellung sollte weiterhin die klinische Ausprägung herangezogen werden.

Es folgt nun eine allgemeine Einteilung der klassischen Rett-Syndrom-Variante, die typischerweise in vier Stadien verläuft (Hagberg und Witt-Engerstrom 1986; siehe dazu Abbildung 1): 
1. Stadium des Entwicklungsstillstands (6.-18. Lebensmonat)

2. Phase der schnellen Regression (innerhalb des 1.-3. Lebensjahres)

3. Plateauphase, pseudostationäre Phase (innerhalb des 2-10. Lebensjahres)

4. Phase des motorischen Verfalls (ab dem 10. Lebensjahr)

Zunächst erfahren die Neugeborenen bis zu ihrem 6.-18. Lebensmonat eine scheinbar normale psychomotorische Entwicklung. Die Mädchen lernen laufen und manche erwerben ebenfalls ihre ersten sprachlichen Fähigkeiten (Chahrour und Zoghbi 2007). Erste Anzeichen des Rett-Syndroms präsentieren sich durch die Verzögerung des Kopfwachstums, welche im zweiten Lebensjahr zur Mikrozephalie führt. Gleichzeitig kommt es zur generellen Wachstumsverzögerung bzw. -stillstand. Begleitend kann es zu einem Gewichtsverlust und einer Schwäche der Körperhaltung kommen, die durch eine muskuläre Hypotonie hervorgerufen wird. Die Patientinnen vermeiden Blickkontakt. Kommunikation findet seltener statt. Das Interesse zum Beispiel am altersgemäßen Spielen geht verloren (Chahrour und Zoghbi 2007).

Im zweiten Stadium, der Regression, handelt es sich meist um eine schnell abbauende Entwicklung. Im Alter zwischen ein und drei Jahren macht sich ein starker Entwicklungsrückgang bemerkbar. Es zeigen sich autistische Züge. Diese äußeren sich beispielsweise in vermindertem Blickkontakt, fehlender Reaktion bei Ansprache, einer ausdruckslosen Gesichtsmimik, Gleichgültigkeit gegenüber der Umwelt, der verminderten Kontaktaufnahme und einem selbstverletzenden Verhalten (Chahrour und Zoghbi 2007; Nomura und Segawa 2005). Gleichzeitig setzt eine fortschreitende Demenz ein, die sich unter anderem durch Verlust der sprachlichen Fähigkeiten zeigt. Auch der gezielte Einsatz der Hände lässt nach. Es folgen stereotype Bewegungsmuster der Hände, die sich in dem typischen „Händewaschen“, Klatschen oder Knetbewegungen zeigen (Monteiro et al. 2014). Auffällig werden die Patientinnen zudem durch deutliche respiratorische Symptome, die sich meist durch ausgeprägte Atemunregelmäßigkeiten mit Apnoe-Episoden äußern (Chahrour und Zoghbi 2007; Williamson und Christodoulou 2006).

In der pseudostationären Phase (Phase 3) stabilisieren sich einige der Symptome. Motorisch zeigen sich weiterhin die stereotypen Handbewegungen. Es wird eine hinzukommende Gangataxie und das Auftreten von epileptischen Anfällen 
beschrieben (Monteiro et al. 2014). Begleitend ändert sich die Verhaltensweise. Die Patientinnen scheinen ängstlicher, sie fangen an nachts zu schreien oder laut zu lachen. Ebenfalls wurde Zähneknirschen beobachtet (Mount et al. 2001).

In Phase 4 tritt Mobilitätsverschlechterung bzw. -verlust ein. Der Wachstumsrückstand persistiert, die körperliche Schwäche nimmt zu, es bildet sich eine Skoliose der Wirbelsäule. Im jugendlichen Alter sind einige Patientinnen körperlich so beeinträchtigt, dass sie auf einen Rollstuhl angewiesen sind. Hingegen treten die epileptischen Anfälle seltener auf und können besser kontrolliert werden (Chahrour und Zoghbi 2007).

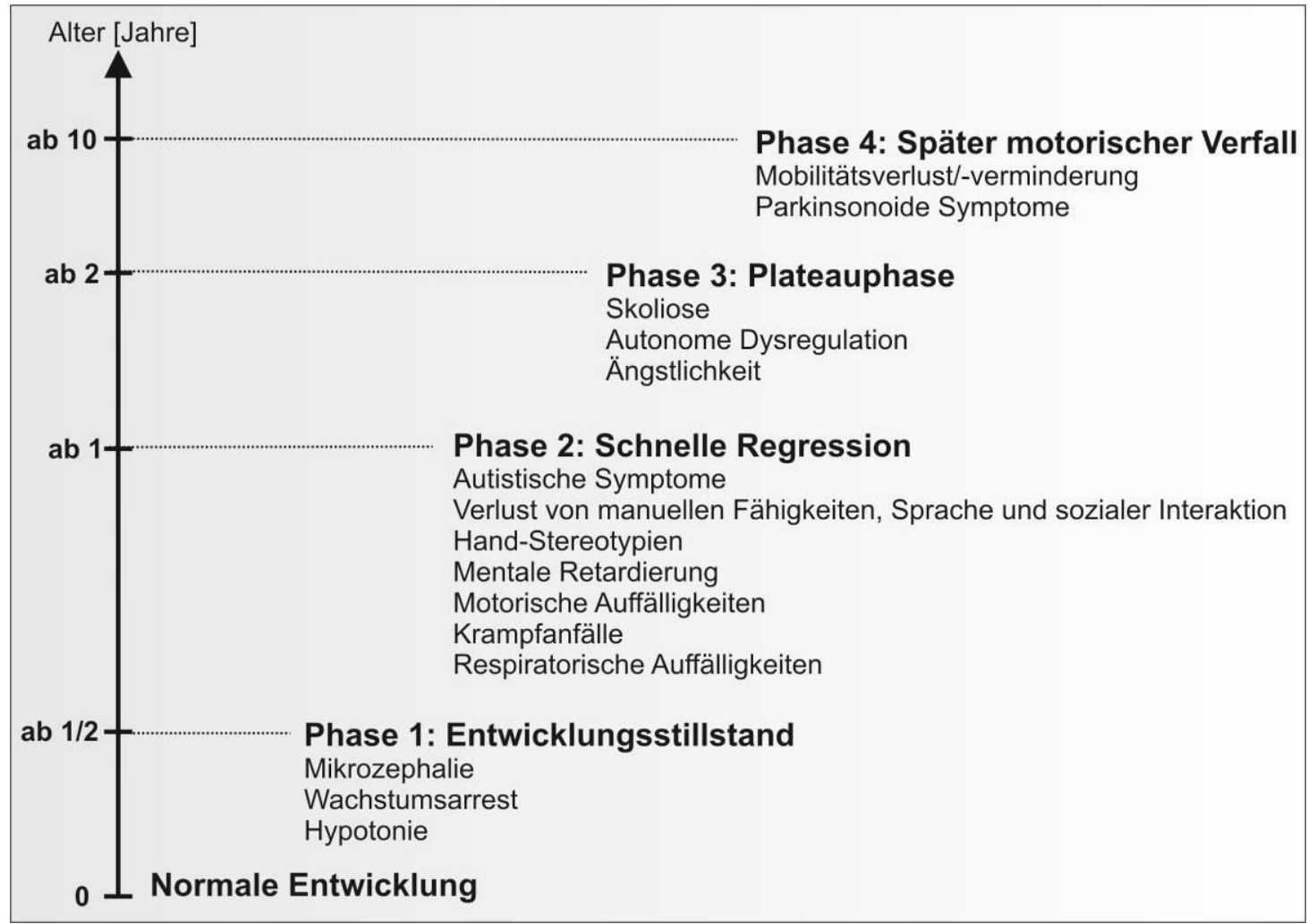

Abbildung 1: Entwicklungsstadien und klinische Symptome des Rett-Syndroms Nach einer zunächst normalen Entwicklung der Rett-Syndrom-Patientinnen beginnt das Stadium des Entwicklungsstillstands ab dem 6.-18. Lebensmonat. Es folgt die Phase der schnellen Regression, in der bereits erlernte Fähigkeiten wieder verloren gehen (1-3. Lebensjahr). Der pseudostationären Plateauphase (2.-10. Lebensjahr) schließt sich ungefähr ab dem 10. Lebensjahr die Phase des motorischen Verfalls an. (modifiziert nach Chahrour und Zoghbi 2007, S. 423) 
Die Lebenserwartung der Rett-Patientinnen ist je nach Ausprägung der Symptome unterschiedlich. Wenn die Symptome ein Plateau erreicht haben, leben trotz körperlicher Schwäche einige Patientinnen bis zum 70. Lebensjahr (Hagberg et al. 2001). Die jährliche Sterberate liegt bei 1,2 \%, wovon $48 \%$ bereits geschwächte Personen sind. Oft tritt der Tod der Erkrankten durch respiratorische Insuffizienz, akute Infektionen oder plötzlichem Tod in der Nacht ein (Hagberg et al. 2001; Kerr et al. 1997).

Bisher gibt es keine kausale Therapie des Rett-Syndroms. Je nach Ausprägung des Phänotyps kann unterstützend beispielsweise mit Physiotherapie, Ergotherapie, Musiktherapie und tiergestützter Therapie gearbeitet werden (Lotan 2007). Ebenfalls sollte eine psychosoziale Betreuung der Familie erfolgen (Weaving et al. 2005). Aufgrund des hohen Energiebedarfs der Patientinnen stellt eine hochkalorische Ernährung einen wichtigen Therapiepunkt dar (Chapleau et al. 2013).

Die Forschung arbeitet weiterhin an zwei weiteren wichtigen Eckpfeilern: Der pharmakologischen Therapie u.a. mit dem Ziel, Signalwege zu reaktivieren sowie durch genetische Manipulation das MECP2-Gen wieder zu exprimieren (Banerjee et al. 2012). Es gibt zudem weitere Versuchsansätze wie beispielsweise die Gabe von humanem insulin-like growth factor 1 (IGF-1) in einem Maus-Modell zur Besserung der Motorik, der Herz- und Atemfrequenz (Castro et al. 2014; Tropea et al. 2009). Diese Versuchsansätze haben sich auch in einer weiteren Studie bestätigt: Rekombinantes IGF-1 wurde in einer Phase I-Studie eingesetzt und verbesserte die Atmungs- und Verhaltensauffälligkeiten. Er wurde zudem gut von den Rett-SyndromPatientinnen toleriert (Khwaja et al. 2014).

Ebenfalls kommt die Applikation von L-Carnitin zur Verbesserung des Schlafs und der Kommunikationsfähigkeiten zum Einsatz (Ellaway et al. 2001). Die Gabe von Naltrexon verbesserte die respiratorische Symptomatik, wirkte sich allerdings negativ auf die Motorik aus und beschleunigte die Krankheitsentwicklung (Percy et al. 1994). Der Einsatz des Vitamins Folsäure (5-Methyltetrahydrofolsäure) zeigte einen geringen Effekt auf Rett-Syndrom-Patientinnen, insbesondere denen, die zur Epilepsie neigten und widerstandfähig gegenüber antiepileptischen Medikamenten waren (Ormazabal et al. 2005). Weitere pharmakologische Therapien beinhalteten die Gabe von 
Magnesium, um Hyperventilation zu reduzieren (Egger et al. 1992), und die Verabreichung von Melatonin zur Verbesserung der Schlafunregelmäßigkeiten (McArthur und Budden 1998).

In der Erythrozytenmembran von Rett-Syndrom-Patientinnen wurden signifikante Fettsäureabnormalitäten registriert. Durch den therapeutischen Einsatz von ungesättigten Omega-3-Fettsäuren, die zum Beispiel in Fischöl vorzufinden sind, ließen sich diese Störungen teilweise verbessern (Signorini et al. 2014). Derselbe Behandlungsansatz wirkte sich auch positiv auf die biventrikuläre myokardiale systolische Leistung aus (Maffei et al. 2014).

Ein weiterer Versuchsansatz ist das Medikament EPI-743. Patientinnen, die in einer Phase II-Studie mit EPI-743 behandelt wurden, zeigten eine statistisch signifikante Zunahme des Kopfumfangs. Die Wirkung dieses Medikaments beruht auf dem Einfluss auf verschiedene Komponenten, die eine Rolle in der Bildung von oxidativem Stress im Rett-Syndrom spielen (Edison Press Release 2014).

Zusammenfassend zeigt sich, dass die pharmakologische Therapie die Lebensqualität steigern kann, jedoch meist nur einzelne Symptome verbessert, aber keine signifikanten Veränderungen des gegenwärtigen Krankheitsstatus hervorruft. Um die Krankheit kausal zu therapieren, fehlen weitere Erkenntnisse in der molekularen bzw. genetischen Forschung (Chapleau et al. 2013).

\subsection{Gliazellen im Rett-Syndrom}

Bei Erkrankten mit Rett-Syndrom zeigt sich ungefähr ab der sechsten Woche post partem eine neuropathologische Symptomatik (Chen et al. 2001; Guy et al. 2001). In Autopsie-Untersuchungen von menschlichen Gehirnen post mortem wurde eine reduzierte Hirngröße sowie ein vermindertes Hirngewicht und -volumen beobachtet. Auf zellulärer Ebene stellten sich die Somata von Neuronen in Abwesenheit von $\mathrm{MeCP} 2$ verkleinert dar. Ebenfalls war die Neuronendichte vermindert, aber es zeigten sich keine Anzeichen deutlicher Neurodegeneration (Armstrong 2005). 
Bisher war davon ausgegangen worden, dass lediglich neuronale Fehlfunktionen auf die Rett-Syndrom-Symptomatik zurückzuführen sind. Dies wurde deutlich durch verminderte Komplexizität der dendritischen Verästelung, die veränderte Anordnung von dendritischen Spines und einer verminderten synaptischen Plastizität (Belichenko et al. 2009; Landi et al. 2011; Moretti et al. 2006).

Die Gliazellen galten dabei vor allem als der Nervenzellen umgebendem Stützapparat. Es stellte sich jedoch heraus, dass neben Neuronen auch Gliazellen MeCP2 exprimieren und somit ebenfalls von der MECP2-Mutation betroffen sind (Ballas et al. 2009). Auch viele weitere neurologische(-degenerative) Erkrankungen, wie beispielsweise Amyotrophe Lateralsklerose (ALS), Spinozerebelläre Ataxie (SCA), Morbus Huntington und Multisystematrophie (MSA) zeigen pathogenetische Zusammenhänge mit Gliazellen. Hierbei rufen mutierte Stoffwechselprodukte in Astrozyten und Mikroglia einen Defekt von umliegenden Neuronen hervor (Lobsiger und Cleveland 2007). Zumindest zwei Typen von Gliazellen, nämlich Astrozyten und Mikroglia, tragen zur Krankheitsprogression des Rett-Syndroms bei, indem sie einen negativen Effekt auf Nervenzellen ausüben. Dabei agieren sie unabhängig von den Neuronen (Derecki et al. 2012; Lioy et al. 2011; Nguyen et al. 2012; Nguyen et al. 2013).

Auch Oligodendrozyten, die dritte Form von Gliazellen, zeigten in Versuchen einen gering messbaren Einfluss auf den Fortschritt der Erkrankung (Nguyen et al. 2013). In einem Maus-Modell für das Rett-Syndrom der Zuchtlinie B6.129P2(C)-Mecp $2^{\text {tm-1-1Bird }}$ (Guy et al. 2001) mit vollständig MeCP2-defizienten Tieren hat die spezifische ReExpression von MECP2 in Astrozyten gezeigt, dass sich die Symptomatik und Progression reduzierte. Bewegungsabläufe, Atemunregelmäßigkeiten, Angstempfinden und die Lebenszeit verbesserten sich signifikant im Vergleich zu MeCP2defizienten Mäusen (Lioy et al. 2011).

Die relative Konzentration von $\mathrm{MeCP} 2$ in Gliazellen im Vergleich zu Neuronen scheint dabei von der Art von Neuron abhängig zu sein. Es zeigte sich, dass Gliazellen und zerebellare Neurone gleiche Mengen an MeCP2 exprimieren. Die Konzentration von MeCP2 in kortikalen und hippocampalen Neuronen lag hingegen signifikant höher (Ballas et al. 2009). Mikroglia ist auch imstande, den Beginn und die 
Progression der Erkrankung zu beeinflussen. Durch erhöhte Glutamatspiegel, die von Mikroglia freigesetzt werden, entstanden morphologische Fehlbildungen von Dendriten, mikrotubuläre Risse und Schäden von postsynaptischen glutaminergen Komponenten. In der Glutamat-Synthese von Mikroglia ist daher auch ein möglicher therapeutischer Ansatz zu sehen (Maezawa und Jin 2010).

\subsection{Mitochondrien-Veränderungen im Rett-Syndrom}

Mitochondrien sind strukturell komplexe, biochemisch hochgradig aktive und dynamische Organellen. Je nach Zellart befinden sich hunderte bis tausende Mitochondrien innerhalb einer Zelle. Mitochondrien erfüllen viele Funktionen, wie beispielsweise die ATP-Synthese durch oxidative Phosphorylierung („Kraftwerk der Zelle"), die Generierung von reaktiven Sauerstoff-Spezies (ROS), die Funktion als $\mathrm{Ca}^{2+}$-Ionen-Puffer und die Biosynthese von Aminosäuren (Duchen et al. 2003; McBride et al. 2006; Shetty et al. 2012; Valenti et al. 2014). Mitochondrien spielen auch eine zentrale Rolle im Leben und Tod einer Zelle. Etliche Proteine innerhalb der Mitochondrien spielen eine Schlüsselrolle in der Regulation von Zelltod oder Apoptose (Duchen et al. 2003).

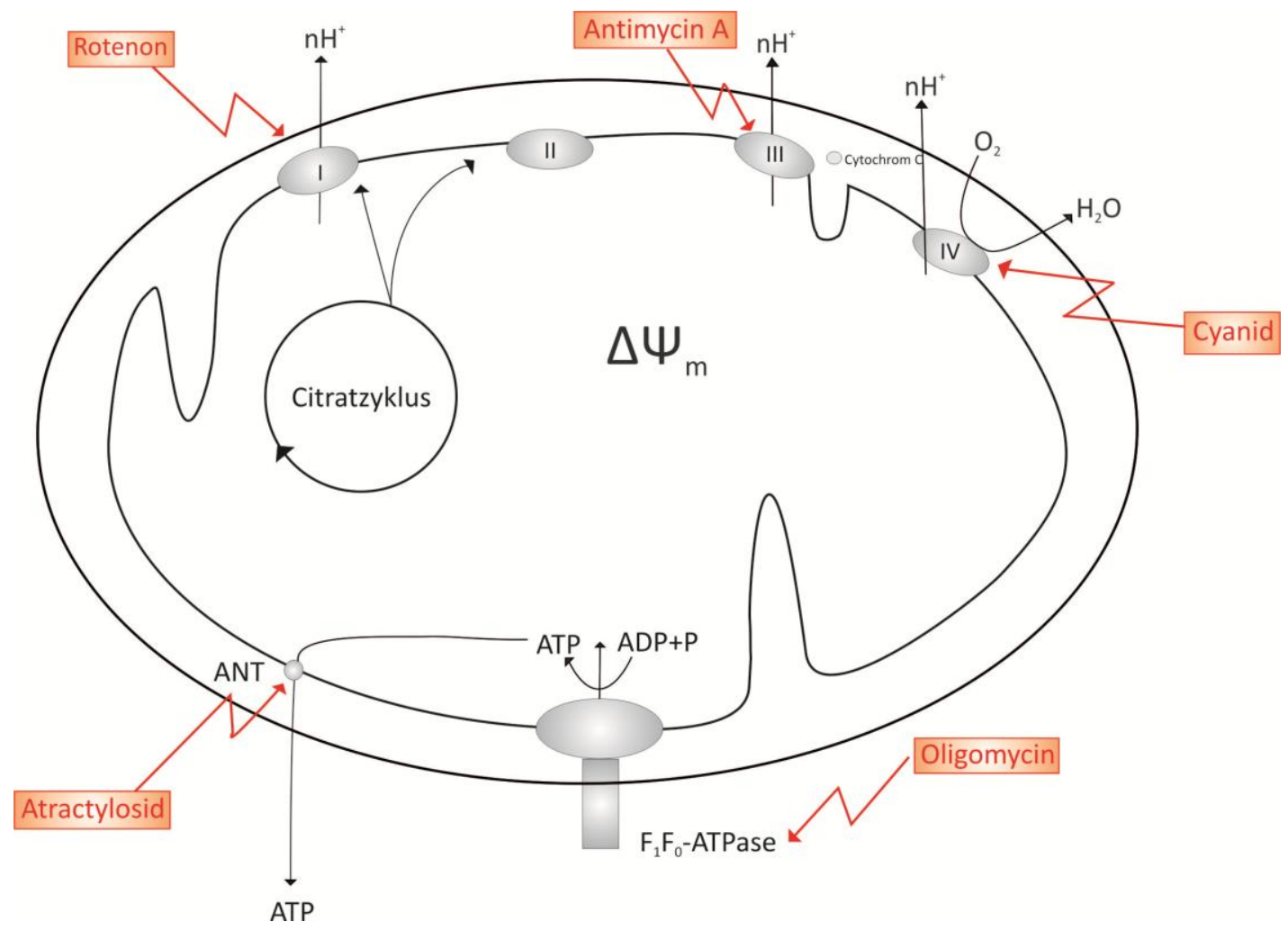




\section{Abbildung 2: Darstellung der chemisch-osmotischen Grundlagen zur Steuerung der oxidativen Phosphorylierung in Mitochondrien}

Die Substrate NADH- $\mathrm{H}^{+}$und $\mathrm{FADH}_{2}$, die im Zitronensäurezyklus bereitgestellt werden, beliefern die Komplexe I $\left(\mathrm{NADH}-\mathrm{H}^{+}\right)$und II $\left(\mathrm{FADH}_{2}\right)$ der Atmungskette. Durch Redox-Reaktionen werden dabei Elektronen auf das Coenzym Q (Ubichinon) übertragen. Die Weiterleitung der Elektronen erfolgt dann auf Komplex IV. Dieser überführt die Elektronen unter Bildung von Wasser auf molekularen Sauerstoff. Die $\mathrm{H}^{+}$-Ionen werden immer wieder über die innere Mitochondrienmembran in den Intermembranraum abgegeben. Hierdurch wird ein elektrochemischer Protonengradient $(\Delta \Psi \mathrm{m})$ generiert, der die $\mathrm{F}_{0} \mathrm{~F}_{1}$-ATPase zur ATP-Synthese antreibt. Das erzeugte ATP wird anschließend ins Zytosol transportiert. Dieser Vorgang wird oxidative Phosphorylierung genannt. Weiterhin zeigt die Abbildung pharmakologische oder biochemische Manipulationsmöglichkeiten dieser Stoffwechselwege (modifiziert nach Duchen et al. 2003, S. 355. Die Verwendung erfolgt mit freundlicher Genehmigung des Elsevier-Verlags.)

Im Jahr 1988 entdeckte der Arzt Eeg-Olofsson mitochondriale Veränderungen in Muskelbiopsien zweier Rett-Patientinnen (Eeg-Olofsson et al. 1988). Die Mitochondrien stellten sich elektronenmikroskopisch geschwollen und hantelförmig dar. Der Pädiater vermutete, dass mitochondriale Abnormalitäten auf X-chromosomale Mutationen zurückzuführen und ursächlich für das Rett-Syndrom seien. Für männliche Zygoten würde dieses zu einer Fehlimplantation führen oder zu einem frühzeitigen embryonalen Tod (Eeg-Olofsson et al. 1988). Auch in weiteren Muskelbiopsien von Rett-Syndrom-Patientinnen zeigten sich veränderte Mitochondrien mit granulären Einschlüssen, Vakuolisierungen und membranösen Veränderungen (Dotti et al. 1993; Cornford et al. 1994).

Weiterhin zeigten sich in Frontallappenbiopsien einer Rett-Syndrom-Patientin im Alter von drei Jahren und post mortem im Alter von 15 Jahren veränderte Mitochondrien-Strukturen (Cornford et al. 1994). Weitere Belege gab es auch durch die Untersuchungsergebnisse von ultrastrukturell veränderten Mitochondrien des motorischen Kortex und Hippocampus von $M e c p 2^{-/ y}$-Mäusen im Alter von drei Wochen (Belichenko et al. 2009). Anhand dieser hier aufgeführten Beispiele zeigen sich deutliche Hinweise dafür, dass im Rett-Syndrom morphologische Veränderungen der Mitochondrien vorliegen.

Es kommt neben den morphologischen Veränderungen auch $\mathrm{zu}$ funktionellen Abweichungen. Biochemische Analysen zeigten eine verminderte Expression einer 
Untereinheit der Cytochrom C-Oxidase (Komplex IV der Atmungskette) im Frontalkortex. Die verminderten Enzymspiegel könnten einen großen Einfluss auf die ATP-Synthese im Gehirn haben (Gibson et al. 2010). In einem Maus-Modell für das Rett-Syndrom haben sich bei den symptomatischen Tieren ebenfalls reduzierte Enzymaktivitätslevel der Atmungskettenkomplexe II, III, IV und verminderte Glutathionspiegel im Skelettmuskel gezeigt, nicht jedoch in prä-symptomatischen Tieren. Dies führt zur Annahme, dass mitochondriale Abnormalitäten durch Akkumulation von freien Radikalen in Skelettmuskel zu der in Abschnitt 1.1 erwähnten motorischen Symptomverschlechterung beisteuern (Gold et al. 2014). Erhöhte Laktat- und Pyruvatspiegel im Blut lassen darauf schließen, dass Defekte in der mitochondrialen Atmungskette und im Harnstoffzyklus vorliegen (Matsuishi et al. 1994). Durch starke Atemstörungen und häufige Apnoephasen bei Rett-SyndromPatientinnen, die zur systemischen Hypoxie führen, kommt es zur weiteren Herabsetzung der Mitochondrienfunktion. Bestätigt wurde die Annahme der systemischen Hypoxie durch Messungen des Hämatokrits, der in Blutuntersuchungen von $M e c p 2^{-/ y}$-Mäusen erhöht war (Fischer et al. 2009). Weiterhin wurde beobachtet, dass das ANT1-Gen, welches für das mitochondriale Enzym Adenin-NukleotidTranslokase kodiert, in $M e c p 2^{-/ y}$-Mäusen und in Fibroblasten von Rett-SyndromPatientinnen hochreguliert ist (Forlani et al. 2010). Die Konsequenz der mitochondrialen Veränderungen ist eine weniger effiziente Atmungskette und somit eine verminderte ATP-Synthese in den Mitochondrien. Mithilfe von Magnetresonanztomographie-Untersuchungen ließen sich auch genau diese verminderten ATP-Spiegel im Gehirn von MeCP2-defizienten Mäusen nachweisen (Saywell et al. 2006).

Die vielen physiologischen und biochemischen Veränderungen der Mitochondrien dürfen somit als ein zentraler Punkt des Rett-Syndroms betrachtet werden und könnten zur Entstehung einiger Symptome und dem Fortschreiten der Krankheit beitragen (Müller und Can 2014). 


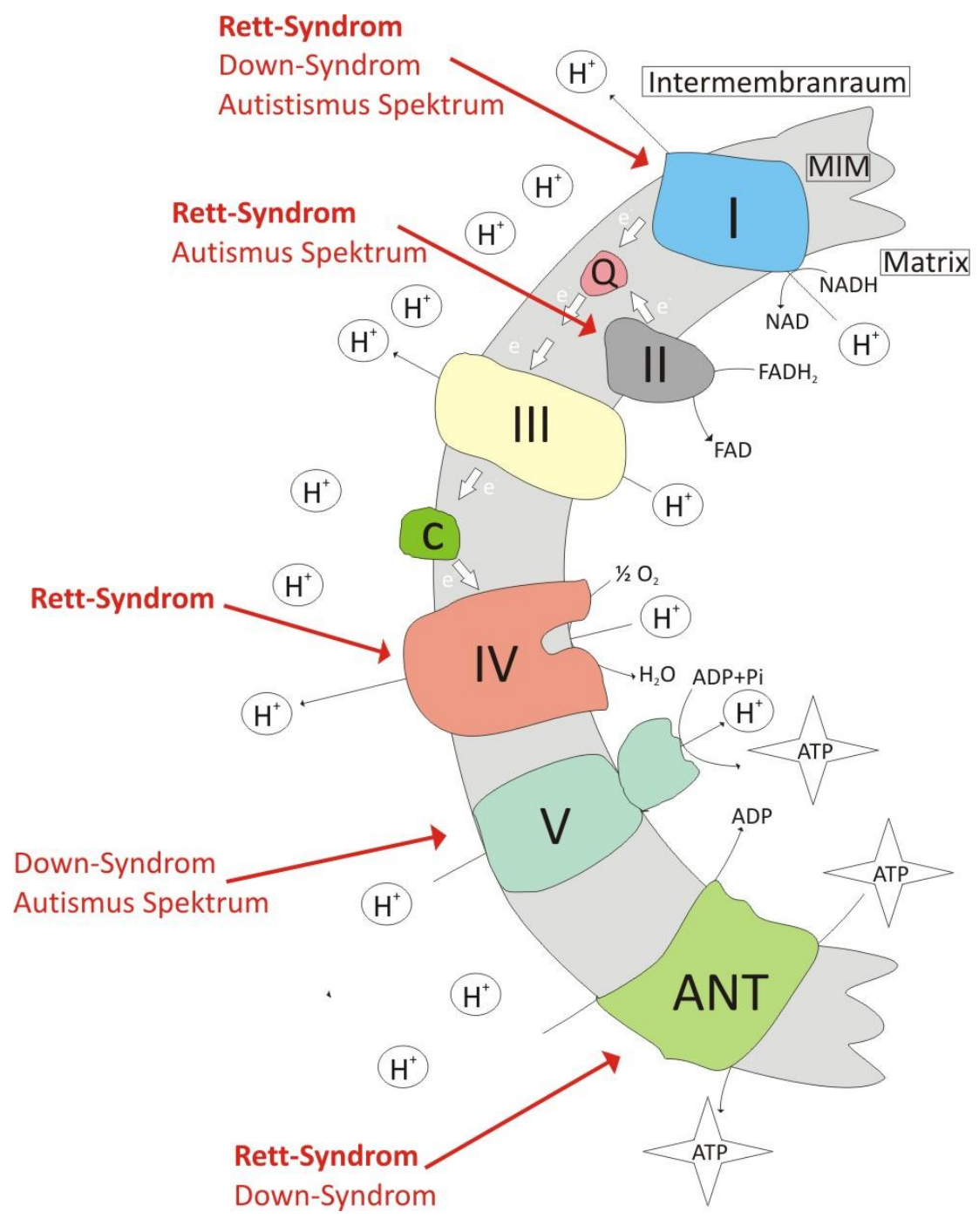

\begin{abstract}
Abbildung 3: Beeinträchtigung der mitochondrialen oxidativen Phosphorylierung im Rett-Syndrom, Down-Syndrom und bei autistischen Störungen
\end{abstract}

Dargestellt sind die mitochondriale Atemkette und der Adenin-Nukleotid-Transporter (ANT). Die roten Pfeile zeigen die Lage der mitochondrialen Proteinkomplexe der oxidativen Phosphorylierung, die bei den jeweiligen Syndromen betroffen sind. Die weißen Pfeile zeigen den Elektronenfluss durch die Atmungskette.

Abkürzungen: Matrix $=$ mitochondriale Matrix; MIM $=$ innere Mitochondrienmembran; $\mathrm{e}^{-}=$Elektronen; Atmungskettenkomplexe $\mathrm{I}=$ Komplex I (NADHUbichinon-Dehydrogenase); II = Komplex II (Succinat-Ubichinon-Oxidoreduktase); Q = Coenzym Q; III = Komplex III (Ubihydrochinon-Cytochrom-C-Oxidoreduktase; $\mathrm{C}=$ Cytochrom C; IV = Komplex IV (Cytochrom-C- Oxidase); V = ATP-Synthase bzw. $\mathrm{F}_{0} \mathrm{~F}_{1}$-ATPase

Im Rett-Syndrom sind die Komplexe I, II, IV und der Adenosin-NukleotidTransporter in den Mitochondrien betroffen (modifiziert nach Valenti et al. 2014, S. 3. Die Verwendung erfolgt mit freundlicher Genehmigung des Elsevier-Verlags.) 


\subsection{Optische Darstellung und Analyse der Mitochondrien mithilfe von JC-1}

Mitochondrien variieren innerhalb einer Zelle neben der Morphologie auch in ihrer Verteilung und Funktion (Collins und Bootman 2003). Die Hauptaufgabe der Mitochondrien besteht in der ATP-Synthese. Diese ist essentiell vom mitochondrialen Membranpotential $\left(\Delta \Psi_{\mathrm{m}}\right)$ abhängig und bestimmt das Überleben der Zelle und die verschiedenen Zellfunktionen. Bereits Mitchell beschrieb im Jahre 1961 anhand seiner chemiosmotischen Theorie die Zusammenhänge zwischen Redoxreaktion und Phosphorylierung in der mitochondrialen Atmungskette (Mitchell 1961). Anhand von Protonenpumpen (Komplexe I, III und IV der Atmungskette) wird über der inneren Mitochondrienmembran ein elektrochemischer Protonengradient aufgebaut. Hierdurch entsteht ein $\mathrm{pH}-$ Gradient sowie durch die verschiedenen Ladungen innerhalb der Mitochondrienräume ein Membranpotential $\left(\Delta \Psi_{\mathrm{m}}\right)$. Innen ist die Membran negativ, außen ist sie relativ dazu positiver geladen. Das Membranpotential und der $\mathrm{pH}-$ Gradient generieren eine protonenmotorische Kraft, die die membrangebundene ATPSynthase antreibt. Hierdurch kann ATP (Adenosintriphosphat) synthetisiert werden (Mitchell 1961, 1979; Reers et al. 1995).

Zur optischen Darstellung von Mitochondrien können verschiedene Methoden angewandt werden, unter anderem konfokale Mikroskopie, 2-Photonen-Mikroskopie, Hellfeldmikroskopie, videogesteuerte- und Phasen-Kontrast-Mikroskopie (Dedov et al. 2001). Die Methode der Wahl ist die Fluoreszenzmikroskopie. Sie ermöglicht je nach Anwendungsart die vergleichsweise bestmögliche Auflösung. Weiterhin können mitochondrienspezifische fluoreszierende Substanzen angewandt werden, um beispielsweise Membranpotentialunterschiede zu messen (Bereiter-Hahn und Voth 1994). Da biologische Strukturen meist keine oder nur eine sehr schwache Eigenfluoreszenz zeigen, werden diese im Rahmen von Versuchen meist mit einem Fluoreszenzfarbstoff markiert. Es sollte sichergestellt sein, dass der Farbstoff ausschließlich die Strukturen markiert, die untersucht werden sollen. Zur Markierung von Mitochondrien existiert eine Vielzahl von Fluorophoren, die entweder nur färben oder aber auch funktionelle Aspekte der Mitochondrien liefern (zum Beispiel das Membranpotential, die $\mathrm{Ca}^{2+}$-Konzentration, den Redox-Status oder den pH-Wert). 
Salvioli und Kollegen verglichen drei bekannte Fluoreszenzfarbstoffe untereinander, um mitochondriale Membranpotentialunterschiede zu analysieren: JC-1 (5,5',6,6'Tetrachloro-1,1',3,3'-Tetraethylbenzimidazolylcarbocyanine Iodid), R123 (Rhodamine 123) und $\mathrm{DiOC}_{6}(3)$ (Salvioli et al. 1997). R123 wurde als erstes Fluoreszenzmessverfahren von Membranpotentialunterschieden eingesetzt. Jedoch wurde die Bindung von R123 innerhalb der Mitochondrien mit verschiedenen Intensitäten beschrieben und ist somit nur eingeschränkt einsetzbar. Auch der Effekt des Photobleichens ist bei R123 deutlich ausgeprägter (Poot et al. 1996). $\mathrm{DiOC}_{6}(3)$ erweist sich als verlässlicher Farbstoff zur Detektion des Plasmamembranpotentials. Für Messungen von Membranpotentialunterschieden ist er allerdings ungeeignet. Die Erklärung hierfür ist, dass $\mathrm{DiOC}_{6}(3)$ auch von anderen intrazellulären Membranen aufgenommen wird, beispielsweise der Membran des Endoplasmatischen Retikulums. Dies kann zu fehlerhaften Ergebnissen führen. Die Hinzugabe von sogenannten Stressoren führte ebenfalls zu abweichenden Ergebnissen. Der Farbstoff JC-1 erwies sich hingegen als hochgradig sensitiv bei Messungen von Membranpotentialunterschieden. Es veränderte sich linear zum Membranpotentialunterschied und zeigte sich beständiger in Hinblick auf die Depolarisierung der Mitochondrien. Da die Farbstoffe R123 und $\mathrm{DiOC}_{6}(3)$ ein inkohärentes Färbeverhalten aufwiesen, stellt JC-1 somit den einzigen ratiometrischen Marker für das Membranpotential dar (Salvioli et al. 1997; Smiley et al. 1991).

Auch in dieser Arbeit kam der Mitochondrienfarbstoff JC-1 zum Einsatz. JC-1 (Molecular Probes/Invitrogen®, Oregon, USA) akkumuliert je nach Membranpotential $\left(\Delta \Psi_{\mathrm{m}}\right)$ in den Mitochondrien und ermöglicht es als einziger Mitochondrienfarbstoff, ratiometrische Messungen des Mitochondrienmembranpotentials durchzuführen. In Mitochondrien mit Potentialen mehr als $-140 \mathrm{mV}$, wie es z.B. bei zellulären Arbeiten oder bei Zelltod der Fall ist, liegt JC-1 als Monomer vor, der bei 527 nm grün fluoresziert. In hyperpolarisierten Mitochondrien formt JC-1-Oligomere, sogenannte JAggregate (nach ihrem Entdecker Jelley benannt), die ihr Emissionsmaximum bei $590 \mathrm{~nm}$ (rot) aufweisen (Keil et al. 2011; Reers et al. 1991; Sims et al. 1974; Cossarizza et al. 1993). Demzufolge stellt das Fluoreszenzverhältnis grün/rot ein Maß für das Membranpotential der einzelnen Mitochondrien dar. Insbesondere die flach wachsenden hippocampalen Zellkulturen ermöglichten es, Mitochondrien von 
einzelnen Zellen mithilfe von JC-1 zu analysieren. Die J-Aggregat-Bildung von JC-1 ist hierbei vollständig reversibel (Reers et al. 1995).

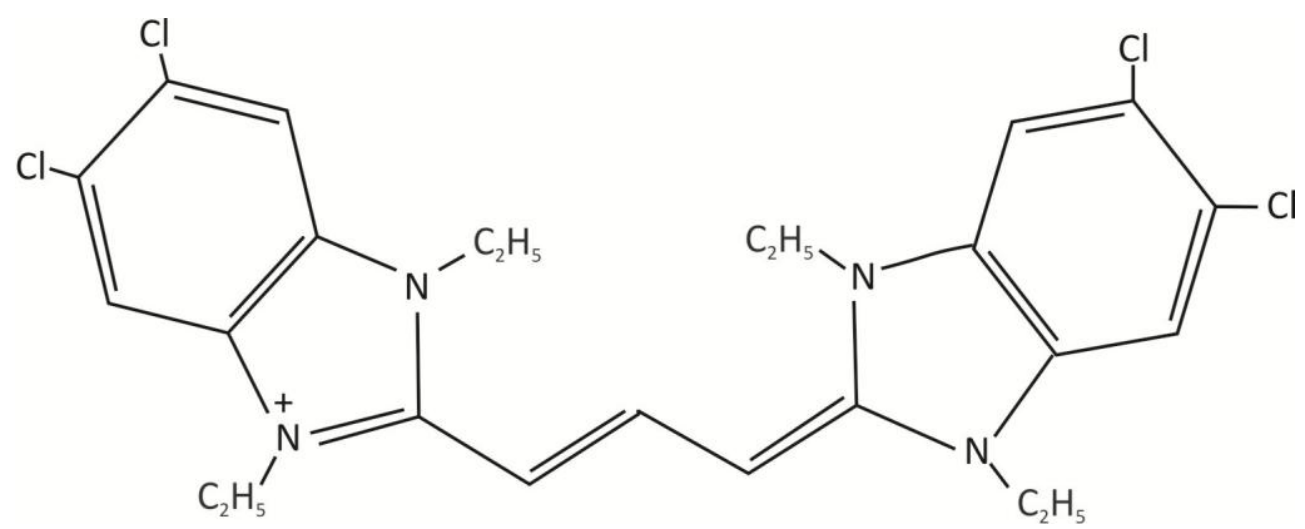

Abbildung 4: Chemische Struktur des Mitochondrienfarbstoffs 5,56,6,6'tetrachloro-1,1',3,3'-tetraethylbenzimidazolocarbocyanine Jodid (JC-1) (modifiziert nach Reers et al. 1995. Die Verwendung erfolgt mit freundlicher Genehmigung des Elsevier-Verlags.)

\subsection{Ziele der Arbeit}

Basierend auf der Tatsache, dass beim Rett-Syndrom mitochondriale Veränderungen beschrieben wurden, wurde im Rahmen dieser Arbeit eine detaillierte vergleichende Analyse der Mitochondrien von Wildtyp- und Mecp $2^{-/ y}$-Mäusen durchgeführt. Dabei kam die 2-Photonen-Mikroskopie zum Einsatz, um einen möglichst hohen Kontrast sowie eine optimale axiale (z-)Auflösung zu gewährleisten. Als Präparate wurden aus dem Hippocampus stammende dissoziierte Zellkulturen verwendet, die aus einem Maus-Modell für das Rett-Syndrom der Zuchtlinie B6.129P2(C)-Mecp2 $2^{\text {tm-1-1Bird }}$ (Guy et al. 2001) isoliert worden. Zunächst erfolgten die Aufnahmen unter Kontrollbedingungen mithilfe des Mitochondrienfarbstoffs JC-1. Dieser Farbstoff ermöglicht es, nicht nur mitochondriale Membranpotentialschwankungen zu detektieren, sondern auch das bestehende Membranpotential einzelner Mitochondrien zu quantifizieren. Hierbei stellte sich die grundlegende Frage, inwieweit sich die Verteilung, die Masse, das Membranpotential und die Morphologie der Mitochondrien in Wildtyp- und $M e c p 2^{-/ y}$-Mäusen voneinander unterscheiden. Anschließend wurde der Einfluss verschiedener Pharmaka, das heißt Entkoppler der Atmungskette (FCCP) und Zellgifte (Cyanid, Oligomycin) untersucht, um gezielt metabolischen und/oder pharmakologischen Stress auf die Mitochondrien und ihre Stoffwechselprozesse 
auszuüben. Frühere Arbeiten der Arbeitsgruppe zeigten nämlich, dass $M e c p 2^{-/ y}$ Hirngewebe offenbar vulnerabler auf Hypoxie reagiert (Fischer et al. 2009; Kron et al. 2011) und sich bei Mitochondrienvergiftung auch deutlich stärkere Änderungen der Redox-Balance zeigten (Grosser et al. 2012). Hierbei ergab sich die Fragestellung, welche Auswirkungen die einzelnen Stressoren auf die Mitochondrien im direkten genotyptischen Vergleich Wildtyp - Knockout haben. Im Vorfeld der eigentlichen Mitochondrien-Analysen erfolgten Messungen mit fluoreszierenden Mikrokügelchen (beads), um das 2-Photonen-Laser-Mikroskop zu kalibrieren und das bestmögliche räumlich auflösende Objektiv für die Mitochondrienanalysen zu identifizieren. 


\section{Material und Methoden}

Der folgende Abschnitt gibt einen detaillierten Überblick über das Maus-Modell sowie die Instrumente und Techniken, die für diese Arbeit verwendet worden sind.

\subsection{Mausmodell für das Rett-Syndrom}

Die Durchführung der Versuche erfolgte an dissoziierten Zellkulturen aus isoliertem Hirngewebe von zwei bis sechs Tage alten Mäusen (P2-P6). Das Gewebe bzw. die Proben wurde ausschließlich nach der Tötung der Tiere entnommen und präpariert; es wurden keine Eingriffe oder Versuche an lebenden Tieren durchgeführt. Die Mäuse stammten aus der zentralen tierexperimentellen Einrichtung der Universitätsmedizin Göttingen. Da bei dem Rett-Syndrom eine heterozygote Mutation im XChromosomen-gekoppelten Gen MECP2 nachgewiesen ist, wurde in dieser Arbeit das Maus-Modell für das Rett-Syndrom der Zuchtlinie B6.129P2(C)-Mecp $2^{\text {tm-1-1Bird }}$ (Guy et al. 2001) verwendet. Hierbei werden Knockout (KO)-Mäuse gezüchtet, bei denen der Transkriptionsfaktor MeCP2 fehlt. Nach Mendelschem Erbgang entstehen bei der Paarung von heterozygoten Weibchen $\left(\right.$ Mecp $\left.^{+/}\right)$mit Wildtyp-Männchen (C57BL/6J)

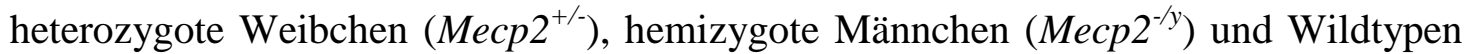
beider Geschlechter. Da die Muttertiere die Pflege der Jungtiere meist vernachlässigen, wird der Nachwuchs sogenannten Ammentieren zur Aufzucht gegeben. Diese Art der Aufzucht hat sich in Göttingen bewährt.

Für diese Arbeit wurden ausschließlich männliche Rett-Mäuse, das heißt $M e c p 2^{-/ y_{-}}$ Mäuse, verwendet. Hierbei fand ein Vergleich zwischen Präparaten der KnockoutMäuse und der Wildtyp-Mäuse statt. Bei den männlichen Tieren, bei denen das X-Chromosom von der Mutation betroffen ist, handelt es sich zwangsläufig um Knockout-Tiere. Die weiblichen Tiere zeigen nämlich durch die Inaktivierung des möglich betroffenen X-Chromosoms eine unterschiedlich starke Ausprägung des Phänotyps. Es ist somit viel sicherer, dass sich der Phänotyp der männlichen Knockout-Tiere homogener präsentiert und schwerer ausgeprägt ist. Die Bedingungen sind kontrollierbar, da bei allen Zellen der MeCP2-Transkriptionsfaktor fehlt. Weibliche Mäuse werden weiterhin deshalb ausgeschlossen, weil die Symptome des 
Rett-Syndroms zeitlich später und weniger stark ausgebildet werden. Zudem werden sie zur Aufrechterhaltung der Zucht benötigt. Die Genotypisierung der Tiere erfolgte mittels Polymerase-Kettenreaktion aus Schwanzspitzenbiopsien und wurde durch die technische Assistentin der Arbeitsgruppe durchgeführt.

\subsection{Präparation und Herstellung der Zellkultur}

Die Zellen wurden bis sechs Tage nach der Präparation für die Versuche verwendet. Die Präparation der Zellkultur fand nach der Dekapitation und Isolierung der Hippocampi in einer Sterilbank statt. Das verwendete Präparationsbesteck und Instrumente bestanden aus folgenden Komponenten: 1 Präparationskasten mit folgendem sterilem Inhalt: 1 Schere, 1 Skapell, 1 Spatel, 3 Pinzetten, 1 Löffel-Spatel, 1 Pasteurpipette, 1 Augenschere. Des Weiteren: Reagenzgläser, 3 kleine GlasPetrischalen, Mikroliterpipetten inkl. auswechselbaren Spitzen $(10 \mu 1,200 \mu$, $1000 \mu 1$ ), Gasbrenner, Glaspasteurpipetten, 1 Styropordeckel, Eis, 1 steriles Plastikschälchen mit Deckel, Filteraufsätze für Spritze, Metallplatte als Arbeitsfläche auf dem mit Eis gefüllten Styropordeckel, Vortex®-Rührgerät, Zentrifuge.

Die Kulturplatten (4-well plates, Thermo Fisher Scientific®, Dänemark) wurden mit autoklavierten Deckgläschen bestückt, die zuvor mit Salzsäure, Aceton und Ethanol gereinigt und dann trocken hitzesterilisiert wurden. Anschließend wurden die Deckgläschen mit einer Lösung (Verhältnis 1:50) aus Matrigel und Platierungsmedium (s. 2.3.) zu je $50 \mu \mathrm{l}$ benetzt, die mindestens eine Stunde lang im Inkubator vorinkubiert wurden. Die Aufbewahrung erfolgte über mindestens 24 Stunden kontrolliert in einem Inkubator $\left(37^{\circ} \mathrm{C}\right.$, Raumluft mit $5 \% \mathrm{CO}_{2}, 95 \%$ Luftfeuchtigkeit). Die Zellkultur wurde aus P2-P5 (postnatal) alten männlichen Wildtyp- bzw. Mecp2 $2^{-/ y}$-Mäusen hergestellt.

Nach rascher Dekapitation wurde der Schädel mithilfe einer feinen Augenschere eröffnet und das vorsichtig entfernte Gehirn in eiskalten Puffer (Hanks Buffered Salt Solution $=$ HBSS $+20 \%$ Fetales Kälberserum $=$ FCS $)$ in eine sterile Petrischale getaucht. In allen folgenden Schritten wurden ebenfalls eiskalte Lösungen eingesetzt, sofern dies nicht gesondert genannt wurde. Zur besseren Betrachtung der Präparation 
kam eine Stereolupe zum Einsatz. Die Großhirnhemisphären wurden mit einem Skapell durchtrennt und der Hirnstamm entfernt, sodass die Hippocampi isoliert werden konnten. Nach Überführung der Hippocampi in eine weitere sterile Petrischale erfolgte mit einem Skalpell die Zerkleinerung in ca. 1-2 $\mathrm{mm}^{3}$ kleine Stücke. Daraufhin wurden die Hippocampi mithilfe einer abgebrochenen feuerpolierten Pasteurpipette in ein steriles Reagenzglas überführt und dreimal mit je $10 \mathrm{ml}$ HBSS $+20 \%$ FCS und daraufhin dreimal mit je $10 \mathrm{ml}$ HBSS gewaschen. Für den Folgeschritt wurden der Überstand soweit wie möglich mit einer Unterdruckpumpe entfernt ohne dabei Gewebe mitzusaugen. Anschließend fand die Trypsinierung der Hippocampi mit Zugabe von $40 \mu \mathrm{l}$ DNAse, $10 \mathrm{mg}$ Trypsin (0,5\%) und $2 \mathrm{ml}$ Digestionslösung statt. Nach Zusammenführung der einzelnen Substanzen wurden diese mit dem Vortex®Gerät vermischt und anschließend durch einen Sterilfilter zum Gewebe in das Reagenzglas filtriert.

Nach Überführen des Gemisches inklusive der Gewebeanteile in eine kleine sterile Petrischale mit Deckel wurden die Hippocampi bei $37^{\circ} \mathrm{C}$, Raumluft mit $5 \% \mathrm{CO}_{2}$ und $95 \%$ Luftfeuchtigkeit für zehn Minuten inkubiert. Trypsin bewirkte die Spaltung der extrazellulären Proteine, die zur Zelladhäsion beitrugen. Dadurch blieben die Gewebsteile voneinander getrennt. Nach der Inkubation wurde der Ansatz wieder in ein neues steriles Röhrchen überführt. Erneut wurde die Lösung mit je 10 ml HBSS + $20 \%$ FCS (3x) und anschließend mit 10 ml HBSS (3x) gewaschen, um die Trypsinierung $\mathrm{zu}$ unterbrechen. Nach Zugabe von $40 \mu \mathrm{l}$ DNAse und $2 \mathrm{ml}$ Dissoziationslösung wurden die Hippocampi zunächst mithilfe von Pasteurpipetten in circa $0,5 \mathrm{~mm}^{3}$ große Stückchen zerkleinert und anschließend mit feuerpolierten und somit verengten Pasteurpipetten weiter dissoziiert, bis mit bloßem Auge keine Partikel mehr zu erkennen waren. Die vorhandenen $2 \mathrm{ml}$ Zellsuspension wurde mit $3 \mathrm{ml} \mathrm{HBSS}$ $+20 \%$ FCS aufgefüllt und bei $4^{\circ} \mathrm{C}, 1500 \mathrm{rpm}$ (rounds per minute) für zehn Minuten zentrifugiert.

Anschließend wurde der Überstand abgesaugt und das Pellet mit $800 \mu l$ Platierungsmedium resuspendiert und aufgelockert. Nach Absaugen des Matrigels von den Deckgläschen, wurde die Suspension zu je $50 \mu$ l auf Kulturplatten (Thermo Fisher Scientific ${ }^{\circledR}$, Dänemark) überführt. In der Regel ergab dies eine ungefähre Anzahl von 100.000 Zellen pro Deckgläschen. Nach einstündiger Inkubation $\left(37^{\circ} \mathrm{C}\right.$, Raumluft mit 
$5 \% \mathrm{CO}_{2}, 95 \%$ Luftfeuchtigkeit), in der die Neurone und Gliazellen sich an den Deckgläschen anheften konnten, wurden die einzelnen Kammern mit je $600 \mu 1$ vorgewärmten Platierungsmedium aufgefüllt. Das Platierungsmedium wurde mindestens eine Stunde mit leicht angeschraubtem Deckel im Röhrchen im Inkubator zur Äquilibrierung von Temperatur und pH-Wert vorgewärmt. Die Kulturplatten verblieben dann für die Zeit der Wachstumsphase bzw. der Messungen im Inkubator. Am ersten Tag in Kultur (DIC 1) erfolgte ein Mediumwechsel, indem das Platierungsmedium vorsichtig mit einer Saugpipettte abgesaugt und durch $800 \mu \mathrm{l}$ Wachstumsmedium ersetzt wurde. Nach zwei Tagen waren die Zellen voll ausdifferenziert, so dass die Messungen stattfinden konnten. Am vierten und sechsten Tag wurde das Medium jeweils zur Hälfte (400 $\mu$ l) erneuert. Hier erfolgten ebenfalls die Aufnahmen mithilfe des 2-Photonen-Laser-Mikroskops (TPSLM).

\subsection{Verwendete Lösungen und Drogen}

\begin{tabular}{|l|l|l|}
\hline Substanz/Reagenz & Konzentration & Lieferant \\
\hline ACSF & $1,2 \mathrm{mM}$ & \\
$\mathrm{MgSO}_{4}$ & $1,2 \mathrm{mM}$ & Merck \\
$\mathrm{CaCl}_{2}$ & $130 \mathrm{mM}$ & Sigma-Aldrich \\
$\mathrm{NaCl}$ & $3,5 \mathrm{mM}$ & Merck \\
$\mathrm{KCl}$ & $1,25 \mathrm{mM}$ & Merck \\
$\mathrm{NaH}_{2} \mathrm{PO}_{4}$ & $24 \mathrm{mM}$ & Merck \\
$\mathrm{NaHCO}_{3}$ & $10 \mathrm{mM}$ & Sigma-Aldrich \\
Dextrose & $137 \mathrm{mM}$ & Merck \\
\hline Digestionslösung & $5 \mathrm{mM}$ & \\
NaCl & $7 \mathrm{mM}$ & Roth \\
$\mathrm{KCl}_{\mathrm{Na}} \mathrm{HPO}_{4}$ & $25 \mathrm{mM}$ & Roth \\
$\mathrm{HEPES}$ & & Roth \\
\hline Dissoziationslösung & $*)$ & Sigma-Aldrich \\
$\mathrm{HBSS}$ & $0,166 \mathrm{mM}$ & \\
MgSO & $*$ Sigma-Aldrich \\
\hline DNAse & $*)$ & Merck \\
\hline FCS (Fetales Kälberserum) & $*)$ & Sigma-Aldrich \\
\hline HBSS (Hanks balanced salt & $*)$ & Biochrom \\
solution) Hanks & $1 \mathrm{mM}$ & Sigma-Aldrich \\
HEPES & $4 \mathrm{mM}$ & Sigma-Aldrich \\
NaHCO & Roth \\
\hline Matrigel & $*)$ & BD Biosciences \\
& & \\
\hline
\end{tabular}




\begin{tabular}{|l|l|l|}
\hline Platierungsmedium & $*$ ) & Invitrogen \\
MEM & $5 \%$ & Biochrom \\
FCS & $2 \mathrm{mM}$ & Invitrogen \\
L-Glutamin & $25 \mu \mathrm{g} / \mathrm{ml}$ & Sigma-Aldrich \\
Insulin & $10 \mathrm{mg} / 2 \mathrm{ml}$ & Sigma-Aldrich \\
\hline Trypsin & $*)$ & \\
\hline Wachstumsmedium & $5 \%$ & Invitrogen \\
MEM & $0,5 \mathrm{mM}$ & Biochrom \\
FCS & $20 \mu \mathrm{g} / \mathrm{ml}$ & Invitrogen \\
L-Glutamin & $100 \mu \mathrm{g} / \mathrm{ml}$ & Invitrogen \\
B27-Supplement & & Biochrom \\
Penicillin/Streptomycin & & \\
\hline
\end{tabular}

Tabelle 1: Zusammenfassung der Reagenzien inklusive Lieferanten (*) vom Hersteller nicht näher spezifiziert)

Bei den Messungen der Zellkulturen kam ACSF zum Einsatz. Diese kam in der Zusammensetzung der zerebrospinalen Flüssigkeit gleich. Zur Herstellung eines Liters ACSF wurde destilliertes Wasser zunächst mit 1,2 $\mathrm{mM} \mathrm{CaCl}_{2}$ und 1,2 $\mathrm{mM} \mathrm{MgSO}_{4}$ in einem Glaskolben gut durchmischt. Hierbei kam ein Magnetrührer zum Einsatz. Um ein Ausfällen der Salze zu verhindern, wurde erst danach die ACSF-Stammlösung (130 mM NaCL, 3,5 mM KCl, 1,25 mM NaH${ }_{2} \mathrm{PO}_{4}, 24 \mathrm{mM} \mathrm{NaHCO}{ }_{3}$ ) und $10 \mathrm{mM}$ Dextrose beigemengt. ACSF war somit eine bicarbonatgepufferte Salzlösung. ACSF wurde vor den Versuchen mindestens eine halbe Stunde in einem Wasserbad kontinuierlich bei $38^{\circ} \mathrm{C}$ erwärmt und zeitgleich mit Carbogen begast. Carbogen setzte sich aus $95 \% \mathrm{O}_{2}$ und $5 \% \mathrm{CO}_{2}$ zusammen und diente bei den Messungen dazu, einen physiologischen $\mathrm{pH}-$ Wert von 7,4 zu schaffen und die Versorgung der Präparate mit Sauerstoff zu gewährleisten.

HBSS (Hanks balanced salt solution) wurde bei der Präparation als Dissoziationslöung verwendet. Um einen Liter HBSS anzusetzen, wurde 9,5 g HanksPulver zu voll entsalzendem Wasser gegeben. Anschließend wurden $4 \mathrm{mM} \mathrm{NaHCO}$ und $1 \mathrm{mM}$ HEPES (Puffer-System) beigefügt.

Das Aussaatmedium (auch: Platierungsmedium) beinhaltete: MEM, FCS $10 \%$, LGlutamin $2 \mathrm{mM}$, Insulin $25 \mu \mathrm{g} / \mathrm{ml}$. Einen Tag nach der Präparation wurde das Aussaatmedium durch das Wachstumsmedium ersetzt. Um dieses herzustellen, wurde dem MEM $5 \%$ FCS, 0,5 mM L-Glutamin, $20 \mu \mathrm{g} / \mathrm{ml}$ B27-Supplement, 
Penicillin/Streptomycin hinzugefügt. Hierbei fungierte das B27-Supplement als Wachstumsfaktor und Penicillin/Streptomycin beugten mikrobieller Kontamination vor.

\subsection{Spezifische Pharmaka und Inhibitoren}

Im Rahmen der Versuche wurden auch diverse pharmakologische Inhibitoren und Radikalfänger eingesetzt. Einen Überblick gibt die nachfolgende Tabelle.

\begin{tabular}{|l|l|l|l|l|}
\hline Droge & Firma & Aufbewahrung & Konz. & Funktion \\
\hline $\begin{array}{l}\text { DMSO } \\
\text { (Dimethylsulf- } \\
\text { oxid) }\end{array}$ & Sigma & Raumtemperatur & $0,134 \%$ & Lösungsmittel \\
\hline $\begin{array}{l}\text { FCCP } \\
\text { (Carbonyl- } \\
\text { cyanid-p- } \\
\text { trifluoromethoxy- } \\
\text { phenylhydrazon) }\end{array}$ & Tocris & $+4^{\circ} \mathrm{C}$ & $1 \mu \mathrm{M}$ & $\begin{array}{l}\text { Entkoppler der } \\
\text { Atmungskette, } \\
\text { Abbau des } \\
\text { Protonengradienten } \\
\text { innerhalb der } \\
\text { Mitochondrien }\end{array}$ \\
\hline $\begin{array}{l}\text { NaCN } \\
\text { (Natriumcyanid) }\end{array}$ & Sigma & $\begin{array}{l}\text { Feststoff bei } \\
\text { Raumtemperatur } \\
\text { gelöst und } \\
\text { aliquotiert bei } \\
-20^{\circ} \mathrm{C}\end{array}$ & $1 \mathrm{mM}$ & $\begin{array}{l}\text { Inhibitor von } \\
\text { Komplex IV der } \\
\text { Atmungskette }\end{array}$ \\
\hline $\begin{array}{l}\text { Oligomycin ABC } \\
\text { Shama }\end{array}$ & $-20^{\circ} \mathrm{C}$ & $10 \mu \mathrm{g} / \mathrm{ml}$ & $\begin{array}{l}\text { Inhibitor der ATP- } \\
\text { Synthase durch } \\
\text { Blockierung der }\end{array}$ \\
$\begin{array}{l}\text { Fo-Untereinheit } \\
\text { Vitamin-E-Derivat, } \\
\text { Antioxidans }\end{array}$ \\
$\begin{array}{l}\text { (6-Hydroxy- } \\
\text { 2,5,7,8- } \\
\text { chtramethyl- } \\
\text { carboman-2- }\end{array}$ & Sigma & $+4^{\circ} \mathrm{C}$ & $1 \mathrm{mM}$ & \\
\hline
\end{tabular}

Tabelle 2: Verwendete pharmakologische Inhibitoren und Radikalfänger

DMSO wurde parallel zu Trolox eingesetzt, um mögliche Effekte von DMSO auszuschließen. Die nicht wasserlöslichen Pharmaka FCCP und Oligomycin wurden zunächst in DMSO gelöst und als 10-100 mM Stammlösungen im Kühlschrank bei $4^{\circ} \mathrm{C}$ (FCCP) oder im Gefrierschank bei $-20^{\circ} \mathrm{C}$ (Oligomycin) aufbewahrt. Die EndDMSO-Konzentration lag unter 0,2 \%, um mögliche Eigeneffekte zu minimieren. 
FCCP agiert als Entkoppler der Atmungskette, indem es Protonenkanäle an der inneren Mitochondrienmembran bildet. Dies hat eine vollständige Depolarisation der Mitochondrien zur Folge (Cotton et al. 1981). Zur Vorbereitung wurden $5 \mu$ l FCCP (1 $\mu \mathrm{M})$ in $50 \mathrm{ml}$ ACSF gelöst und fünf Minuten vor den optischen Aufnahmen durch die Messkammer laufen gelassen. Um diese Versuche zu vervollständigen, wurde auch das mitochondriale Modulans Oligomycin in Zusammenhang auf mitochondriale Veränderungen untersucht (Endkonzentration $10 \mu \mathrm{g} / \mathrm{ml}$ ). Oligomycin inhibiert die $\mathrm{F}_{0^{-}}$ Untereinheit der ATP-Synthase.

Natriumcyanid durchlief bereits fünf Minuten vor der Messung kontinuierlich die begaste Messkammer. Die Inkubation mit Trolox erfolgte einen Tag zuvor in einer Endkonzentration von $100 \mu \mathrm{M}$.

Zur Darstellung der Mitochondrien und deren Potentialschwankungen kam in dieser Arbeit der Mitochondrienfarbstoff JC-1 (Molecular Probes/Invitrogen ${ }^{\circ}$, Oregon, USA) zum Einsatz. Die Aufbewahrung erfolgte bei $-20^{\circ} \mathrm{C}$ in $2 \mathrm{mM}$ DMSO. Für die Versuche wurden zunächst JC-1 $(0,4 \mu \mathrm{l} / \mathrm{ml})$ in ACSF gelöst. Die $800 \mu 1$ Wachstumsmedium der jeweiligen Zellkultur wurden abgesaugt und das in ACSF gelöste JC-1 hinzugegeben. Nach 15 -minütiger Inkubation $\left(37^{\circ} \mathrm{C}\right.$, Raumluft mit $5 \%$ $\mathrm{CO}_{2}, 95 \%$ Luftfeuchtigkeit) wurden die Versuche mit dem 2-Photonen-LaserMikroskop (TPSLM) durchgeführt. 
grüne Monomere

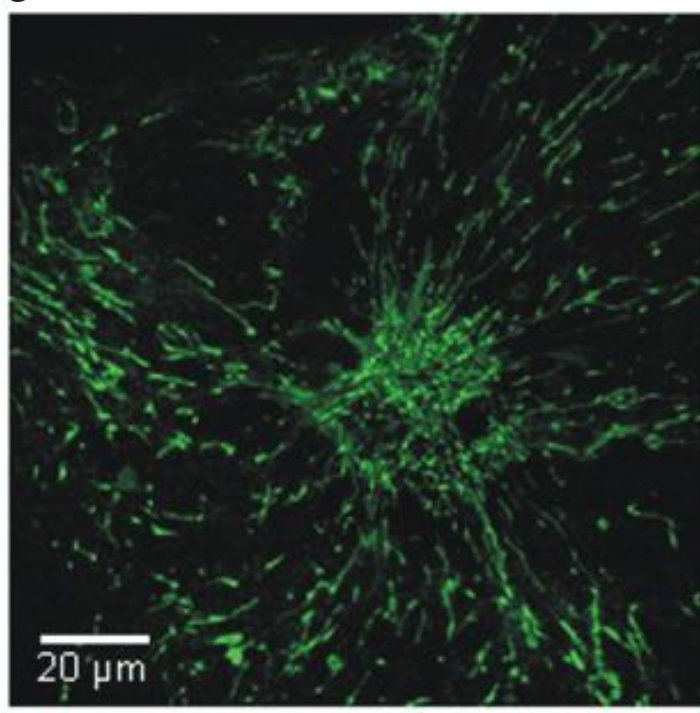

Überlagerung

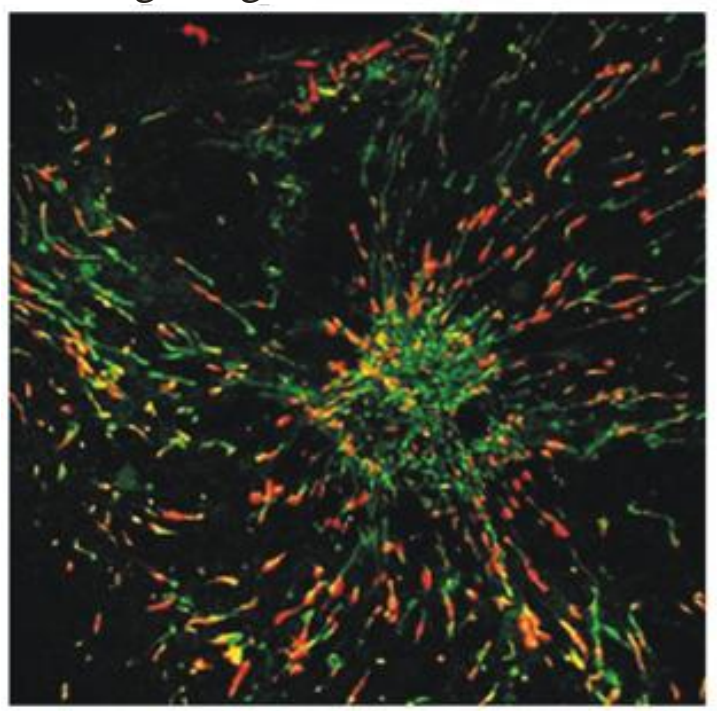

rote Aggregate

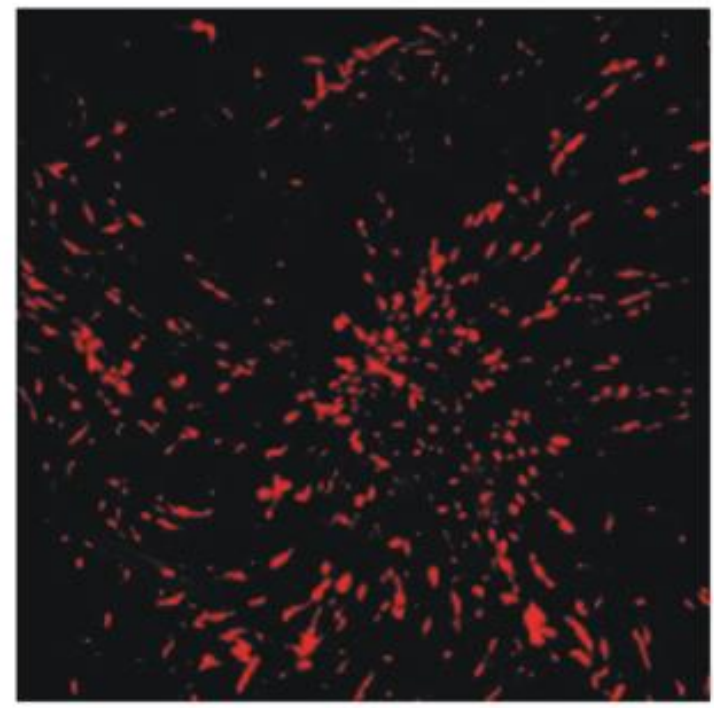

Ratio $\left(\mathrm{F}_{\text {rot }} * 200 / \mathrm{F}_{\text {grün }}\right)$

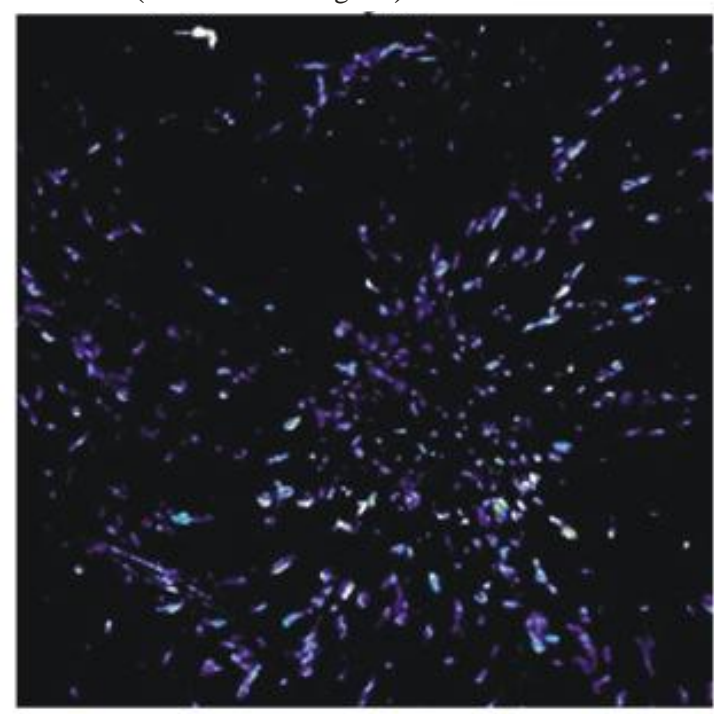

depolarisiert

polarisiert

Abbildung 5: 2-Photonenaufnahmen eines mit JC-1-gefärbten Astrozyten

Dargestellt sind jeweils in Fehlfarben die grünen Monomere sowie die roten Aggregate nach Inkubation mit dem Mitochondrienmarker JC-1, anschließende Überlagerung sowie das entsprechende Fluoreszenzverhältnis.

\subsection{Aufbau des Messgerätes: 2-Photonen-Laserscanning- Mikroskop (TPLSM)}

Die Ursprünge der 2-Photonen-Laser-Mikroskopie wurden schon 1931 von Maria Göppert-Mayer theoretisch beschrieben (Diaspro et al. 2006; Göppert-Mayer 1931), 
allerdings etablierte sich diese Technik durch Denk und Kollegen erst 1990 (Denk et al. 1990). 2-Photonen-Laser-Mikroskopie ist die Methode der Wahl zur Bildgebung von intakten biologischen Strukturen. Sie ermöglicht im Gegensatz zu anderen konventionellen Verfahren eine hohe dreidimensionale Auflösung, reduziert phototoxische Schäden und verhindert so die Destruktion (Kurtz et al. 2006). Durch eine relativ große Wellenlänge, die im nahen Infrarotbereich liegt, kann ebenso eine verbesserte Penetrationstiefe erreicht werden, weil größere Wellenlängen weniger stark gestreut werden. Dies ermöglicht die Abbildung auch tieferliegender Gewebeschichten. Hierbei ist weiterhin mit einer guten Auflösung zu rechnen. Der größte Vorteil ist, dass nur der Bereich, der im Laser-Fokus steht, tatsächlich angeregt wird und dass eine Beschränkung auf ein kleinstes fokales Volumen erfolgt. Eine Anregung der Umgebung wird somit vermieden. 2-Photonen-Mikroskopie ist demnach eine nicht-invasive Methode zur Visualisierung und Messung von Submikrometerbereichen und dynamischen Prozessen in Zellen und Geweben (Müller et al. 2003). Allerdings ist das 3D-Scannen einer Probe und dessen Verarbeitung recht zeitintensiv. Zur Durchführung der optischen Messungen wurde für diese Arbeit ein speziell angefertigtes 2-Photonen-Laser-Mikroskop (TPLSM, two-photon laser scanning microscope) verwendet. Es wurde aus einzelnen Komponenten zusammengebaut, ist somit sehr effizient und flexibel. Die meisten kommerziellen 2-Photonen-Laser-Mikroskope sind sehr kostspielig. Sie bestehen aus einem festen Aufbau, der schwierig erweiterbar ist (Müller et al. 2003).

Das Prinzip der 2-Photonen-Laser-Mikroskopie ist ein sogenanntes Rasterpunktverfahren. Dabei wird ein definierter Bereich des Präparates punkteweise waagerecht und senkrecht mit einem Laser gescannt. Der 2-Photonen-Laserstrahl, der im Vergleich zu einem 1-Photon-Lasermikroskop etwa die doppelte Wellenlänge hat, regt den speziellen Farbstoff (hier: JC-1) zur Fluoreszenzemission an. Diese Emission wird auf den Detektoren, sogenannten Photomultipliern, abgebildet und mithilfe der Steuersoftware wird aus den einzelnen Bildkoordinaten und den Helligkeiten ein Bild berechnet. Dabei kann der fluoreszierende Bereich in dreidimensionaler Auflösung visualisiert werden, das heißt nicht nur in der xy-Ebene sondern auch in verschiedenen Tiefen (z-Achse). 
A

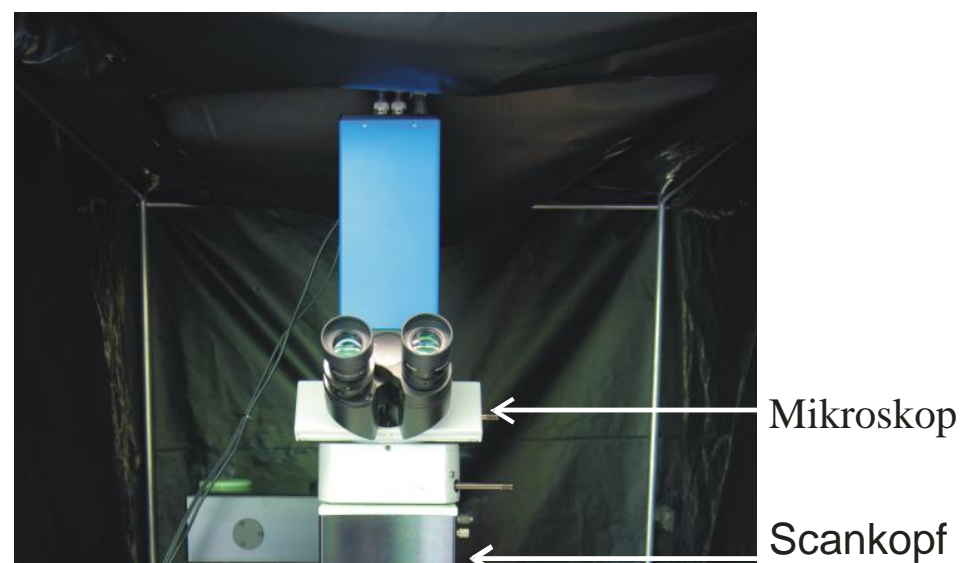

mit Shutter

Objektiv

Messkammer

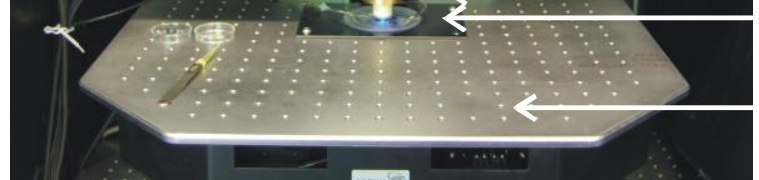

$\mathrm{x} / \mathrm{y}$-Tisch

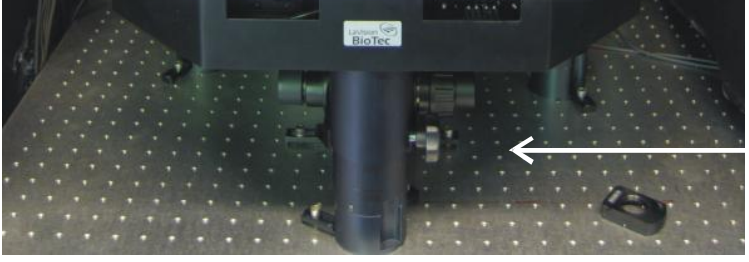

Schwingungsgedämpfter Tisch

B

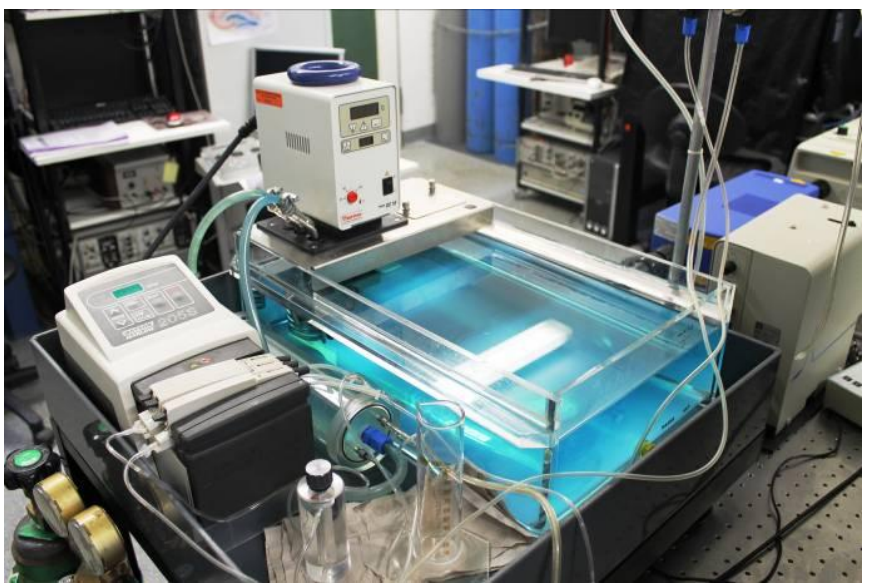

\section{Abbildung 6: Aufbau des optischen Messsystems}

A Gezeigt ist ein allgemeiner Überblick über das TPSLM. Zur Sicherung und Kontrolle von Vibrationen wurden alle optischen Komponenten auf einem schwingungsdämpfenden Tisch aufgestellt. Der Arbeitsplatz ist mit einer schwarzen Plastikfolie abgedeckt, um Lichteinstrahlung aus dem Raum zu minimieren. Das Wasserbad befindet sich räumlich gesehen direkt hinter dem Messplatz, um eine geringe Distanz zu der Messkammer einzuhalten.

B Beheiztes Wasserbad mit Rollenpumpe und Wärmetauscher, die eine kontinuierliche Lösungszufuhr und konstante Temperaturen gewährleisten. 
Der Titan-Saphir-Laser (Mai Tai eHP DeepSee, Newport Spectra-Physics) generiert ultra-kurze Laserpulse von 90-100 fs bei einer Repititionsfrequenz von $80 \mathrm{MHz}$. Dieser liefert die gewünschte Intensität, um 2-Photonen-Anregungsprozesse zu ermöglichen. Der Laserstrahl passiert anschließend im System zwei Scanspiegel und diverse Kontrolleinheiten. Anschließend gelangt der Laserstrahl durch Umlenkung an einem dichroitischen Filter DC670XXR bei einer Exzitationswellenlänge von $925 \mathrm{~nm}$ in das Mikroskop Olympus BX51 WI sowie das Objektiv. Der dichroitische Filter hat eine spezielle Beschichtung, die die Anregungswellenlänge reflektiert, für die Fluoreszenzwellenlängen aber hochtransparent ist. Der Arbeitsabstand des Objektivs beträgt $2 \mathrm{~mm}$. Der Feintrieb des Mikroskops ist motorisiert. Beim Auftreffen des Laserstrahles auf das Objekt ändern die Moleküle des Fluoreszenzfarbstoffs ihren angeregten elektronischen Zustand in den elektronischen Grundzustand und geben die freiwerdende Energie in Form von Photonen als Strahlung ab. Diese wird in das Mikroskop umgelenkt, wo sie schließlich einen weiteren $570 \mathrm{~nm}$ dichroitischen Strahlteiler (570 DXCR) passiert. Dabei werden die verschiedenen EmissionsWellenlängenbereiche voneinander getrennt. Wellenlängen von 617/73 nm werden vom roten Detektor $(\mathrm{PMT}=$ photo multiplier tube, hier: PMT 2) verarbeitet, Bereiche von 525/50 nm werden vom grünen Kanal (PMT 1) detektiert. Photomultiplier detektieren Lichtsignale, die in elektrische Signale umgewandelt werden. Diese werden mit dem Systemsteuerungsprogramm ImSpector (LaVision BioTec) dargestellt und weiter verarbeitet. Zur Anwendung kam das Objektiv Zeiss Plan-Apochromat 63x 1,0 W VIS-IR. An dieser Stelle sei erwähnt, dass sich aus Sicherheitsgründen der gesamte Laserstrahl-Weg in einem röhrenförmigen System befindet. Zudem gibt es eine Sicherheitverschluss, ein sogenannter shutter, nur für den Scanprozess bzw. Lasereinstellungen geöffnet wird. Um eine geeignete Zelle zu finden, wurde vor der Aufnahme eine LED-Anregungslichtquelle mit $490 \mathrm{~nm}$ eingesetzt (Cool LED pE1).

Um während des Laserscans eine möglichst physiologische Umgebung für die verwendeten Zellkulturen zu schaffen, wurde die Messkammer kontinuierlich mit ACSF durchspült. Eine Kassettenpumpe (Watson Marlow 205S/CA) förderte die ACSF über einen PVC-Schlauch mit jeweils 35 Drehungen pro Minute zur Messkammer. Dies gleicht einer Geschwindigkeit von 1,6 m/min bzw. circa $4 \mathrm{ml} / \mathrm{min}$ innerhalb des zuführenden Schlauchsystems. Die ACSF hatte beim Erreichen der Kammer eine optimale Temperatur für hippocampale Zellkulturen von $33-34^{\circ} \mathrm{C}$. Die 
Vorlaufzeit betrug eine Minute. Die ACSF durchlief bei den normalen Versuchen einen Kreislauf und gelangte nach Durchlaufen der Messkammer wieder in die im Wasserbad befindliche Flasche. Bei den Versuchen mit Zugabe der oben genannten Pharmaka wurde die ACSF über einen PVC-Schlauch in eine gesonderte Flasche abgeführt.

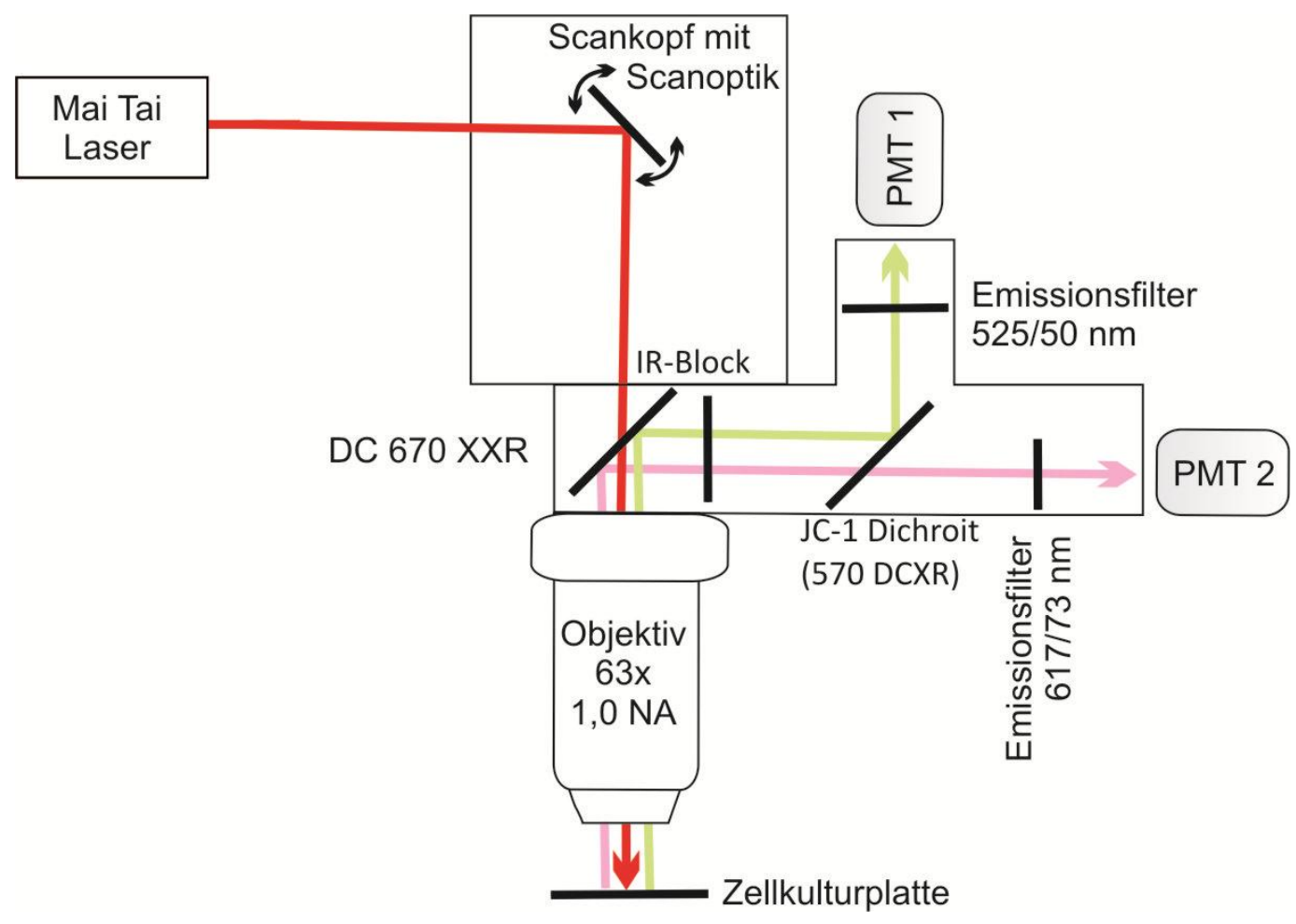

\section{Abbildung 7: Schematische Darstellung der TPLSM}

Die rote Linie zeigt den Verlauf des Laserstrahls. Der grüne und rote Strahl stellt die emittierte Fluoreszenz dar, die im dichroitischen JC-1-Filter (570 DCXR) separiert werden und daraufhin in den Photomultiplier-Röhren (PMT 1 und PMT 2) detektiert und in elektronische Signale umgewandelt werden.

\subsection{Bearbeitungssoftware}

Zur Verarbeitung und Auswertung der 2-Photonen-Laser-Mikroskop-Messungen kamen folgende Programme zum Einsatz:

Mai Tai Steuersoftware ist die Lasersteuersoftware, die mit der Steuersoftware des TPSLM ImSpector Pro gekoppelt ist. Das Programm reguliert unter anderem die Wellenlängensteuerung sowie einen Sicherheitsverschluss (shutter) und liefert diverse Kontrollmessdaten der Laserleistung. 
ImSpector Pro (LaVision, BioTec) ist ein Steuerungsprogramm des Herstellers Lavision Biotech, das den TriM-Scope Scankopf sowie Datenaufzeichnung und Scanvorgänge kontrolliert. Mit diesem Programm wurden die Feineinstellungen für den Laserscan getroffen. Hierzu gehörten u.a. die Festlegung des Scanbereiches, der Empfindlichkeit der PMTs, die Abstandsgröße zwischen den einzelnen Ebenen und die Räumlichkeit der Scanebene (zwei- oder dreidimensional).

Auto Deblur/Autovisualize® (Bio Vision Technologies®, USA) ist eine Software, die dazu beiträgt, Unschärfe und die optischen Beugungsfehler einer mikroskopischen Aufnahme zu minimieren. Dies ist die häufigste Ursache, wenn Licht durch ein Medium sowie durch optische Komponenten wie zum Beispiel Blenden oder Objektive dringt und dort gebrochen wird. Das Programm berücksichtigt hierbei die drei Dimensionen der Aufnahme (sogenannte z-Stapel) und berechnet basierend auf den optischen Parametern (Wellenlänge, Numerische Apertur des Objektivs etc.) den $\mathrm{zu}$ erwartenden theoretischen Fehler und führt eine entsprechende Korrektur (Dekonvolution) durch.

Metamorph Offline® (Version 6.1/7.0, Universal Imaging Corporation/Molecular Devices $\left.{ }^{\circledR}\right)$ ist eine Bildbearbeitungssoftware. Einzelne Aufnahmen von ImSpector Pro, die durch das 2-Photonen-Laser-Mikroskop generiert wurden, können mit dieser Software zu einer Sequenz (Stapel) zusammengesetzt werden. Weiterführende Bearbeitungsformen ermöglichen beispielsweise die individuelle Darstellung von Aufnahmen in verschiedenen Intensitätsbereichen, die 3D-Ansicht der Aufnahmen sowie die Darstellung in verschiedenen Farbpaletten. Hierbei kam die sogenannte Fehl- oder Pseudofarbenfunktion zum Einsatz, die dazu beitrug, Mitochondrienpotentiale darzustellen. Durch Kombination der Farbkanäle (color combine) war es möglich, die grün und rot detektierten Emissionsanteile miteinander zu vereinen. Mit Anwendung der Schwellenwertfunktion (threshold) wählt Metamorph ${ }^{\circledR}$ Bereiche aus, wie beispielsweise den Intensitätsbereich der ausgewählten Mitochondrien. Anschließend erfolgt eine tabellarische Darstellung der detektierten Partikel bzw. Objekte, die in Microsoft Excel® exportiert werden kann. Dabei kann man einen vorher angegebenen Bereich eingrenzen, um zum Beispiel mögliche Artefakte oder Mitochondrien, die sich am Rand der Aufnahme befinden und somit nicht vollständig dargestellt werden, auszuschließen. 
Alle statistischen Auswertungen der intensitätsbasierten (JC-1) oder der morphologischen Mitochondrienparameter und Darstellungen dieser Arbeit erfolgten mithilfe von Microsoft Excel®. Der Export von Metamorph®-Tabellen nach Microsoft Excel® ermöglichte eine weiterführende statistische Analyse und Auswertung der Daten. Zur Errechnung der statistischen Parameter von Mittelwert und Standardabweichung wurden die Funktionen des Programms Microsoft Excel® genutzt. Ebenfalls wurden die graphischen Darstellungsfunktionen des Programms zur Erstellung von Balkendiagrammen, Zeitverläufen etc. verwendet.

\subsection{Statistik}

Die Daten dieser Arbeit wurden insgesamt an dissoziierten Zellkulturen von 20 Mäusen erhoben (acht Wildtyp-Mäuse und zwölf Mecp2 $2^{-/ y}$-Mäuse). Im Vorfeld der eigentlichen Messreihen wurden drei NMRI-Mäuse zur Etablierung der Methode und Technik verwendet.

Die Ergebnisse sind in dieser Arbeit als Mittelwert \pm Standardabweichung dargestellt. Die Anzahl der Experimente (n) bezieht sich auf die Anzahl der jeweils gemessenen Zellen. Diese stammten grundsätzlich aus mehreren unterschiedlichen Tieren. Die Daten wurden mit dem Programm Microsoft Excel ${ }^{\circledR}$ ausgewertet und die statistische Signifikanztestung mit dem ungepaarten zweiseitigen T-Test nach Student bestimmt. Signifikante Unterschiede sind in den Diagrammen und Tabellen auf dem $5 \%$-Niveau $(\mathrm{p}<0,05)$ mit einem Stern $(*)$, auf dem $1 \%$-Niveau $(\mathrm{p}<0,01)$ mit zwei Sternen(**) und auf dem $0,1 \%$-Niveau $(\mathrm{p}<0,001)$ mit drei Sternen $(* * *)$ dargestellt. 


\section{Ergebnisse}

\subsection{Kalibrierung des 2-Photonen-Laser-Scanning-Mikroskops}

Die Entwicklung des 2-Photonen-Laser-Scanning-Mikroskops im Jahr 1990 war ein deutlicher Fortschritt in der Darstellung von biologischem Material (Denk et al. 1990). Seitdem wurde dieses Konzept ausgebaut und weiterentwickelt; es kam auch im Rahmen dieser Arbeit zum Einsatz.

Für die Bestimmung der besten erreichbaren Auflösung des hier verwendeten 2Photonen-Laser-Scanning-Mikroskop-Systems und der Auswahl des idealen Objektivs wurden im Vorfeld der eigentlichen Messreihen Auflösungstests mithilfe von fluoreszierenden Mikrokügelchen, sogenannten „Beads“ (Speck TM Tricolor Microscope Image Intensity Calibration Kit, Molecular Probes) durchgeführt. Bei Beads handelt es sich um kleine fluoreszierende Latexkügelchen mit einer standardisierten Größe, die sich durch eine hohe Photostabilität auszeichnen und kein Flimmern zeigen oder Ausbleichen erleiden. Aufnahmen mit derartigen Beads stellen eine ideale Methode dar, um die erreichbare Auflösung eines Objektivs bzw. eines optischen Systems festzustellen. Die Auflösung ist definitionsgemäß der kleinstmögliche Abstand zwischen zwei Strukturen, bei dem diese noch als getrennt wahrgenommen werden.

Die Ermittlung der maximal erreichbaren Auflösung erfolgt mit der Visualisierung bzw. Bestimmung der point spread function $(P S F)$ in lateraler und axialer Ebene. Die experimentell ermittelte PSF gibt an, wie die Beads durch das 2-Photonen-LaserScanning-System abgebildet würden. Dabei entspricht die axiale PSF der z-Achse xz-Ebene/yz-Ebene), sprich wie die Punktquelle sich ausweitet, wenn man sich von der fokalen Ebene entfernt. Die laterale Auflösung bezieht sich auf die xy-Ebene und beschreibt, wie die Punktquelle sich in der fokalen Ebene ausweitet. Alternativ kann die $P S F$ auch theoretisch durch Berechnungen ermittelt werden.

Zunächst wurden die theoretischen Auflösungsgrenzen für die folgenden fünf vorhandenen Objektive ermittelt: Olympus 20x 0.95 NA XLUMP, Zeiss 40x 0.8 NA 
IR Achroplan, Zeiss 63x 0.9 NA IR, Zeiss 63x 1.0 NA UV VIS, 63x 1.2 NA CApochromat. Dabei wurde die theoretische laterale und axiale Auflösung mit folgenden Formeln berechnet:

lateral $r(x, y)=0,7 \lambda(\mathrm{em}) / N A$

axial $r(z)=2,3 \lambda(\mathrm{em}) *_{n} / N A^{2}$

Erläuterung:

$\mathrm{r}=$ Auflösung; $\mathrm{x}, \mathrm{y}, \mathrm{z}=$ betrachtete Achse; $\lambda(\mathrm{em})=$ Emissionswellenlänge; $\mathrm{n}=$ Brechungsindex von Wasser $=1,33 ; \mathrm{NA}=$ Numerische Apertur des Objektivs

A

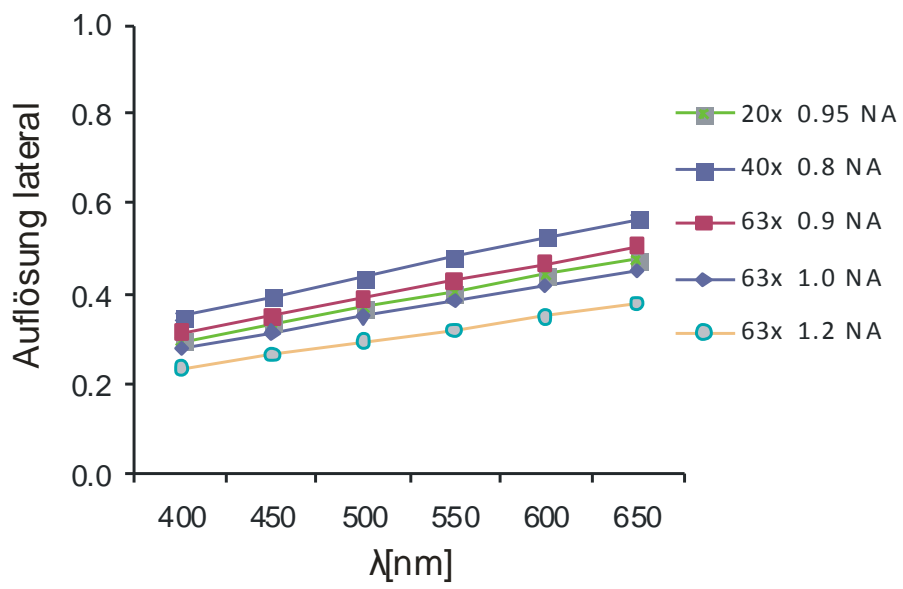

B

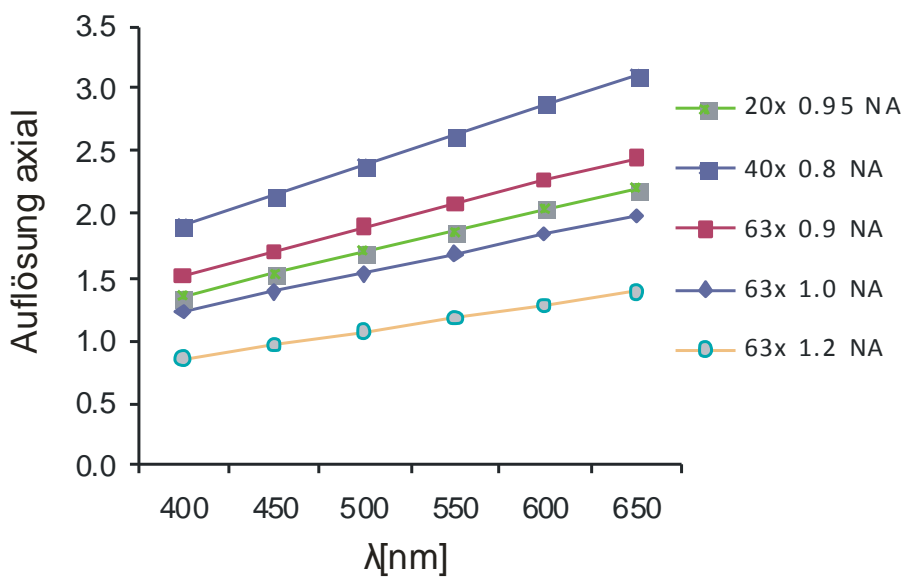

\section{Abbildung 8: Darstellung der theoretischen Auflösung bei unterschiedlichen Objektiven}

A) zeigt die theoretische Auflösung lateral (xy) und B) die theoretische Auflösung axial (xz). Als Kennzeichnung sind die Vergrößerung sowie die Numerische Apertur (NA) des jeweiligen Objektivs angegeben. Die laterale und die axiale Auflösung steigen jeweils linear an. Es zeigt sich, dass die Auflösung der Objektive präziser ist, je größer die Numerische Apertur ist. Das 63x 1.2 NA C-Apochromat-Objektiv hat somit die größte theoretisch zu erwartende Auflösung. 
Die ausgewählten Objektive sollen für die gesamte Aufnahmereihe die Voraussetzung eines Immersionsobjektivs erfüllen, da die Versuche in ACSF stattfanden. Immersionsobjektive sind solche, die beim Einsatz von Immersionsflüssigkeiten verwendet werden. Sie zeichnen sich durch eine hohe Auflösung und eine große Numerische Apertur meist um 1,0 aus. Theoretisch zeigte sich das 63x 1.2 NA CApochromat durch die beste theoretische Auflösung am Geeignetsten. Es erfüllte allerdings nicht die Voraussetzung eines universell einsetzbaren Immersionsobjektivs, da die zwingend erforderliche Beschichtung für physiologische Salzlösungen fehlte und somit potentielle Korrosionsprobleme zu erwarten waren. Zudem kann dies zu Auflösungsverlusten und Korrekturverschlechterungen kommen. Ausgewählt wurde deshalb das 63x 1.0 NA Objektiv, das eine entsprechende Beschichtung für physiologische Lösungen und, wie in Abbildung 8 abgebildet, über die nächsthöhere theoretische Auflösung lateral und axial verfügt.

Zur experimentellen Ermittlung der PSF kamen 100-nm-Beads zum Einsatz. Zur Vorbereitung wurde ein Tropfen der Bead-Suspension auf einen gläsernen StandardObjektträger aufgetragen. Nach einer kurzen Trocknungsphase zur Anheftung der Beads wurden diese dann mit ACSF überschichtet, die auch bei den Aufnahmen mit der Zellkultur zum Einsatz kam. Von Vorteil hierbei ist eine klar separate Platzierung der Beads auf dem Deckgläschen, da sie nur dann korrekt auszuwerten sind. Die Beads wurden durch den 2-Photonen-Laser bei $800 \mathrm{~nm}$ angeregt. Bei den Aufnahmen wurden immer dreidimensionale Bildstapel, sogenannte z-Stapel, aufgenommen. Diese z-Stapel beinhalteten neben dem Bereich der angegebenen Bead-Größe auch einige Mikrometer ober- und unterhalb des jeweiligen Beads, um sicherzustellen, dass die Beads vollständig abgerastert werden. Die folgende Tabelle zeigt die Standardeinstellungen zur Kalibrierung des 2-Photonen-Laser-Mikroskops (TPLSM). Zur Messung der 100-nm-Beads (subresolution beads) kam das lichtstärkere 40x 0.8 NA Objektiv zum Einsatz, da diese Beads aufgrund ihrer geringen Größe nur eine äußerst schwache Fluoreszenzemission erzeugen. 


\begin{tabular}{|c|c|}
\hline Parameter des Lasermikroskops & 100-nm-Beads \\
\hline Wellenlänge Anregung [nm] & 800 \\
\hline Scanfeldgröße $[\mu \mathrm{m}]$ & $68 \times 68$ \\
\hline Pixelzahl & $1125 \times 1125$ \\
\hline Gemittelte Linien & 5 \\
\hline Scanfrequenz [Hz] & 1200 \\
\hline Objektiv & $40 \mathrm{x} 0.8 \mathrm{NA}$ \\
\hline $\mathrm{z}$-Stapel $[\mu \mathrm{m}]$ & $-7 \rightarrow+7$ \\
\hline$\Delta \mathbf{z}[\mu \mathbf{m}]$ & 0,15 \\
\hline PMT 1, Empfindlichkeit [\%] & 65 \\
\hline PMT 2, Empfindlichkeit [\%] & 65 \\
\hline Laserleistung [\%] & 1,5 \\
\hline
\end{tabular}

Tabelle 3: Parameter des Lasermikroskops

Aufgelistet sind die jeweiligen Einstellungen des Lasermikroskops, die zur Ermittlung der point spread function (PSF) anhand 100-nm-Beads gewählt wurden. Zu beachten war hierbei ein ausreichender Scanbereich jeweils nach oben und unten (z-Stapel), um die Detektierung der Beads in ihrem gesamten Durchmesser gewährleisten zu können.

Die Lasereinstellungen wurden so gewählt, dass die Beads maximal leuchteten, jedoch nicht überstrahlt dargestellt worden sind. Zur Ermittlung der PSF wurden entsprechend der gängigen Praxis subresolution beads mit einer Größe von nur 100 $\mathrm{nm}$ verwendet. Es wurden die Helligkeitsprofile dieser Beads in $\mathrm{x}-$, $\mathrm{y}-\mathrm{und} \mathrm{z}-\mathrm{Richtung}$ bestimmt und diese für mehrere Beads gemittelt. Die Breite dieser Helligkeitsverteilung am 50 \%-Level (halbmaximale Intensität) wird Halbwertsbreite bzw. Full Width at Half Maximum (FWHM) genannt und dient als Maßgröße für die jeweils in dieser Achse erreichbare räumliche Auflösung. 
A

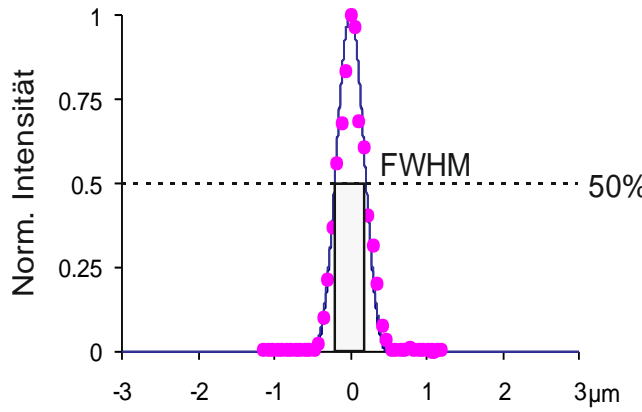

C

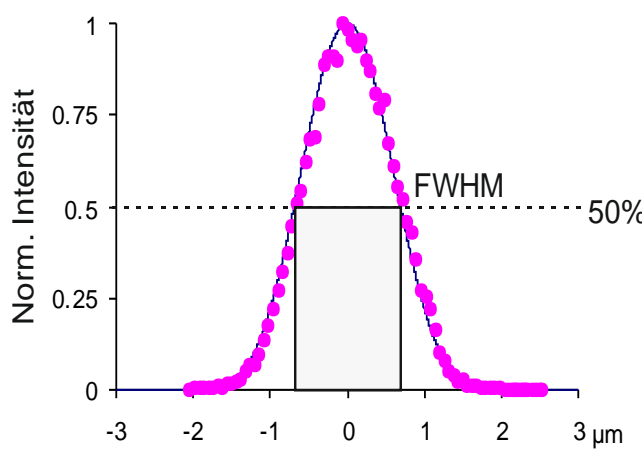

B

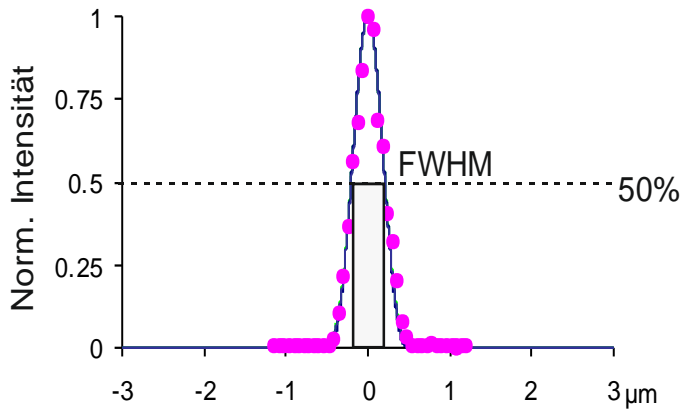

D

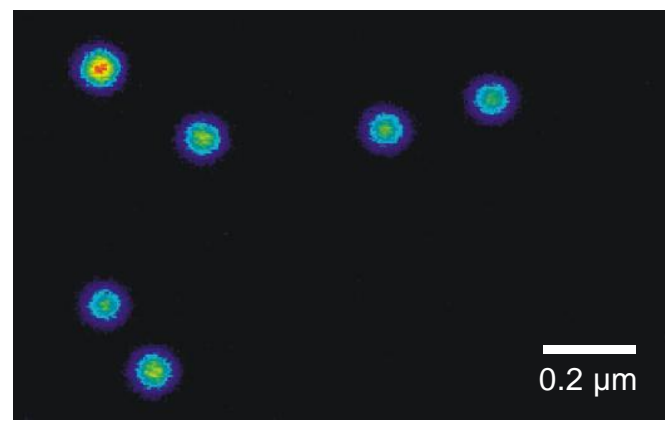

Abbildung 9: Darstellung der normalisierten point spread function (PSF) in den verschiedenen Achsen mittels 100-nm-Beads

Gezeigt sind die Intensitätsprofile der Beads und sie liefern mit der Halbwertsbreite ein Maß für das räumliche Auflösungsvermögen des TPSLM.

Die Intensitätskurven enthalten die gemittelten Daten von 24 Beads. Die Profile wurden normiert und gemittelt, um eine mögliche Variabilität von Beadform und Beadgröße auszugleichen. Der Durchmesser der Beads $(100 \mathrm{~nm})$ liegt unter dem Auflösungsvermögen des TPSLM, so dass hier die PSF des optischen Systems erhalten wurde. Die Halbwertsbreite der PSF ergibt eine laterale Auflösung von $\mathrm{r}_{\mathrm{xy}} \approx$ $0,4 \mu \mathrm{m}$ und eine axiale Auflösung von $\mathrm{r}_{\mathrm{z}} \approx 1,4 \mu \mathrm{m}$.

A) Angefittete $P S F$ in der $\mathrm{x}$-Achse.

B) Angefittete $P S F$ in der der $y$-Achse.

C) Angefittete $P S F$ in der z-Achse. In der Grafik ist zusätzlich die Halbwertsbreite $(F W H M)$ dargestellt.

D) Beispielaufnahme von 100-nm-Beads gemessen bei einer Wellenlänge von 800 $\mathrm{nm}$. 
A

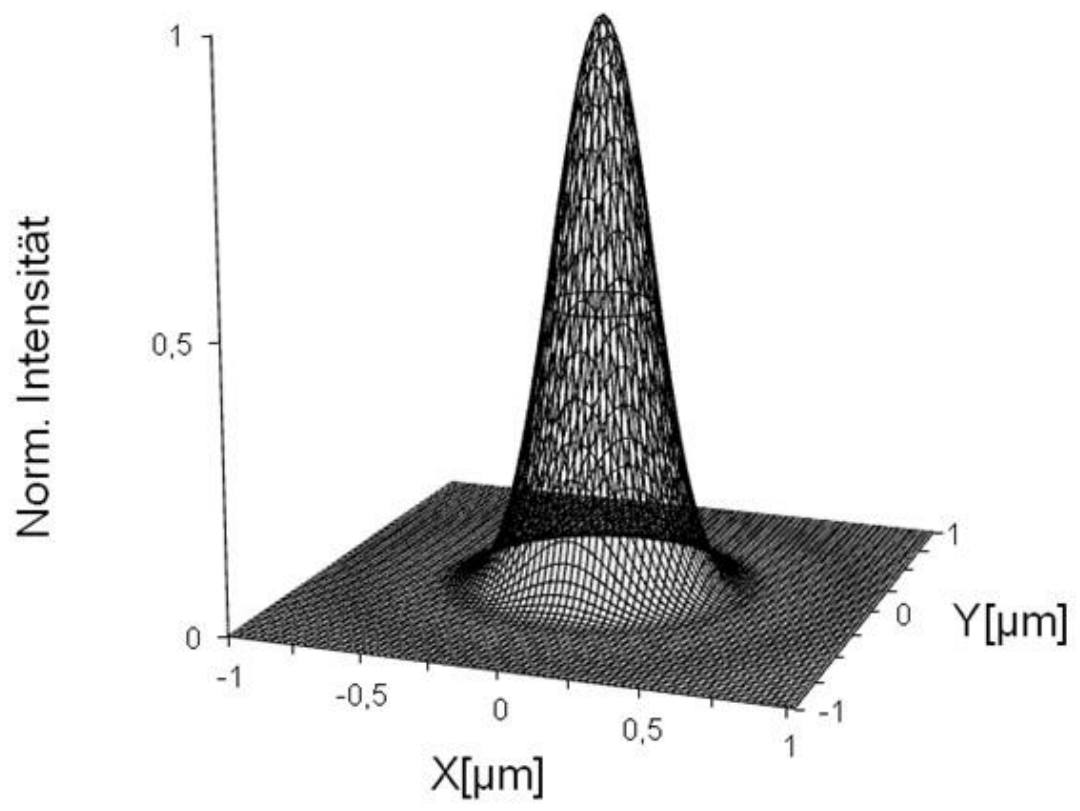

B

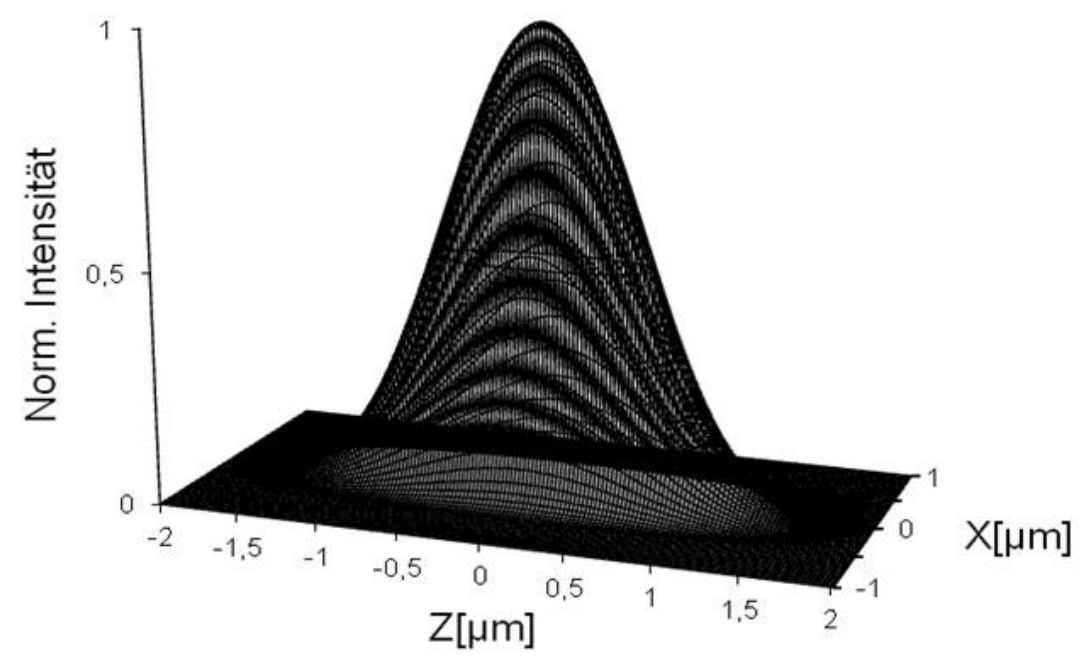

\section{Abbildung 10: 3-D Rekonstruktionen der point spread function (PSF)}

Die PSF wurde jeweils von den aufgenommen Aufnahmen der Beads in A) lateraler (xy) Richtung und B) in axialer (z) Richtungen gemessen. Sämtliche Beads wurden in verschiedenen Schichten (4 $\mu \mathrm{m}$ Gesamtausdehnung) gemessen, um sie trotz unterschiedlicher Lage korrekt detektieren zu können.

Im Rahmen der Bead-Aufnahmen wurden außerdem die theoretisch erwartete und gemessene Auflösung in nm/pixel von 10- $\mu$ m-Beads für verschiedene ScanfeldBereiche errechnet und überprüft. Damit wurden die Angaben der Auswertungssoftware des TPLSMs verifiziert. Es wurden Werte für die Objektive Olympus 20x 0.95 NA XLUMP, Zeiss 40x 0.8 NA IR Achroplan und Zeiss 63x 1.0 NA UV VIS ermittelt. 
In den eigentlichen Versuchen kam dann letztlich das Zeiss 63x 1.0 NA UV VISObjektiv zum Einsatz. Es ist zwar nicht speziell IR-optimiert, hat aber im Gegensatz zu dem höher auflösenden 63x 1.2 NA C-Apochromat Objektiv eine spezielle Immersionsbeschichtung. Es bewies sich zudem beim räumlichen Auflösungsvermögen als gut geeignet und auch entsprechend lichtstark, was eine sensitive Detektion der schwachen Fluoreszenzemission einzelner Mitochondrien erwarten ließ. Für alle weiteren Aufnahmen wurde daher dieses Objektiv und ein Scanfeldbereich von $273 \times 273 \mu \mathrm{m}$ in Imspector Pro® gewählt.

\begin{tabular}{|c|c|c|c|c|}
\hline Objektiv & Scanfeld $[\mu \mathrm{m}]$ & Pixel & $\begin{array}{l}\text { Pixelgröße } \\
\text { erwartet } \\
\text { [nm/pixel] }\end{array}$ & $\begin{array}{l}\text { Pixelgröße } \\
\text { gemessen } \\
\text { [nm/pixel] }\end{array}$ \\
\hline \multirow[t]{5}{*}{ 63x 1.0 NA } & 21,6 & 1125 & 19,2 & 17,7 \\
\hline & 43,2 & 900 & 48 & 43,1 \\
\hline & 86,7 & 1000 & 86,7 & 79,2 \\
\hline & 115,6 & 1000 & 115,6 & 105 \\
\hline & 147,6 & 937 & 157,6 & 140,4 \\
\hline \multirow[t]{5}{*}{$40 \times 0.8 \mathrm{NA}$} & 34 & 1125 & 30,2 & 28,1 \\
\hline & 68 & 900 & 75,6 & 70 \\
\hline & 136,5 & 1000 & 136,5 & 128,1 \\
\hline & 182 & 1000 & 182 & 168,7 \\
\hline & 232,5 & 937 & 248,2 & 226,5 \\
\hline \multirow[t]{5}{*}{$20 \times 0.95$ NA } & 68 & 1125 & 60,4 & 60,9 \\
\hline & 136 & 900 & 151,1 & 153,2 \\
\hline & 273 & 1000 & 273 & 282,3 \\
\hline & 364 & 1000 & 364 & 364,6 \\
\hline & 465 & 937 & 496,3 & 487,8 \\
\hline
\end{tabular}

Tabelle 4: Verifizierung von Scanfeldgröße und Pixelgröße anhand des 20x-, 40xund 63x-Objektivs mithilfe normierter Beads

\subsection{Veränderungen von Morphologie, Masse und Membranpotential der Mitochondrien von MeCP2-defizienten Mäusen}

Wie einleitend im Detail bereits dargestellt, wurden bisher mitochondriale Stoffwechselveränderungen und Strukturveränderungen im Rett-Syndrom beschrieben. Diese Veränderungen wurden aber bisher nicht auf Ebene einzelner Mitochondrien betrachtet. Da die hochauflösende Mikrokopie, wie hier zum Einsatz 
kommend, genau dieses ermöglicht, lag der Fokus im Rahmen dieser Arbeit auf der Betrachtung dieser strukturellen und funktionellen Veränderungen. Zur Untersuchung der Mitochondrienveränderungen im Rett-Syndrom kam der in Kapitel 2.4. beschriebene emissions-ratiometrische Mitochondrienfarbstoff JC-1 zum Einsatz. Durch die gezielte Akkumulation in den Mitochondrien und anschließenden Aufnahmen mit dem 2-Photonen-Laser-Mikroskop liefert JC-1 funktionelle Aussagen über den Zustand einzelner Mitochondrien. Hierbei können die mitochondriale Morphologie, die Anzahl der einzelnen Mitochondrien pro Zelle und insbesondere das Membranpotential individueller Mitochondrien ermittelt werden. Im Fokus standen bei diesen Untersuchungen mögliche mitochondriale Unterschiede zwischen Wildtypund $M e c p 2^{-/ y}$ Tieren. Nach fünfminütiger Inkubation mit JC-1 wurden die Aufnahmen mithilfe des TPSLM (63x 1.0 NA Objektiv) gestartet und die relevanten Mitochondrienparameter halbautomatisiert erfasst. Dabei wurden grundsätzlich dreidimensinoale $\mathrm{z}$-Stapel bestehend aus 40 Einzelbildern $(\Delta \mathrm{z}=0,25 \mu \mathrm{m})$ erstellt, um die Gliazellen ausreichend hochauflösend zu erfassen. Nach erfolgreicher Detektion wurden die Mitochondrienaufnahmen mithilfe der Software-Programme AutoDeblur®, Metamorph ${ }^{\circledR}$ und Microsoft Excel ${ }^{\circledR}$ im Detail analysiert.

Hierfür musste zunächst eine optimale Auswertungsstrategie entwickelt werden, um die Mitochondrien möglichst zuverlässig und halbautomatisch zu detektieren. Zunächst wurden sämtliche z-Stapel mit Autodeblur® einer Deconvolution unterzogen, um das Pixelrauschen zu minimieren. Diese Korrekturberechungen erfolgten unter Anwendung der theoretischen point spread function (PSF), die auf den optischen Daten des 63x NA 1.0 Objektivs und den jeweiligen Detektionswellenlängen der grünen und roten JC-1-Fluoreszenzen (525 und $617 \mathrm{~nm}$ ) basierte. Diese Detektionswellenlängen entsprachen den mittleren Transmissionswellenlängen des verwendeten JC-1-Filtersatzes der vor den Photomultiplier (grüner Emissionskanal Bandpass 525/50 nm und roter Emissionskanal Bandpass 617/73 nm) montiert war. Der genaue experimentelle Aufbau ist in Kapitel 2.5 beschrieben.

Für die weiteren automatisierten Analysen wurden folgende Einstellungen bei Metamorph ${ }^{\circledR}$ gewählt: Da die Aufnahmen in der X-, y- und z-Ebene erfolgten, wurde basierend auf der besten Fokusebene, in der die fluoreszierenden Mitochondrien gut 
sichtbar waren, zunächst fünf flankierende z-Ebenen gewählt und in eine MaximalProjektion kollabiert, um die einzelnen Mitochondrien möglichst intensiv darzustellen und gut vom Hintergrund abgrenzen zu können. Die entstandenen Bilder wurden dann in eine 8-bit-Fehlfarben-Skala (entspricht 256 Farbstufen) umgewandelt, um die Mitochondrien vom umgebenden Zytosol optisch besser abgrenzen zu können. Um ein ratiometrisches Bild der JC-1-Fluoreszenz zu erhalten, wurden die Intensitätswerte der roten JC-1-Emission durch die grünen JC-1-Intensitätswerte dividiert, und mit einem konstanten Faktor 200 multipliziert. Dadurch sollten Intensitätsunterschiede der beiden Kanäle ausgeglichen und vor allem die 8-bit-Farbskala adäquat ausgenutzt werden.

Die Funktion eines Intensitätsschwellenwertes (sogenanntes threshold) wurde verwendet, um die fluoreszierenden Mitochondrien eindeutig $\mathrm{zu}$ identifizieren. Dadurch entstand ein binäres Bild (schwarz/weiß), dass das Vorhandensein von Mitochondrien anzeigte oder eben das Fehlen derselben. Diese Matrize wurde dann zur Vermessung der Mitochondrien genutzt und diente ebenfalls als Maske zur JC-1Intensitätsbestimmung der grünen Monomer-Fluoreszenz und der roten Emission der J-Aggregate und der anschließenden Berechnung der entsprechenden JC-1-Ratios.

Um systematische Messabweichungen zu reduzieren, wurde ein Software-basierter Filter zur Partikelanalyse ausgewählt. Dieser ließ eventuelle Färbeartefakte aus JC-1Aggregationen unberücksichtigt, die zum Teil außerhalb der Zellen vorlagen. Weiterhin wurden Mitochondrien ausgeschlossen, die sich zusammengehäuft hatten und daher nicht eindeutig als individuelle Organellen zu identifizieren waren. Zudem wurden alle Strukturen ausgegrenzt, die sich im Randbereich der mikroskopischen Bilder befanden und somit nicht komplett darstellen ließen. Dies ermöglichte korrekte morphologische Auswertungen. Im Detail wurden folgende Parameter mit Metamorph® analysiert: Anzahl der eindeutig zu identifizierenden Partikel (Mitochondrien), deren mittlere Intensität sowie deren Länge (in $\mu \mathrm{m})$. Für jede Gliazelle wurde die größtmögliche Anzahl von Mitochondrien gewählt. Begleitend zur Partikelanalyse wurde aus den binären Bildern zudem die gesamte Mitochondrienmasse einer jeden Zelle erfasst. Dazu wurde die Summe alle überschwelligen Pixel ermittelt und die so bestimmte Gesamtmasse der Mitochondrien zusätzlich auf die Zellgröße normiert. 


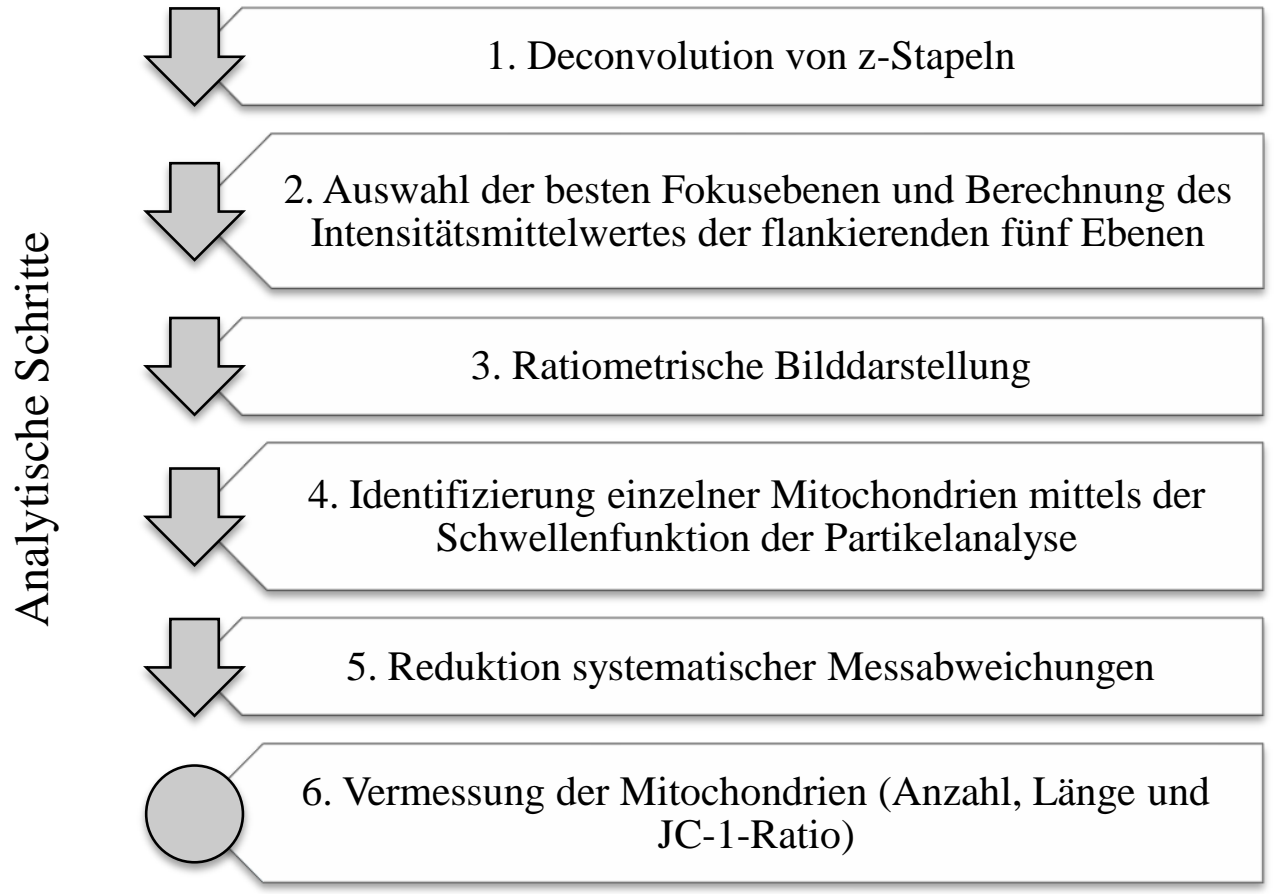

Abbildung 11: Schematischer Ablauf der Mitochondrienanalyse

Die Bearbeitung von Schritt 1 erfolgte mithilfe von Autodeblur®; die Schritte 2-6 wurden anhand Metamorph ${ }^{\circledR}$ bearbeitet.

Bei den nachfolgenden detaillierten optischen Analysen auf subzellulärer Ebene der kultivierten Gliazellen lag der Fokus zunächst auf den möglichen genotypischen Unterschieden zwischen Wildtyp- und $M e c p 2^{-/ y}$-Mäusen. Dabei wurde speziell die Größe der einzelnen Mitochondrien, die JC-1-Ratio der einzelnen Organellen sowie die Anzahl der eindeutig zu identifizierenden individuellen Mitochondrien pro Zelle ausgewertet. Um mögliche Unterschiede zu verdeutlichen, wurden die Mitochondrien sowohl als Einzelpartikel betrachtet als auch ihre Eigenschaften auf der Ebene jeder einzelnen Zelle gemittelt. 

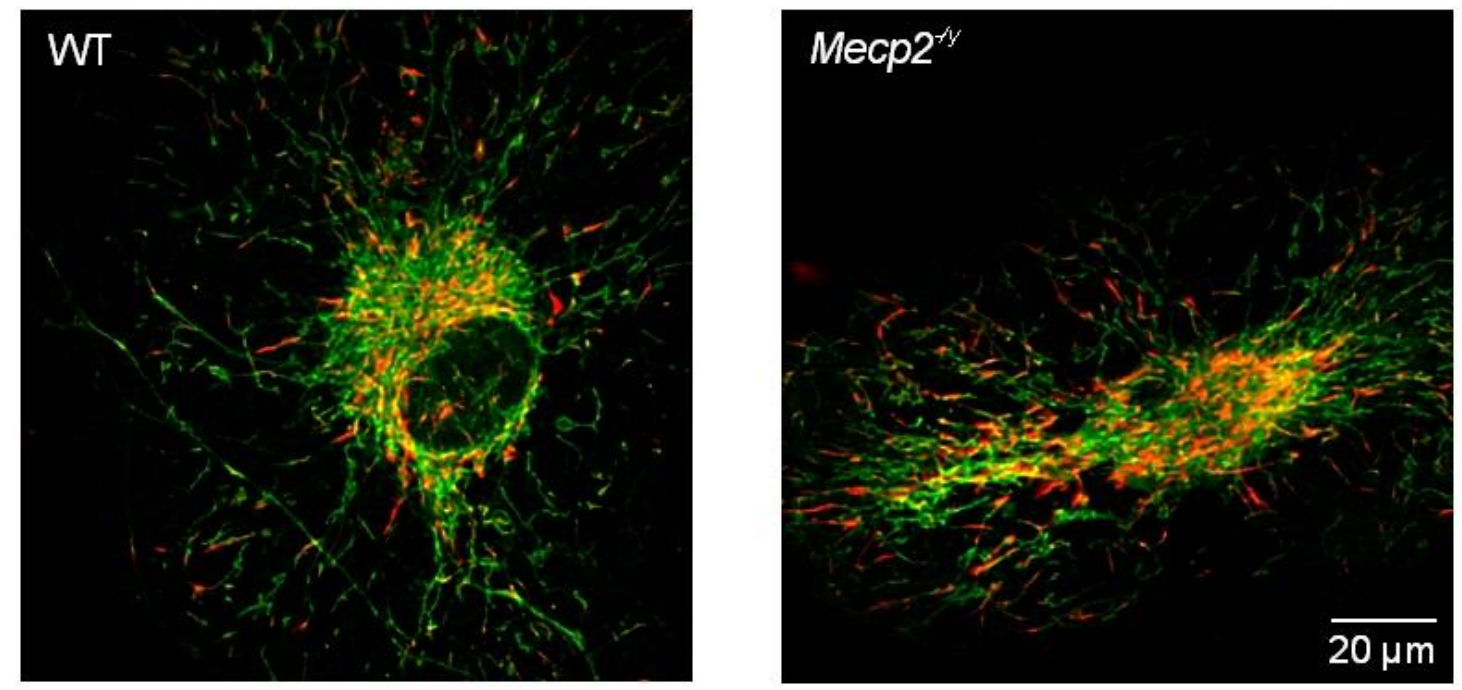

Abbildung 12: Beispielaufnahmen JC-1-markierter Mitochondrien von Wildtyp

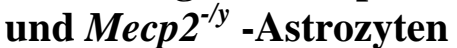

Sie stellen die Überlagerung der roten und grünen Spektralkomponenten der JC-1Fluoreszenz dar. $\mathrm{Zu}$ beachten ist hierbei die ungleiche Verteilung und die unterschiedliche Form und Polarisation der jeweiligen Mitochondrien.

Es wurden die Mitochondrien von Wildtyp-Astrozyten und von Mecp $2^{-/ y}$-Astrozyten mit den in Text beschriebenen halbautomatisierten Analysen erfasst und miteinander verglichen. Dies lieferte morphologische und funktionelle Daten von insgesamt 9769 Mitochondrien aus Wildtyp-Astrozyten sowie 21424 Mitochondrien aus Mecp $2^{-/ y}$ Astrozyten. Weitere Analysen dieser großen Anzahl von Mitochondrien erfolgten sowohl auf der Ebene der einzelnen Partikel als auch gemittelt pro Zelle, um gegebenenfalls zellspezifische Unterschiede zu erfassen. Die mittlere Länge der einzelnen Mitochondrien und ihre Verteilungshäufigkeit waren zwischen Wildtyp- und Mecp $2^{-/ y}$-Astrozyten nicht zu unterscheiden und betrugen 2,34 $\mu \mathrm{m}$ und 2,32 $\mu \mathrm{m}$ (Abb. 13 A). Auch die durchschnittliche Polarisation der einzelnen Mitochondrien wies keine markanten Unterschiede auf, wie aus der kumulativen Verteilung der Mitochondrienpotentiale zu entnehmen ist (Abb. 13 B). 
A

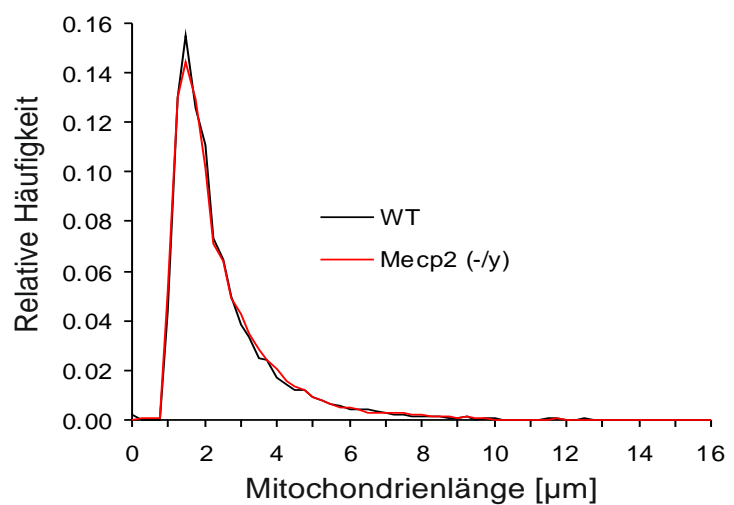

B

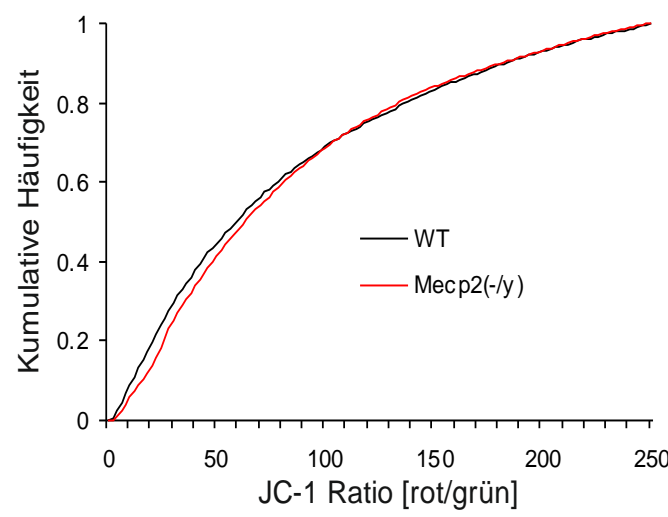

Abbildung 13: Mitochondrienlänge und JC-1-Ratio bei normalen Versuchsbedingungen in ACSF

A) Morphologische Analysen zeigten keine genotypischen Unterschiede in der Mitochondrienlänge von Wildtyp- und Mecp $2^{-/ y}$ - Mitochondrien.

B) Die JC-1-Ratio unterschied sich nicht zwischen den zwei Genotypen. Die aufgetragenen Daten beruhen auf einer Einzelpartikelanalyse aus 9769 Mitochondrien aus Wildtyp-Astrozyten und 21424 Mitochondrien aus Mecp $2^{-/ y}$-Astrozyten.

Eine Korrelationsanalyse zeigte, dass ein Zusammenhang zwischen JC-1-Ratio und der Länge der einzelnen Mitochondrien weder für Wildtyp- noch für Mecp $2^{-/ y}$ Mitochondrien bestand (Korrelationskoeffizienten WT 0,09 und $M_{\text {ecp }} 2^{-/ y} 0,10$ ).

Auch auf zellulärer Ebene gemittelt unterschieden sich Wildtyp- und Mecp $2^{-/ y}$ Mitochondrien nicht in ihrer Länge. Im Mittel hatten die Wildtyp-Mitochondrien bei einer Astrozytenanzahl von $\mathrm{n}=104$ eine Länge von 2,26 $\pm 0,67 \mu \mathrm{m}$ und $M e c p 2^{-/ y_{-}}$ Mitochondrien bei einer Astrozytenanzahl von $n=156$ eine Länge von 2,25 $\pm 0,32 \mu \mathrm{m}$ (Abb. 14 A). Die JC-1-Ratio war bei Wildtyp- und Mecp2 $2^{-/ y}$-Mitochondrien gleich (Abb. 14 B). Signifikante Unterschiede ergaben sich allerdings bei der mitochondrialen Dichte. Es zeigte sich, dass bei der verwandten Partikelanalyse in Astrozyten von $M e c p 2^{-/ y}$-Mäusen eine größere Anzahl einzelner Mitochondrien pro Zelle eindeutig identifiziert werden konnten. Im Mittel waren dies bei $M e c p 2^{-/ y}$ Astrozyten 136,5 \pm 81,5 und bei Wildtyp-Astrozyten aber nur 93,1 \pm 62,0 Mitochondrien pro Zelle. Um zu überprüfen, ob dies eventuell aus Größenunterschieden der Wildtyp- und $M e c p 2^{-/ y}$-Astrozyten resultiert, wurde die Mitochondrienanzahl auf die jeweilige Zellgröße normiert. Dabei blieb dieser genotypische Unterschied jedoch erhalten. Wildtyp-Astrozyten wiesen eine Mitochondriendichte von 0,020 $\pm 0,013$ pro $\mu \mathrm{m}^{2}$ Zellfläche auf $(\mathrm{n}=104)$ und Mecp ${ }^{-/ y}$ Astrozyten enthielten $0,029 \pm 0,015$ pro $\mu \mathrm{m}^{2}$ Zellfläche $(\mathrm{n}=156)$. Unterschiede der 
Zellgröße waren zwischen Wildtyp- und $M e c p 2^{-/ y}$-Astrozyten nicht nachzuweisen (Wildtyp: $4702 \pm 950 \mu \mathrm{m}^{2}$, Mecp $^{-/ y}: 4774 \pm 1097 \mu \mathrm{m}^{2}$ ).

A

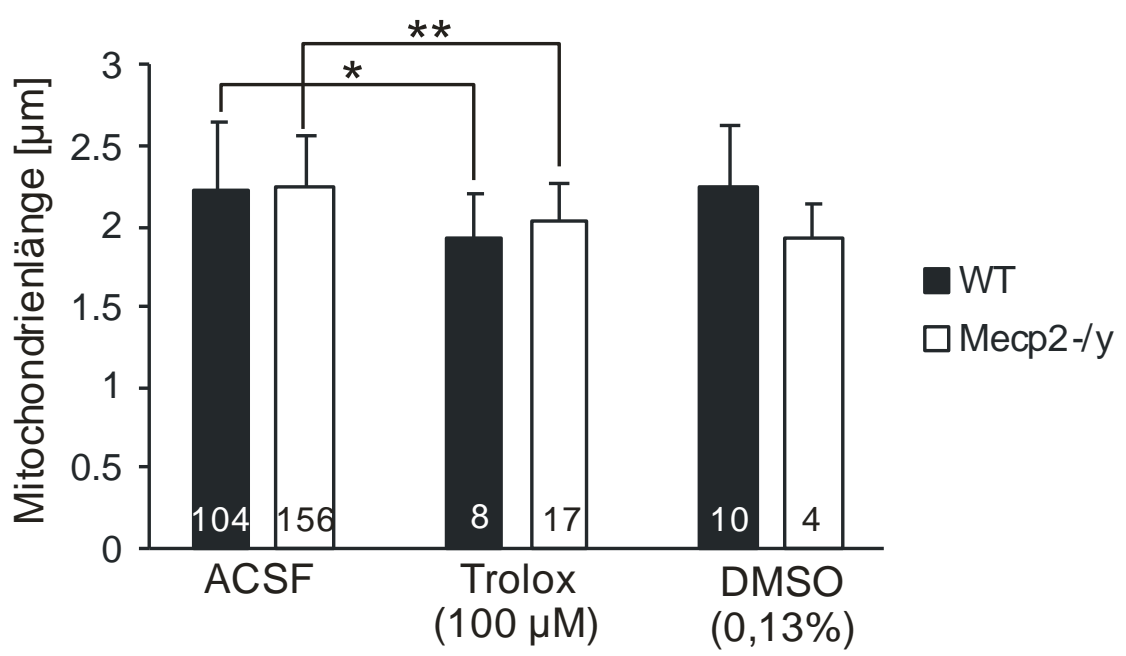

B
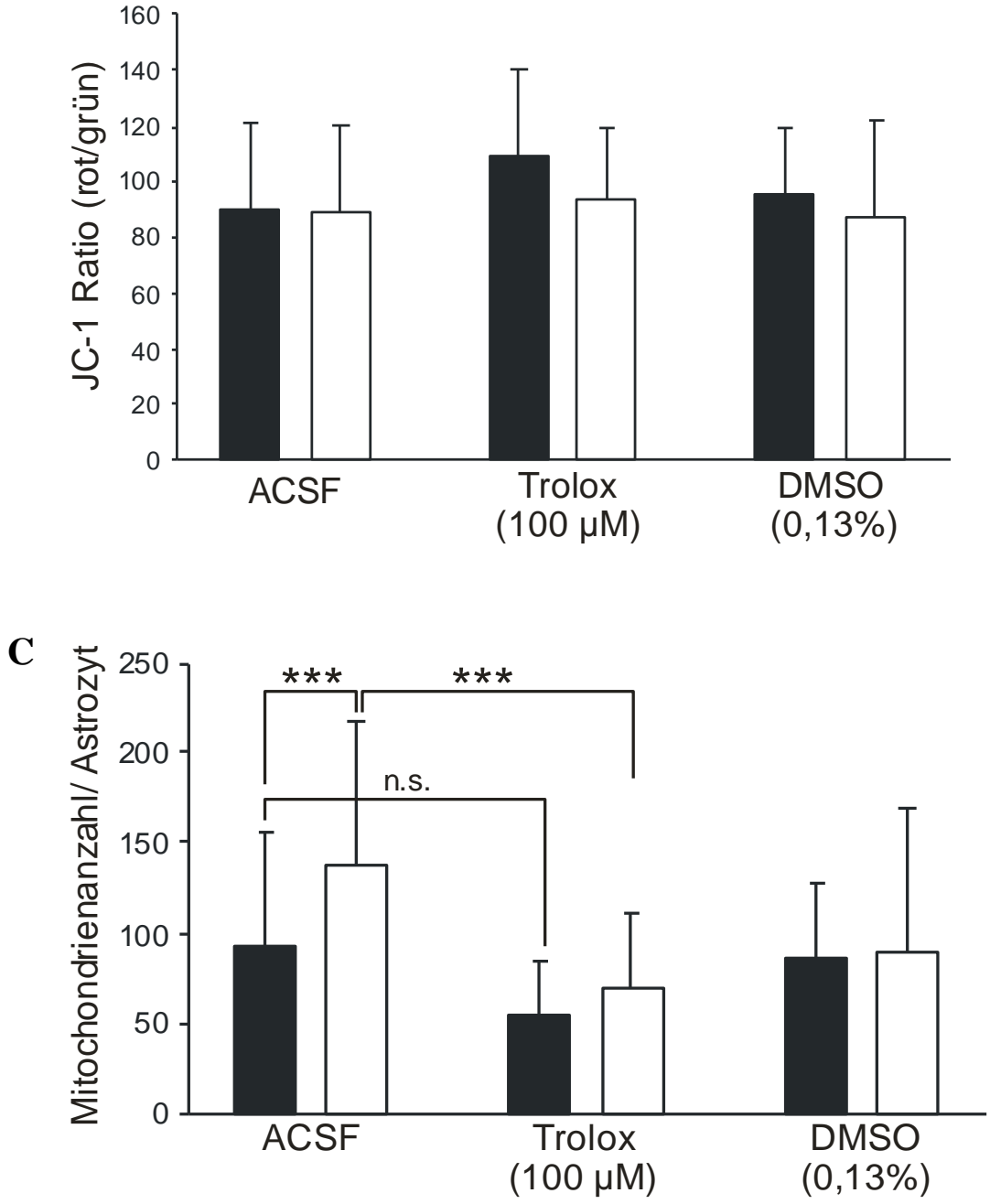
Abbildung 14: Darstellung der Mitochondrienlänge, der JC-1-Ratio und der Mitochondrienanzahl pro Zelle in ACSF, Trolox und DMSO

A)-C) stellen jeweils auf zellulärer Ebene die Mitochondrienlängen in $\mu \mathrm{m}$, die JC-1Ratio und Mitochondrienanzahl von Wildtyp-Astrozyten im Vergleich zu Mecp2 $2^{-1 y}$ Astrozyten in folgenden Lösungen dar: 1. ACSF (artifizielle zerebrospinale Flüssigkeit), die in den Versuchen als Basismedium zum Einsatz gekommen ist. 2. Trolox $(100 \mu \mathrm{M})$, das als Antioxidans fungiert. 3. DMSO $(0,13 \%)$ um mögliche Einflüsse dieses Lösungsmittels zu erkennen (siehe auch Kapitel 2.4). Zu beachten ist hierbei, dass bei Trolox und DMSO Behandlung nur verschiedene Populationen verglichen werden konnten. Die Anzahl der jeweils analysierten Zellen ist angegeben.

Die Bestimmung der gesamten absoluten Mitochondrienmasse auf zellulärer Ebene bestätigte die aus der Partikelanalyse erhaltenen Daten (Abbildung 15). Trotz gleicher Zellgröße war die Gesamtmasse der Mitochondrien in Mecp2 $2^{-/ y}$-Astrozyten $(440 \pm 214$ $\left.\mu \mathrm{m}^{2}\right)$ signifikant höher als bei Wildtyp-Astrozyten $\left(348 \pm 160 \mu^{2}\right)$. Dieser genotypische Unterschied blieb auch bei Normierung der mitochondrialen Masse auf die Zellgröße bestehen (Abbildung 15).

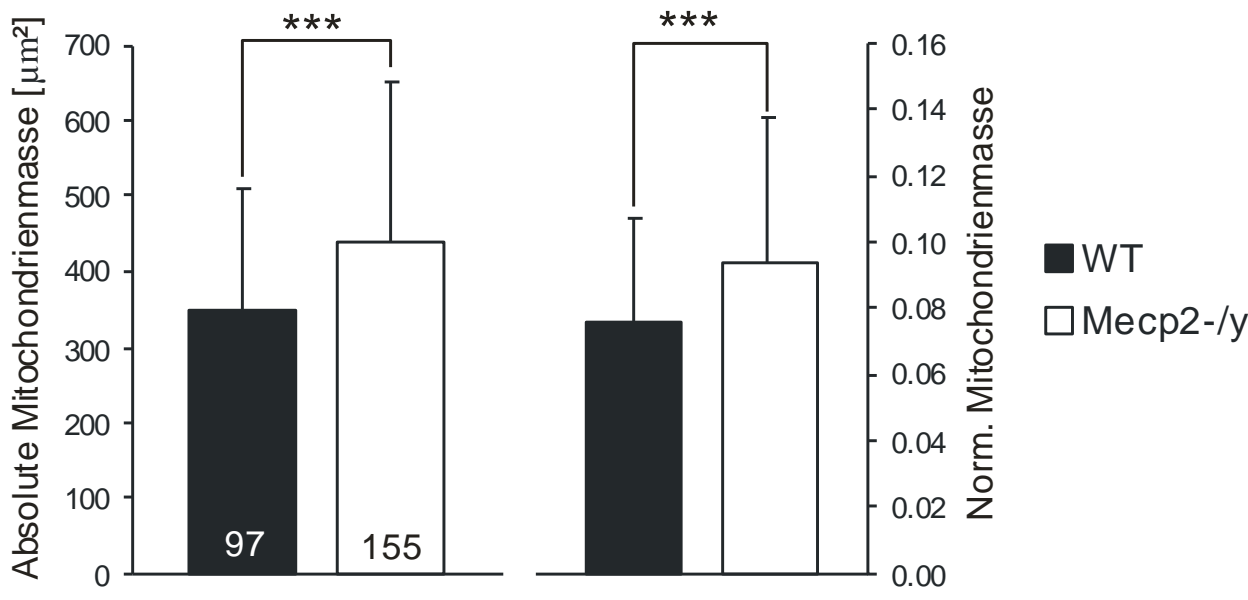

Abbildung 15: Darstellung der absoluten sowie normierten Mitochondrienmasse

\subsection{Modulation der mitochondrialen Eigenschaften durch Radikalfängerbehandlung}

Da im Rett-Syndrom ein Vitamin E-Mangel festgestellt wurde (Formichi et al. 1998) und in begleitenden Versuchen unserer Arbeitsgruppe eine positive Wirkung des Vitamin E-Derivats Trolox in isoliertem hippocampalen Gewebe von Mecp $2^{-/ y_{-}}$ Mäusen nachgewiesen wurde (Grosser et al. 2012, Janc und Müller 2014), kam auch 
im Rahmen dieser Arbeit der Radikalfänger Trolox zum Einsatz. Die Zellkulturen wurden unmittelbar vor den optischen Analysen für 12-14 Stunden mit Trolox (100 $\mu \mathrm{M})$ inkubiert. Üblicherweise erfolgte dies als eine Inkubation über Nacht, so dass nur verschiedene Populationen von Kontrollzellen und Trolox behandelten Zellen miteinander verglichen werden konnten. Auf zellulärer Ebene betrug nach Trolox Behandlung die Mitochondrienanzahl pro Astrozyt bei den Wildtyp-Astrozyten mit 53,4 \pm 31 Mitochondrien pro Zelle $(\mathrm{n}=8)$ und bei den $M e c p 2^{-/ y}$-Astrozyten 69,0 \pm 42 Stück pro Zelle $(\mathrm{n}=17)$. Wildtyp- und $M e c p 2^{-/ y}$-Astrozyten waren in Trolox nicht signifikant verschieden, aber beide hatten jeweils signifikant weniger Mitochondrien als die nicht behandelten Wildtyp- und $M e c p 2^{-/ y}$-Astrozyten. Die Mitochondrienlänge wich nicht signifikant zwischen Wildtyp- und $M e c p 2^{-/ y}$-Astrozyten voneinander ab, war aber nach Trolox-Behandlung jeweils geringfügig kleiner als zu nicht behandelten Wildtyp- und Mecp2 $2^{-/ y}$-Astrozyten (Abbildung 14A). Die JC-1-Ratio (rot/grün) betrug bei den in Trolox inkubierten Wildtyp-Astrozyten 109,3 $\pm 31(\mathrm{n}=8)$ und unterschied sich statistisch nicht von Mecp $2^{-/ y}$-Astrozyten 94,0 $\pm 26(\mathrm{n}=17$; Abbildung 14B) oder den unbehandelten Kontrollzellen.

Da der Radikalfänger Trolox nur in sehr geringen Konzentrationen zuverlässig wasserlöslich ist, wurde diese Substanz zunächst in DMSO gelöst. Daher wurde im Rahmen dieser Arbeit auch eine mögliche Auswirkung des Lösungsmittels DMSO selbst geprüft, indem auch hier eine entsprechende Übernacht-Inkubation $(0,13 \%)$ stattfand. Bei der eingehenden Analyse zeigte sich, dass der Zusatz von DMSO keine signifikanten Auswirkungen auf die Mitochondrienanzahl pro Astrozyt, die Mitochondrienlänge oder die JC-1-Ratio hatte (Abbildung 14).

\subsection{Einfluss verschiedener mitochondrialer Inhibitoren}

Da der Hippocampus der $M e c p 2^{-/ y}$-Mäuse eine höhere Anoxievulnerabilität als der Wildtyp-Hippocampus aufzeigt (Fischer et al. 2009), liegt der Gedanke nahe, dass die Mitochondrien empfindlicher für Hypoxie oder anderen mitochondrialen Stress sind. Dies könnte in Anbetracht der Atemstörungen im Rett-Syndrom und der assoziierten systemischen Hypoxie den Krankheitsverlauf erleichtern oder sogar vorantreiben. Daher wurden im Rahmen dieser Arbeit auch gezielt Versuche durchgeführt, die den 
Einfluss verschiedener mitochondrialer Inhibitoren auf Wildtyp- und Mecp $2^{-/ y}$ Astrozyten vergleichen und mögliche genotypische Unterschiede aufdecken sollten. Zum Einsatz kamen hierbei FCCP, Natriumcyanid und Oligomycin (siehe Kapitel 2, Tabelle 2). Diese Messungen fanden als paarige Analysen statt, wobei die Zellen zunächst unter Kontrollbedinungen (ACSF) und anschließend nach erfolgter pharmakologischer Behandlung erneut optisch analysiert wurden.

FCCP (Carbonylcyanid-4-(trifluoromethoxy)-phenylhydrazon) ist ein sogenannter Entkoppler. Durch den Einbau von Protonenkanälen in die innere Mitochondrienmembran werden die Mitochondrien nahezu vollständig depolarisiert. Daraus resultiert eine maximale Stimulation der Atmungskette (Cotton et al. 1981). Bei Applikation von FCCP $(1 \mu \mathrm{M}, 5 \mathrm{~min})$ zeigte bezogen auf Kontrollbedingungen sich eine deutliche Verminderung der JC-1-Ratio um 62,7 $\pm 25 \%(\mathrm{n}=29)$ in Wildtyp-Astrozyten, was eine ausgeprägte Depolarisation der Mitochondrien anzeigt. Das Ausmaß dieser Depolarisation war in Wildtyp- und Mecp $2^{-/ y}$-Astrozyten identisch (Abbildung 13A).

A

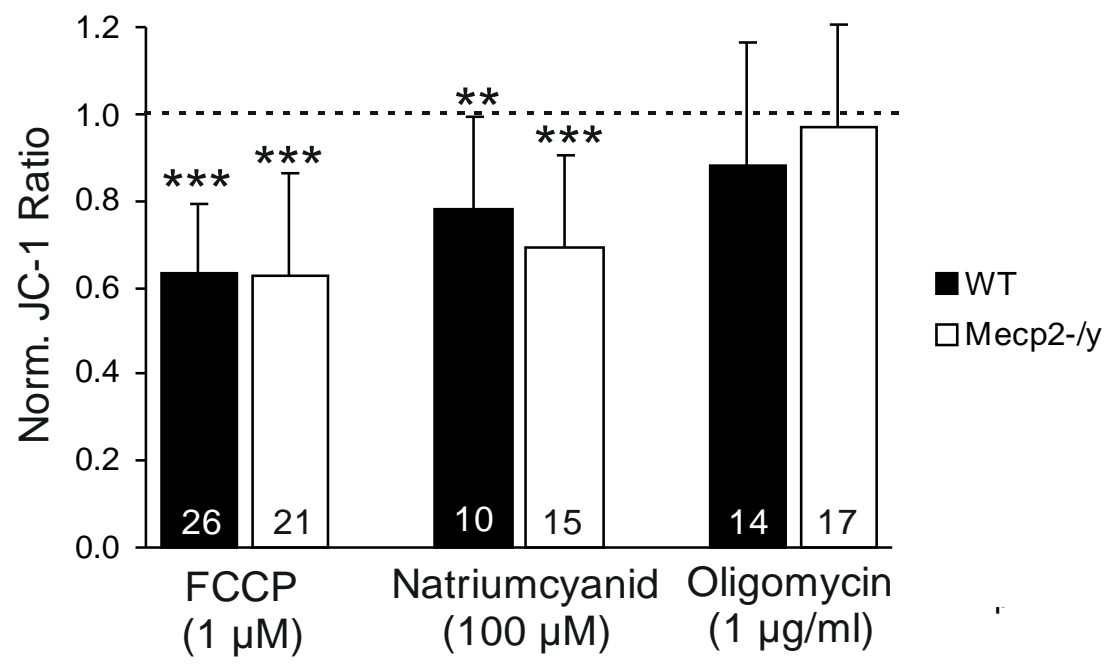



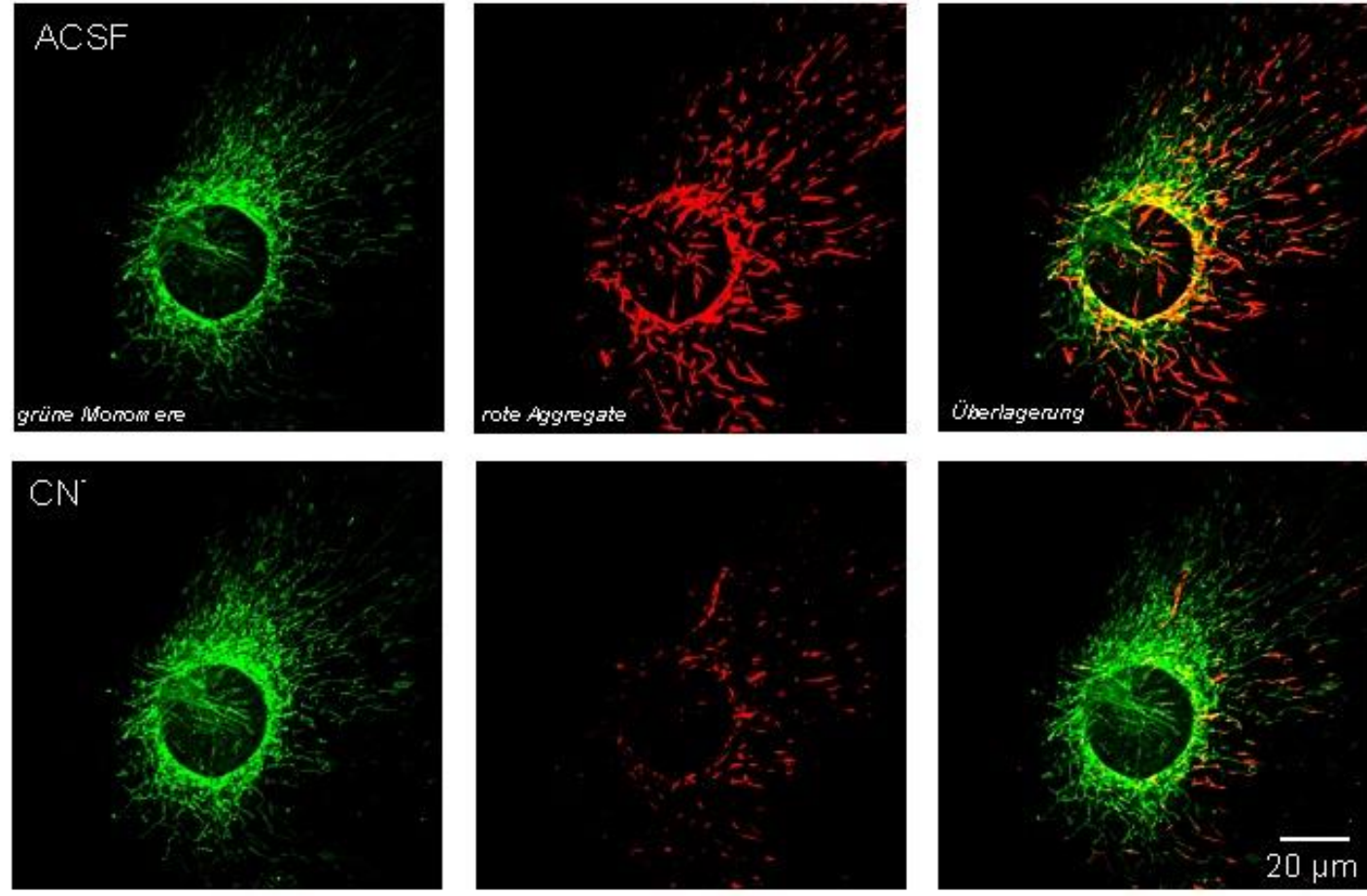

Abbildung 16: JC-1-Ratio von Wildtyp- und Mecp2 $2^{-/ y}$-Astrozyten nach pharmakologischer Inhibition sowie Beispielaufnahmen von Astrozyten unter Kontrollbedingungen sowie nach Natriumcyanidbehandlung

A) Das Diagramm stellt die JC-1-Ratio (jeweils normiert auf den Kontrollzustand mit ACSF vor der Behandlung) mit FCCP, Natriumcyanid sowie Oligomycin dar. Die morphologischen Analysen offenbarten keine genotypischen Unterschiede in der Wirkung der getesteten Inhibitoren auf das Membranpotential.

B) Vergleichende Beispielaufnahmen von Mecp2 ${ }^{-/ y}$-Astrozyten unter Kontrollbedingungen nach Natriumcyanidbehandlung ( $\mathrm{NaCN}, 100 \mu \mathrm{M}, 5 \mathrm{~min}$ ), das die Depolarisation von Mitochondrien reduziert. Gezeigt sind jeweils die grünen JC-1Monomere und roten Aggregate sowie deren Überlagerung.

Natriumcyanid ist ein Inhibitor von Komplex IV der Atmungskette, der trotz der Anwesenheit von Sauerstoff die oxidative Phosphorylierung zum Erliegen bringt und so die Bedingungen einer chemischen Anoxie hervorruft. Die Applikation von Natriumcyanid (100 $\mu \mathrm{M}, 5 \mathrm{~min})$ führte ebenfalls zu einer deutlichen Depolarisation der Mitochondrien; bei den Wildtyp-Astrozyten verminderte sich die JC-1-Ratio um 73,9 $\pm 19 \%$ und bei den Mecp $2^{-/ y}$-Astrozyten 66,4 $\pm 23 \%(\mathrm{n}=10$; Abbildung 16A). Diese Verschiebung des Fluoreszenzverhältnisses von rot-emittierenden JC-1Aggregaten zu den grün fluoreszierenden Monomeren zeigt sich auch eindrucksvoll in den 2-Photonen-Aufnahmen eines Mecp2 $2^{-/ y}$-Astrozyten in Abbildung $16 \mathrm{~B}$. Genotypische Unterschiede waren auch bei der Cyanid-induzierten Depolarisation der Mitochondrien nicht zu erkennen. 
Oligomycin ist ein Inhibitor der ATP-Synthase, der deren F0-Untereinheit blockiert. Zugabe von Oligomycin $(10 \mu \mathrm{g} / \mathrm{ml}, 5 \mathrm{~min})$ führte $\mathrm{zu}$ keinen signifikanten Veränderungen der JC-1-Ratio in Wildtyp- oder Mecp $2^{-/ y}$-Astrozyten (Abb. 16A). Neben den Potentialeffekten wurden auch Veränderungen der Mitochondrienmorphologie und -anzahl untersucht, die in Abbildung 17 zusammengefasst und statistisch verglichen wurden. Dabei zeigte sich jedoch, dass weder FCCP noch Natriumcyanid zu signifikanten Veränderungen der Mitochondrienanzahl pro Zelle führt. Lediglich bei Oligomycin war eine geringe Verminderung der Mitochondrienanzahl in $M e c p 2^{-/ y}$-Astrozyten zu verzeichnen. Änderungen der Mitochondrienlänge waren häufiger zu beobachten. Diese können insbesondere dann auftreten, wenn der mitochondriale Metabolismus oder die mitochondriale Polarisation durch Pharmaka stark moduliert werden. Dementsprechend führten FCCP in Wildtypen, Natriumcyanid in $M e c p 2^{-/ y}$-Astrozyten und Oligomycin in beiden Genotypen zu moderaten Verkürzungen der Mitochondrienlänge (Abbildung 17B).

A

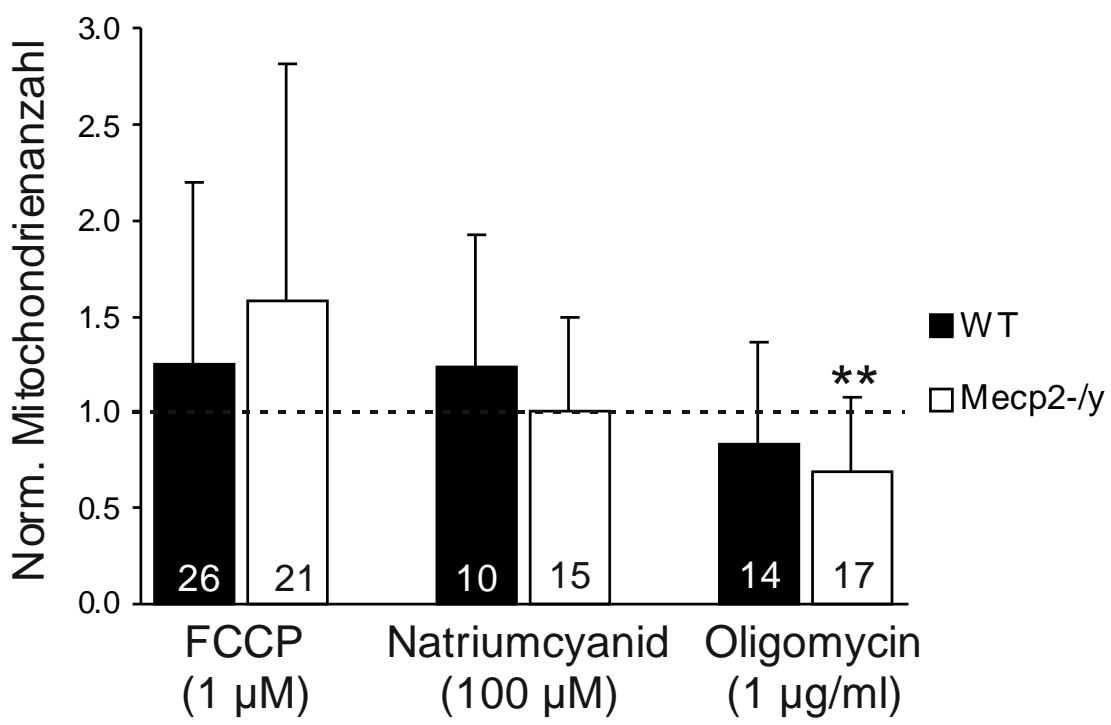


B

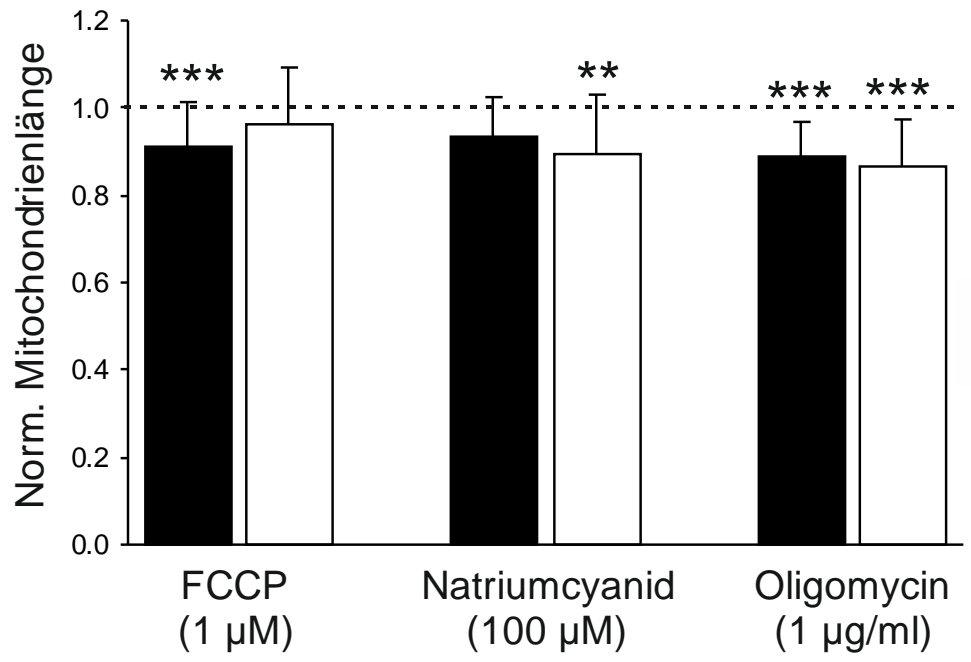

Abbildung 17: Statistischer Vergleich der Mitochondrienanzahl und -länge nach Blockade des Mitochondrienmetabolismus

A) Das Diagramm zeigt die normierte Mitochondrienanzahl nach der Behandlung mit FCCP, Natriumcyanid und Oligomycin.

B) Darstellung der normierten Mitochondrienlänge. Die Angaben sind jeweils normiert auf den Kontrollzustand (ACSF) vor der Behandlung. Die Anzahl der analysierten Zellen ist in Diagramm A und B identisch. 


\section{Diskussion}

Im Rahmen dieser Arbeit wurden optische Analysen der Mitochondrien von Wildtypund $M e c p 2^{-/ y}$-Mäusen durchgeführt, um mitochondriale Veränderungen im RettSyndrom weiter untersuchen $\mathrm{zu}$ können. Bereits in vorherigen Arbeiten wurden mitochondriale Störungen im Rett-Syndrom beschrieben, die offenbar zum Krankheitsverlauf beitragen oder diesem sogar kausal zu Grunde liegen könnten (Coker und Melnyk 1991; Cornford et al. 1994; Dotti et al. 1993; Filosa et al. 2015; Gold et al. 2014; Mak et al. 1993; Müller und Can 2014).

Die Mitochondrienanalysen erfolgten mittels eines 2-Photonen-Laser-ScanningMikroskops (TPSLM) und der Verwendung des Mitochondienfarbstoffs JC-1 als emissionsratiometrischer Ansatz. Die prinzipielle Verfahrensweise und der Ansatz der 2-Photonen-Imagings mit JC-1 wurde bereits zuvor von der Arbeitsgruppe getestet und verifiziert (Keil et al. 2011). Für die Versuche in dieser Arbeit wurde allerdings ein neues 2-Photonen-Laser-Scanning-Mikroskop verwendet, das durch den individuellen Zusammenbau eine höhere Flexibilität und Effizienz ermöglichte. Bevor die eigentlichen Versuche durchgeführt werden konnten, erfolgten zunächst Kalibrierungstests mit standardisierten Mikrokügelchen, sogenannten beads. Durch Ermittlung der maximal erreichbaren Auflösung und die Wahl des optimalen Objektivs konnten die Mitochondrien anschließend problemlos optisch dargestellt werden. Bei den Analysen handelte es sich dabei nicht nur um reine 2-PhotonenMikroskopie. Durch Verrechnung der zwei Detektionskanäle (PMT 2 = rot: 617/73 nm und PMT 1 = grün: 525/50 nm) konnten emissionsratiometrische Analysen durchgeführt werden. Dies erlaubt die Quantifizierung der hier eingesetzten JC-1Fluoreszenz und somit die Quantifizierung der Mitochondrienpolarisation. Der Mitochondrienmarker JC-1 erlaubt es bekanntlich, nicht nur Mitochondrien optisch darzustellen, sondern auch ihre Membranpotentialveränderungen zuverlässig zu erfassen (Reers et al. 1991; Reers et al. 1995).

Im Vergleich zum 2-Photonen-Laser-Scanning-Mikroskop ermöglichen elektronenmikroskopische Aufnahmen eine viel höhere optische Auflösung. Durch den Einsatz der Elektronenmikroskopie wurden in vorherigen Arbeiten anderer Gruppen Detailveränderungen im Feinbau der Mitochondrien, wie z.B. Matrixveränderungen 
beschrieben (Ruch et al. 1989; Eeg-Olofsson et al. 1988). Allerdings kann hiermit kein lebendes Gewebe dargestellt werden und somit sind keine funktionellen Aussagen möglich. Gerade an diesen funktionellen Aussagen liegt somit der große Vorteil der 2Photonen-Laser-Scanning-Mikroskopie.

Es gibt verschiedene Farbstoffe, die Veränderungen des Mitochondrienpotentials anzeigen ((Salvioli et al. 1997; Foster et al. 2006), siehe Kapitel 1.4). JC-1 ist allerdings der einzige emissionsratiometrische Farbstoff, der sich durch eine gute Sensitivität bei Membranpotentialenunterschieden auszeichnet und den es zum Zeitpunkt dieser Arbeit für derartige Mitochondrienanalysen gab. Mittlerweile ist eine noch weiter optimierte Version dieses Farbstoffes erhältlich. Dieser weiterentwickelte Mitochondrienmarker trägt die Bezeichnung JC-10 und bildet genauso wie JC-1 grüne Monomere bei niedrigen Membranpotentialen und formt rote Aggregate bei Hyperpolarisation. JC-10 hat den Vorteil einer höheren Lösbarkeit und kann daher gut eingesetzt werden, wenn höhere Konzentrationen erwünscht sind (Angaben des Herstellers Abcam). Ein Kritikpunkt bei JC-1 ist, dass bei J-Aggregatbildung nur die grünen Monomere oder die roten Aggregate zu finden sind, ohne dass eine richtige Überlappung vorliegt. Dies könnte echte subregionale Unterschiede imMembranpotential reflektieren oder es könnten unterschiedliche JC-1-Gleichgewichtsverhältnisse und somit unterschiedliche Aggregationsformatverhältnisse in subzellulären Regionen vorliegen. (Perry et al. 2011). Die Kinetik bei schnellen Membranpotentialänderunugen ist bei JC-1 im Gegensatz $\mathrm{zu}$ den anderen Mitochondrienmarkern ohne Aggregatbildung (z.B. R123) verlangsamt (Mathur et al. 2000, Keil et al. 2011). Diese Gegebenheiten sollten bei der Anwendung von JC-1 berücksichtigt werden.

Sowohl Neurone als auch Gliazellen sind im Rett-Syndrom von der MECP2-Mutation betroffen (Armstrong 2005; Ballas et al. 2009; Lioy et al. 2011). Neurone haben eine höhere Stoffwechselaktivität und weisen gegebenenfalls deutlichere Veränderungen auf. Allerdings sind Mitochondrien in Neuronen nicht so gut als individuelle Partikel zu identifizieren, da sie kumulierter vorliegen. Zudem sind Neurone kleiner als Gliazellen. Diese Umstände würden Analysen von Mitochondrien deutlich erschweren. Deswegen wurden in dieser Arbeit Gliazellen (Astrozyten) zur Analyse von Mitochondrien gewählt. 
In vorherigen Arbeiten der Arbeitsgruppe wurde bereits in hippocampalen Schnitten von $M e c p 2^{-/ y}$-Mäusen im Alter von P7-P10 gezeigt, dass die FAD/NADHAutofluoreszenz verändert ist, was auf einen intensivierten mitochondrialen Metabolismus hinweisen könnte (Grosser et al. 2012). Weiterhin sind auch in kultivierten hippocampalen Schnittkulturen Redox-Veränderungen nachgewiesen worden. Die Redox-Baseline ist unter Ruhebedingungen oxidierter und die zelluläre Redox-Homöostase ist in hippocampalen $M e c p 2^{-/ y}$-Zellen vulnerabler. Interessanterweise ist dies bereits im neonatalen Stadium der Fall. Dies wurde aber nicht explizit für Gliazellen gezeigt, sondern eher für eine Mischpopulation von Gliazellen und Neuronen (Grosser et al. 2012). Es treten demnach sehr früh Änderungen auf, die zum Teil bereits in den ersten Tagen ausgeprägt werden. Hieraus ergibt sich die Frage, ob dies auch in den Gliazellen der Fall ist und ob es auch in dissoziierten Zellkulturen sichtbar ist.

Zunächst fanden Versuche unter Kontrollbedinungen in ACSF statt. Es wurde neonatales Gewebe (P2-P6) untersucht, solches Gewebe, bevor die Mecp2 ${ }^{-\gamma y}$-Mäuse symptomatisch werden. Analysen aus Vorexperimenten durch andere Arbeitsgruppenmitglieder zeigten, dass die Mecp $2^{-/ y}$-Mäuse erst ab circa Tag 20 offensichtlich symptomatisch werden (Janc 2015). Ab diesem Tag verlangsamt sich das Wachstum und die im Rett-Syndrom beschriebenen Atemprobleme beginnen (Johnson et al. 2015; Katz et al. 2009; Stettner et al. 2007). Bei den Versuchen dieser Arbeit zeigten sich in den neonatalen kultivierten Zellen strukturell keine Veränderungen der Mitochondrien und auch die Polarisation der Mitochondrien war nicht betroffen. Dies suggeriert, dass $\mathrm{zu}$ dem sehr frühen Zeitpunkt möglicherweise noch keine ausgeprägten Veränderung in Mitochondrien von Gliazellen zu erkennen sind. Die Mitochondrien von Neuronen im Rett-Syndrom wurden im Rahmen dieser Arbeit aus oben genannten Gründen nicht untersucht.

Die durchgeführten quantitativen Analysen ergaben zudem, dass die Mitochondrien von Astrozyten im Hippocampus von $M e c p 2^{-/ y}$-Mäusen zahlreicher sind, sich aber nicht in Größe und Membranpotential unterscheiden. Da die Mitochondrien sich nicht in ihrer Größe unterscheiden und auch ein Einfluss der Zellgröße ausgeschlossen werden konnte, könnte diese auf eine mögliche mitochondriale Massenzunahme in Mecp $2^{-/ y}$-Astrozyten hinweisen. Auch durch die ebenfalls bestimmte 
Gesamtmitochondrienmasse absolut und normiert auf die Zellgröße wurde dies bestätigt, dass es sich somit um eine Massenzunahme handelt. Die Mitochondrienmassenzunahme könnte eine kompensatorische Reaktion sein, um andere mitochondriale Defizite ausgleichen zu können (Menzfeld et al. 2014).

Im adulten Hippocampus von Rett-Mäusen (P50) konnte in nachfolgenden Arbeiten mittels biochemischer Proteinanalytik (Western-Blots) keine mitochondriale Massenzunahme in symptomatischen Mecp $2^{-/ y}$-Tieren nachgewiesen werden (Menzfeld et al. 2014). Diese Analysen erfolgten jedoch am kompletten Mischgewebe aus Neuronen und Gliazellen. Es könnte daher sein, dass die in dieser Arbeit beobachtete mitochondriale Mengenzunahme nur in Gliazellen auftritt oder aber nur auf das neonatale Zeitfenster beschränkt ist. Dies ist bedeutsam, da sie in neonatalen Tieren und somit bereits vor der Symptomatik auftritt. Dennoch gilt zu bedenken, dass die vorliegende Arbeit an Zellkulturen durchgeführt wurde und somit nicht der realen Situation entspricht. Die theoretische Erklärungsmöglichkeit wäre, dass aufgrund der Methodik der Analysendurchführung eine lockerere Verteilung der Mitochondrien in Mecp $2^{-/ y}$-Astrozyten dazu geführt hat, dass in diesen Zellen mehr Mitochondrien detektiert werden konnten (semiautomatisch). Dies ist damit zumindest partiell entkräftet, da dieser Auswertungseffekt bei Bestimmung der Gesamtmitochondrienmasse nicht zum Tragen käme. Eine vergleichbare Analyse am intakten neonatalen Gewebe ist nicht vorhanden, da im Gewebeverband eine sinnvoll JC-1-Färbung aufgrund zu hoher Hintergrundfluoreszenz nicht durchführbar ist..

Vorversuche haben bestätigt, dass das Rett-Syndrom mit oxidativem Stress einhergeht. Dabei sind die Mitochondrien die wesentlichen zellulären Produzenten von ROS (reaktive Sauerstoffspezies) in den Zellen (Grosser et al. 2012; Felice et al. 2012). ROS entstehen als normale Nebenprodukte der mitochondrialen Atmungskette. Sie können Schäden in Proteinen, Lipiden und Nukleinsäuren verursachen sowie dadurch das Überleben der Zellen verkürzen. Durch das Beseitigen dieser ROS mithilfe sogenannter Radikalfänger können Schäden in den Zellen reduziert werden (Hamad et al. 2010; Cadenas 1989). Ebenfalls wurden im Rett-Syndrom erniedrigte Vitamin-ESpiegel im Blutserum nachgewiesen (Formichi et al. 1998) sowie eine verminderte Aktivität des ROS-Entgiftungsenzyms Superoxiddismutase (Sierra et al. 2001). Auch 
diese Nachweise unterstreichen die Annahme, dass das Rett-Syndrom mit erhöhten oxidativem Stress eingeht.

Um bereits vorhandene Daten zu stützen, wurden die Effekte des fettlöslichen Radikalfängers Trolox (6-Hydroxy-2,5,7,8-tetramethylchroman-2-carbonsäure) untersucht. Trolox ist ein Vitamin-E Derivat und kann aufgrund seiner antioxidativen Eigenschaften mögliche Auswirkungen von oxidativen Stress reduzieren. Weiterhin wurde in anderen Versuchen der Arbeitsgruppe gezeigt, dass Trolox in adulten hippocampalen Schnitten die Hypererregbarkeit dämpft (Janc und Müller 2014). Zudem wird durch die Behandlung mit Trolox die synaptische Plastizität verbessert, was in Anbetracht der kognitiven Verschlechterung im Rett-Syndrom eine bedeutende Rolle spielen könnte. Es zeigte sich auch eine Verbesserung der Hypoxie-Toleranz im Mecp $2^{-/ y}$-Hippocampus (Janc und Müller 2014).

Nach Inkubation des Vitamin-E-Derivats Trolox zeigte sich kein signifikanter Effekt auf das Membranpotential oder die Größe der Mitochondrien. Dennoch verringerte es die Anzahl von Mitochondrien pro Zelle und beseitigte die genotypischen Unterschiede, die zuvor in Astrozyten beobachtet worden sind. Nachteilige Effekte bei der Verwendung von Trolox auf das mitochondriale Membranpotential wurden nicht beobachtet.

Um eventuelle Einflüsse des Lösungsmittels DMSO zu überprüfen, wurden weiterhin entsprechende Kontrollversuche durchgeführt. Es konnten hierbei keine störenden Auswirkungen nachgewiesen werden. Bei Interpretation dieser Analysen und Stützung auf die Ergebnisse weiterer Versuche könnte die Stabilisierung der zellulären RedoxBalance durch Chemikalien mit antioxidativen Eigenschaften, wie beispielsweise Trolox, als lohnenswertes Ziel der Behandlung des Rett-Syndroms betrachtet werden (Müller und Can 2014).

Im Rahmen dieser Arbeit wurden mögliche Veränderungen bei Einsatz verschiedener Pharmaka untersucht. Die Analysen nach Behandlung mit FCCP ergaben, wie zu erwarten war, eine starke Depolarisation der Mitochondrien. FCCP provoziert einen „Kurzschluss“, der die Potentialdifferenz über der inneren Mitochondrienmembran aufhebt (Cotton et al. 1981). Auch zeigte sich eine moderate Verkürzung der Wildtyp- 
Mitochondrien unter FCCP. Es wurden bereits strukturelle Änderungen der Mitochondrien unter FCCP beschrieben. Mitunter kommt es unter FCCP zu einer Fragmentierung der Mitochondrien (Suen et al. 2008; Cereghetti et al. 2010). Dies könnte eine Abnahme der Mitochondrienlänge oder zumindest deren Tendenz zur Abnahme erklären. Auch Natriumcyanid depolarisierte nachweislich die Mitochondrien, indem es die Blockade von Komplex IV der Atmungskette initiiert.

Zur weiteren Untersuchung kam das Modulans Oligomycin zum Einsatz. Oligomycin blockiert die $\mathrm{F}_{0}$-Untereinheit der ATPase und schließt somit das physiologische Protonenleck, das grundlegend die Protonenpumpe antreibt. Hierdurch erfolgt eine leichte Hyperpolarisation der Mitochondrien. Diese Veränderungen sollten theoretisch $\mathrm{zu}$ einer geringen Rot-Verschiebung der JC-1-Ratio führen, aber oftmals ist die Membranpotentialveränderung zu gering, um sie zu detektieren. Nach der Behandlung mit Oligomycin zeigte sich eine Veränderung der Mitochondrienanzahl bei $M e c p 2^{-/ y}$ Astrozyten. Es wurden weniger Organellen detektiert als bei den Wildtyp-Astrozyten. Dies ist durch mögliche Bleichung und Aufschwellung oder eine mögliche mitochondriale Fusion zu erklären (Legros et al. 2002).

Zusätzlich wurde die Aufmerksamkeit auf die Anzahl der Mitochondrien nach pharmakologischer Behandlung gerichtet. Diese weiterführenden Analysen ergaben weder bei Wildtyp- noch bei $M e c p 2^{-/ y}$-Astrozyten eine signifikante Änderung der Mitochondrienanzahl bei den mit FCCP und Natriumcyanid behandelten Astrozyten. Unter der Behandlung mit Oligomycin zeigte sich, wie bereits im vorherigen Absatz erwähnt, eine geringe Verminderung der Mitochondrienanzahl in Mecp $2^{-/ y}$-Astrozyten.

Mit Blick auf die Mitochondrienlänge zeigte sich, dass diese bei Oligomycin sowohl bei Wildtyp- als auch bei $M e c p 2^{-/ y}$-Astrozyten geringfügig kürzer wurde. Bei Natriumcyanid waren nur Mecp $2^{-/ y}$-Mitochondrien kürzer. Nach Behandlung mit FCCP zeigte sich eine Verkürzung bei den Wildtyp-Mitochondrien. Eindeutige genotypische Veränderungen waren bei keinem der Parameter (Länge und Membranpotential) nach der Drogenbehandlung zu erkennen. Es zeigten sich nur Unterschiede bei der Mitochondrienanzahl zwischen Wildtyp- und Mecp $2^{-/ y}$ Mitochondrien unter Kontrollbedingungen. Deswegen ist davon auszugehen, dass zumindest für die getesteten pharmakologischen Behandlungen die $M e c p 2^{-/ y_{-}}$ 
Astrozyten keine offensichtlich von den Wildtypen unterschiedliche Vulnerabilität aufweisen. Es wurden jedoch ziemlich starke Stimuli verwendet. Dabei wurden nur einzelne Konzentrationen eingesetzt und keine Dosis-Wirkung-Kurven erstellt. Letzteres wäre auch im Rahmen der hier angewandten Methoden nicht durchführbar, sondern müsste durch eine automatisierte High-through-put-Analysen erfolgen.

Zusammenfassend betrachtet, bestätigten die Analysen auf funktioneller Ebene zum einen bereits bestehende Kenntnisse. Sie ergänzten jedoch auch weitere Erkenntnisse, wobei der Fokus speziell auf Gliazellen gerichtet wurde. Dabei wurde eine mitochondriale Massenzunahme im Hippocampus von Mecp $2^{-/ y}$-Astrozyten aufgezeigt. Sowohl absolut als auch normiert ließ sich ein genotypischer Unterschied der mitochondrialen Masse nachweisen. Diese Tatsache bestätigt, dass Gliazellen klare Veränderungen im präsymptomatischen Alter im Rett-Syndrom zeigen. Diese mitochondrialen Veränderungen können eventuell zum Krankheitsverlauf beitragen. Trolox zeigte keine negativen Effekte auf Mitochondrien, was für den Einsatz von Radikalfängern als therapeutisches Konzept bei der Behandlung des Rett-Syndroms von Interesse sein dürfte. 


\section{$5 \quad$ Zusammenfassung und Ausblick}

Ziel dieser Arbeit war es, eine vergleichende Analyse der Mitochondrien von Wildtypund $M e c p 2^{-/ y}$-Mäusen mit Bezug auf die Länge, das Membranpotential und die Anzahl dieser Organellen durchzuführen. Darüber hinaus sollten mögliche Effekte verschiedener Entkoppler der Atmungskette (FCCP) und Zellgifte (Natriumcyanid, Oligomycin) analysiert werden, um damit gezielt metabolischen und/oder pharmakologischen Stress auf die Mitochondrien und ihre Stoffwechselprozesse auszuïben. Da Mitochondrien aufgrund ihrer Verteilung gut in flach gewachsenen Astrozyten darzustellen sind, wurden Zellkulturen aus dem Hippocampus von Wildtyp- und $M e c p 2^{-/ y}$-Mäusen gewonnen.

Zunächst wurden Kalibrierungstests mit dem hier verwendeten 2-Photonen-LaserScanning-Mikroskop durchgeführt, um anschließend Analysen von Mitochondrien durchführen zu können. Zum Einsatz kam der Mitochondrienmarker JC-1, der speziell Membranpotentialunterschiede angibt.

Die detaillierten subzellulären Analysen ergaben keine Unterschiede in der Mitochondrienlänge und im Membranpotential. Allerdings waren die Mitochondrien zahlreicher in $M e c p 2^{-/ y}$-Astrozyten als in Wildtyp-Astrozyten. Mit Blick auf vorherige Arbeiten der Arbeitsgruppe könnte dies auf einen intensivierten mitochondrialen Metabolismus zurückzuführen sein (Grosser et al. 2012). Der Einsatz von Trolox hob die zuvor unter Kontrollbedingungen festgestellten Unterschiede zwischen Wildtypund $M e c p 2^{-/ y}$-Astrozyten auf und stellt somit als Antioxidans einen möglichen Behandlungsansatz dar. Nachteilige Effekte zeigten sich bei der Behandlung mit Trolox nicht. Genotypische Unterschiede nach der Behandlung mit Inhibitoren konnten nicht nachgewiesen werden.

Von zukünftigem Interesse wäre der Einsatz des weiterentwickelten Mitochondrienmarkers JC-10, der erst seit kurzem erhältlich ist. Die detaillierte Untersuchung der Mitochondrien von Neuronen könnte ein weiterer interessanter Aspekt für die Erforschung des Rett-Syndroms sein. 


\section{Anhang}

\subsection{Abbildungsverzeichnis}

Abbildung 1: Entwicklungsstadien und klinische Symptome des Rett-Syndroms ........ 4

Abbildung 2: Darstellung der chemisch-osmotischen Grundlagen zur Steuerung der oxidativen Phosphorylierung in Mitochondrien ....

Abbildung 3: Beeinträchtigung der mitochondrialen oxidativen im Rett-Syndrom, Down-Syndrom und bei autistischen Störungen

Abbildung 4: Chemische Struktur des Mitochondrienfarbstoffs 5,5',6,6'-tetrachloro$1,1^{`}, 3,3^{`}$-tetraethylbenzimidazolocarbocyanine Jodid (JC-1) ..................................... 14

Abbildung 5: 2-Photonenaufnahmen eines mit JC-1-gefärbten Astrozyten.................. 23

Abbildung 6: Aufbau des optischen Messsystems ..................................................... 25

Abbildung 7: Schematische Darstellung der TPLSM ................................................. 27

Abbildung 8: Darstellung der theoretischen Auflösung bei unterschiedlichen Objektiven

Abbildung 9: Darstellung der normalisierten point spread function (PSF) in den verschiedenen Achsen mittels 100-nm-Beads ........................................................... 34

Abbildung 10: 3-D Rekonstruktionen der point spread function (PSF) ...................... 35

Abbildung 11: Schematischer Ablauf der Mitochondrienanalyse................................. 39

Abbildung 12: Beispielaufnahmen von mit JC-1-markierten Mitochondrien von

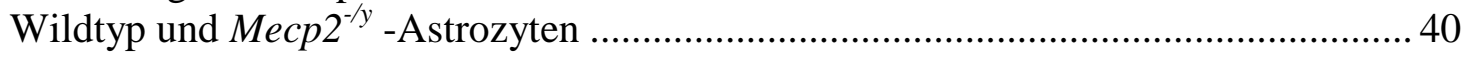

Abbildung 13: Mitochondrienlänge und JC-1-Ratio bei normalen

Versuchsbedingungen in ACSF

Abbildung 14: Darstellung der Mitochondrienlänge, der JC-1-Ratio und der Mitochondriananzahl pro Zelle in ACSF, Trolox und DMSO.

Abbildung 15: Darstellung der absoluten sowie normierten Mitochondrienmasse ..... 43

Abbildung 16: JC-1-Ratio von Wildtyp- und Mecp $2^{-/ y}$-Astrozyten nach pharmakologischer Inhibition sowie Beispielaufnahmen von Astrozyten unter Kontrollbedingungen sowie nach Natriumcyanidbehandlung 45

Abbildung 17: Statistischer Vergleich der Mitochondrienanzahl und -länge nach Blockade des Mitochondrienmetabolismus.

\subsection{Tabellenverzeichnis}

Tabelle 1: Zusammenfassung der Reagenzien inklusive Lieferanten 19

Tabelle 2: Verwendete pharmakologische Inhibitoren und Radikalfänger

Tabelle 3: Parameter des Lasermikroskops 
Tabelle 4: Verifizierung von Scanfeldgröße und Pixelgröße anhand des 20x-, 40x- und 63x- Objektivs mithilfe normierter Beads 36

\subsection{Abkürzungsverzeichnis}

ACSF

CDKL5-Gen

$\mathrm{CN}$

DMSO

FCCP

FWHM

HBSS

IR

JC-1

$\mathrm{KO}$

$\mathrm{MeCP} 2$

$\mathrm{Mecp}^{-/ \mathrm{y}}$

NA

OMC

PSF

ROS

TPLSM

VIS

WT

$\lambda$ artifizielle zerebrospinale Flüssigkeit

cyclin-dependent kinase-like-5-Gen

(Natrium-)Cyanid

Dimethylsulfoxid

Carbonylcyanid-4-(trifluoromethoxy)phenylhydrazon

full width of half maximum (Halbwertsbreite)

Hanks balanced salt solution

infrarot

5,5',6,6'-Tetrachloro-1,1',3,3'-

Tetraethylbenzimidazolylcarbocyanine Iodid

knockout

methyl $C p G$ binding protein 2, vom $M E C P 2-G e n$ kodiertes Protein

Maus-Modell des Rett-Syndroms, MeCP2-Maus, männliches Tier

numerische Apertur

Oligomycin

point spread function

reaktive Sauerstoffspezies

2-Photonen-Laser-Scanning-Mikroskop

visible

Wildtyp

Wellenlänge 


\section{Literaturverzeichnis}

Amir RE, van den Veyver IB, Wan M, Tran CQ, Francke U, Zoghbi HY (1999): Rett syndrome is caused by mutations in X-linked MECP2, encoding methyl-CpG-binding protein 2. Nat Genet $\underline{23}, 185-188$

Armstrong DD (2005): Neuropathology of Rett syndrome. J Child Neurol 20, 747-753

Ballas N, Lioy DT, Grunseich C, Mandel G (2009): Non-cell autonomous influence of MeCP2-deficient glia on neuronal dendritic morphology. Nat Neurosci 12, 311-317

Banerjee A, Castro J, Sur M (2012): Rett syndrome: genes, synapses, circuits, and therapeutics. Front Psychiatry $\underline{3}, 34$

Belichenko PV, Wright EE, Belichenko NP, Masliah E, Li HH, Mobley WC, Francke U (2009): Widespread changes in dendritic and axonal morphology in Mecp2-mutant mouse models of Rett syndrome: evidence for disruption of neuronal networks. $\mathrm{J}$ Comp Neurol 514, 240-258

Bereiter-Hahn J, Voth M (1994): Dynamics of mitochondria in living cells: shape changes, dislocations, fusion, and fission of mitochondria. Microsc Res Tech 27, 198 219

Cadenas E (1989): Biochemistry of oxygen toxicity. Annu Rev Biochem 58, 79-110

Castro J, Garcia RI, Kwok S, Banerjee A, Petravicz J, Woodson J, Mellios N, Tropea D, Sur M (2014): Functional recovery with recombinant human IGF1 treatment in a mouse model of Rett Syndrome. Proc Natl Acad Sci U S A 111, 9941-9946

Cereghetti GM, Costa V, Scorrano L (2010): Inhibition of Drp1-dependent mitochondrial fragmentation and apoptosis by a polypeptide antagonist of calcineurin. Cell Death Differ 17, 1785-1794

Chahrour M, Zoghbi HY (2007): The story of Rett syndrome: from clinic to neurobiology. Neuron 56, 422-437

Chahrour M, Jung SY, Shaw C, Zhou X, Wong STC, Qin J, Zoghbi HY (2008): MeCP2, a Key Contributor to Neurological Disease, Activates and Represses Transcription. Science (New York, N.Y.) $\underline{320}$, 1224-1229

Chapleau CA, Lane J, Larimore J, Li W, Pozzo-Miller L, Percy A (2013): Recent progress in Rett syndrome and $M E C P 2$ dysfunction: assessment of potential treatment options. Future Neurol $\underline{8}, 21-28$

Chen RZ, Akbarian S, Tudor M, Jaenisch R (2001): Deficiency of methyl-CpG binding protein-2 in CNS neurons results in a Rett-like phenotype in mice. Nat Genet 27, 327-331

Coker SB, Melnyk AR (1991): Rett syndrome and mitochondrial enzyme deficiencies. J Child Neurol $\underline{6}, 164-166$

Collins TJ, Bootman MD (2003): Mitochondria are morphologically heterogeneous within cells. J Exp Biol 206, 1993-2000

Cornford ME, Philippart M, Jacobs B, Scheibel AB, Vinters HV (1994):

Neuropathology of Rett syndrome: case report with neuronal and mitochondrial abnormalities in the brain. J Child Neurol $\underline{9}, 424-431$

Cossarizza A, Baccarani-Contri M, Kalashnikova G, Franceschi C (1993): A new method for the cytofluorimetric analysis of mitochondrial membrane potential using 
the J-aggregate forming lipophilic cation 5,5',6,6'-tetrachloro-1,1',3,3'tetraethylbenzimidazolcarbocyanine iodide (JC-1). Biochem Biophys Res Commun $\underline{197}, 40-45$

Cotton NP, Clark AJ, Jackson JB (1981): The effect of venturicidin on light and oxygen-dependent electron transport, proton translocation, membrane potential development and ATP synthesis in intact cells of Rhodopseudomonas capsulata Arch Microbiol. 129, 94-99

Dedov VN, Cox GC, Roufogalis BD (2001): Visualisation of mitochondria in living neurons with single- and two-photon fluorescence laser microscopy. Micron $\underline{32}$, 653660

Denk W, Strickler JH, Webb WW (1990): Two-photon laser scanning fluorescence microscopy. Science 248, 73-76

Derecki NC, Cronk JC, Lu Z, Xu E, Abbott SBG, Guyenet PG, Kipnis J (2012): Wildtype microglia arrest pathology in a mouse model of Rett syndrome. Nature $\underline{484}, 105$ 109

Diaspro A, Bianchini P, Vicidomini G, Faretta M, Ramoino P, Usai C (2006): Multiphoton excitation microscopy. Biomed Eng Online $\underline{5}, 36$

Dotti MT, Manneschi L, Malandrini A, Stefano N de, Caznerale F, Federico A (1993): Mitochondrial dysfunction in Rett syndrome. An ultrastructural and biochemical study. Brain Dev 15, 103-106

Dragich J, Houwink-Manville I, Schanen C (2000): Rett syndrome: a surprising result of mutation in MECP2. Hum Mol Genet $\underline{9}$, 2365-2375

Duchen MR, Surin A, Jacobson J (2003): Imaging mitochondrial function in intact cells. Methods Enzymol 361, 353-389

Eeg-Olofsson O, al-Zuhair AG, Teebi AS, al-Essa MM (1988): Abnormal mitochondria in the Rett syndrome. Brain Dev 10, 260-262

Egger J, Hofacker N, Schiel W, Holthausen H (1992): Magnesium for hyperventilation in Rett's syndrome. Lancet $\underline{340}$, 621-622

Ellaway CJ, Peat J, Williams K, Leonard H, Christodoulou J (2001): Medium-term open label trial of L-carnitine in Rett syndrome. Brain Dev 23 Suppl 1, S85-9

Felice C de, Signorini C, Leoncini S, Pecorelli A, Durand T, Valacchi G, Ciccoli L, Hayek J (2012): The role of oxidative stress in Rett syndrome: an overview. Ann N Y Acad Sci 1259, 121-135

Filosa S, Pecorelli A, DEspositoc M, Valacchi G, Hajek J (2015): Exploring the possible link between MeCP2 and oxidative stress in Rett syndrome. Free Radic Biol Med $\underline{88}, 81-90$

Fischer M, Reuter J, Gerich FJ, Hildebrandt B, Hagele S, Katschinski D, Müller M (2009): Enhanced hypoxia susceptibility in hippocampal slices from a mouse model of rett syndrome. J Neurophysiol 101, 1016-1032

Forlani G, Giarda E, Ala U, Di Cunto F, Salani M, Tupler R, Kilstrup-Nielsen C, Landsberger N (2010): The MeCP2/YY1 interaction regulates ANT1 expression at 4q35: novel hints for Rett syndrome pathogenesis. Hum Mol Genet 19, 3114-3123

Formichi P, Battisti C, Dotti MT, Hayek G, Zappella M, Federico A (1998): Vitamin E serum levels in Rett syndrome. J Neurol Sci 156, 227-230 
Foster KA, Galeffi F, Gerich FJ, Turner DA, Müller M (2006): Optical and pharmacological tools to investigate the role of mitochondria during oxidative stress and neurodegeneration. Prog Neurobiol 79, 136-171

Gibson JH, Slobedman B, K N H, Williamson SL, Minchenko D, El-Osta A, Stern JL, Christodoulou J (2010): Downstream targets of methyl CpG binding protein 2 and their abnormal expression in the frontal cortex of the human Rett syndrome brain. BMC Neurosci 11, 53

Gill H, Cheadle JP, Maynard J, Fleming N, Whatley S, Cranston T, Thompson EM, Leonard H, Davis M, Christodoulou J et al. (2003): Mutation analysis in the MECP2 gene and genetic counselling for Rett syndrome. J Med Genet 40, 380-384

Gold WA, Williamson SL, Kaur S, Hargreaves IP, Land JM, Pelka GJ, Tam PPL, Christodoulou J (2014): Mitochondrial dysfunction in the skeletal muscle of a mouse model of Rett syndrome (RTT): implications for the disease phenotype.

Mitochondrion 15, 10-17

Göppert-Mayer M (1931): Über Elementarakte mit zwei Quantensprüngen. Ann. Phys $\underline{9}, 273-294$

Grosser E, Hirt U, Janc OA, Menzfeld C, Fischer M, Kempkes B, Vogelgesang S, Manzke TU, Opitz L, Salinas-Riester G et al. (2012): Oxidative burden and mitochondrial dysfunction in a mouse model of Rett syndrome. Neurobiol Dis $\underline{48}$, $102-114$

Guy J, Hendrich B, Holmes M, Martin JE, Bird A (2001): A mouse Mecp2-null mutation causes neurological symptoms that mimic Rett syndrome. Nat Genet 27, $322-326$

Hagberg B (1985): Rett syndrome: Swedish approach to analysis of prevalence and cause. Brain Dev $\underline{7}, 276-280$

Hagberg B, Witt-Engerstrom I (1986): Rett syndrome: a suggested staging system for describing impairment profile with increasing age towards adolescence. Am J Med Genet Suppl 1 , 47-59

Hagberg B, Aicardi J, Dias K, Ramos O (1983): A progressive syndrome of autism, dementia, ataxia, and loss of purposeful hand use in girls: Rett's syndrome: report of 35 cases. Ann Neurol 14, 471-479

Hagberg B, Berg M, Steffenburg U (2001): Three decades of sociomedical experiences from West Swedish Rett females 4-60 years of age. Brain Dev 23 Suppl 1, S28-31

Hamad I, Arda N, Pekmez M, Karaer S, Temizkan G (2010): Intracellular scavenging activity of Trolox (6-hydroxy-2,5,7,8-tetramethylchromane-2-carboxylic acid) in the fission yeast, Schizosaccharomyces pombe. J Nat Sci Biol Med 1, 16-21

Hirt U: Extramitochondriale und mitochondriale Produktion reaktiver Sauerstoffspezies im Hippocampus MeCP2-defizienter Mäuse. Med. Diss. Göttingen 2014

Janc OA: Pharmacotreatment of a mouse model of Rett syndrome with the radical scavenger Trolox: Detailed assessment of potential merits in vitro and in vivo. Naturwissenschaftl. Diss. Göttingen 2015

Janc OA, Müller M (2014): The free radical scavenger Trolox dampens neuronal hyperexcitability, reinstates synaptic plasticity, and improves hypoxia tolerance in a mouse model of Rett syndrome. Front Cell Neurosci $\underline{8}, 56$ 
Johnson CM, Cui N, Zhong W, Oginsky MF, Jiang C (2015): Breathing abnormalities in a female mouse model of Rett syndrome. J Physiol Sci 65, 451-459

Katz DM, Dutschmann M, Ramirez J, Hilaire G (2009): Breathing disorders in Rett syndrome: progressive neurochemical dysfunction in the respiratory network after birth. Respir Physiol Neurobiol 168, 101-108

Keil VC, Funke F, Zeug A, Schild D, Müller M (2011): Ratiometric high-resolution imaging of JC-1 fluorescence reveals the subcellular heterogeneity of astrocytic mitochondria. Pflügers Arch $\underline{462}$, 693-708

Kerr AM, Armstrong DD, Prescott RJ, Doyle D, Kearney DL (1997): Rett syndrome: analysis of deaths in the British survey. Eur Child Adolesc Psychiatry 6 Suppl 1, 7174

Khwaja OS, Ho E, Barnes KV, O'Leary HM, Pereira LM, Finkelstein Y, Nelson CA3, Vogel-Farley V, DeGregorio G, Holm IA et al. (2014): Safety, pharmacokinetics, and preliminary assessment of efficacy of mecasermin (recombinant human IGF-1) for the treatment of Rett syndrome. Proc Natl Acad Sci U S A 111, 4596-4601

Kriaucionis S, Paterson A, Curtis J, Guy J, Macleod N, Bird A (2006): Gene expression analysis exposes mitochondrial abnormalities in a mouse model of Rett syndrome. Mol Cell Biol 26, 5033-5042

Kron M, Zimmermann JL, Dutschmann M, Funke F, Müller M (2011): Altered responses of MeCP2-deficient mouse brain stem to severe hypoxia. J Neurophysiol $\underline{105}, 3067-3079$

Kurtz R, Fricke M, Kalb J, Tinnefeld P, Sauer M (2006): Application of multiline twophoton microscopy to functional in vivo imaging. J Neurosci Methods $\underline{151}, 276-286$

Landi S, Putignano E, Boggio EM, Giustetto M, Pizzorusso T, Ratto GM (2011): The short-time structural plasticity of dendritic spines is altered in a model of Rett syndrome. Sci Rep $\underline{1}, 45$

Legros F, Lombes A, Frachon P, Rojo M (2002): Mitochondrial fusion in human cells is efficient, requires the inner membrane potential, and is mediated by mitofusins. Mol Biol Cell $\underline{13}, 4343-4354$

Li Y, Wang H, Muffat J, Cheng AW, Orlando DA, Loven J, Kwok S, Feldman DA, Bateup HS, Gao Q et al. (2013): Global transcriptional and translational repression in human-embryonic-stem-cell-derived Rett syndrome neurons. Cell Stem Cell 13, 446458

Lioy DT, Garg SK, Monaghan CE, Raber J, Foust KD, Kaspar BK, Hirrlinger PG, Kirchhoff F, Bissonnette JM, Ballas N et al. (2011): A role for glia in the progression of Rett's syndrome. Nature $\underline{475}, 497-500$

Lobsiger CS, Cleveland DW (2007): Glial cells as intrinsic components of non-cellautonomous neurodegenerative disease. Nat Neurosci 10, 1355-1360

Lotan M (2007): Alternative therapeutic intervention for individuals with Rett syndrome. ScientificWorldJournal ㄱ, 698-714

Maezawa I, Jin L (2010): Rett syndrome microglia damage dendrites and synapses by the elevated release of glutamate. J Neurosci $\underline{30}$, 5346-5356

Maffei S, Felice C de, Cannarile P, Leoncini S, Signorini C, Pecorelli A, Montomoli B, Lunghetti S, Ciccoli L, Durand T et al. (2014): Effects of omega-3 PUFAs 
supplementation on myocardial function and oxidative stress markers in typical Rett syndrome. Mediators Inflamm 2014, 983178

Mak SC, Chi CS, Chen CH, Shian WJ (1993): Abnormal mitochondria in Rett syndrome: one case report. Zhonghua Yi Xue Za Zhi (Taipei) 52, 116-119

Mari F, Azimonti S, Bertani I, Bolognese F, Colombo E, Caselli R, Scala E, Longo I, Grosso S, Pescucci C et al. (2005): CDKL5 belongs to the same molecular pathway of $\mathrm{MeCP} 2$ and it is responsible for the early-onset seizure variant of Rett syndrome. Hum Mol Genet 14, 1935-1946

Mathur A, Hong Y, Kemp BK, Barrientos AA, Erusalimsky JD (2000): Evaluation of fluorescent dyes for the detection of mitochondrial membrane potential changes in cultured cardiomyocytes. Cardiovasc Res $\underline{46}$, 126-138

Matsuishi T, Urabe F, Percy AK, Komori H, Yamashita Y, Schultz RS, Ohtani Y, Kuriya N, Kato H (1994): Abnormal carbohydrate metabolism in cerebrospinal fluid in Rett syndrome. J Child Neurol $\underline{9}, 26-30$

McArthur AJ, Budden SS (1998): Sleep dysfunction in Rett syndrome: a trial of exogenous melatonin treatment. Dev Med Child Neurol 40, 186-192

McBride HM, Neuspiel M, Wasiak S (2006): Mitochondria: more than just a powerhouse. Curr Biol 16, R551-60

Menzfeld C, Janc OA, Dudek J, Rehling P, Müller M (2014): Mitochondrial dysfunction in Rett syndrome viewed from the biochemical perspective. 13th Rett Syndrome Symposium, Chantilly, VA, abstract, 78

Mitchell P (1961): Coupling of phosphorylation to electron and hydrogen transfer by a chemi-osmotic type of mechanism. Nature 191, 144-148

Mitchell P (1979): Keilin's respiratory chain concept and its chemiosmotic consequences. Science 206, 1148-1159

Monteiro CB, Savelsbergh GJ, Smorenburg AR, Graciani Z, Torriani-Pasin C, Abreu LC de, Valenti VE, Kok F (2014): Quantification of functional abilities in Rett syndrome: a comparison between stages III and IV. Neuropsychiatr Dis Treat $\underline{10}$, $1213-1222$

Moretti P, Levenson JM, Battaglia F, Atkinson R, Teague R, Antalffy B, Armstrong D, Arancio O, Sweatt JD, Zoghbi HY (2006): Learning and memory and synaptic plasticity are impaired in a mouse model of Rett syndrome. J Neurosci 26, 319-327

Mount RH, Hastings RP, Reilly S, Cass H, Charman T (2001): Behavioural and emotional features in Rett syndrome. Disabil Rehabil 23, 129-138

Müller M, Can K (2014): Aberrant redox homoeostasis and mitochondrial dysfunction in Rett syndrome. Biochem Soc Trans $\underline{42}$, 959-964

Müller M, Schmidt J, Mironov SL, Richter DW (2003): Construction and performance of a custom-built two-photon laser scanning system. J. Phys. D: Appl. Phys. $\underline{36}$, 17471757

Nasse MJ, Woehl JC, Huant S (2007): High-resolution mapping of the threedimensional point spread function in the near-focus region of a confocal microscope. Appl. Phys. Lett. 무, 31106

Nguyen MVC, Du F, Felice CA, Shan X, Nigam A, Mandel G, Robinson JK, Ballas N (2012): MeCP2 is critical for maintaining mature neuronal networks and global brain 
anatomy during late stages of postnatal brain development and in the mature adult brain. J Neurosci 32, 10021-10034

Nguyen MVC, Felice CA, Du F, Covey MV, Robinson JK, Mandel G, Ballas N (2013): Oligodendrocyte lineage cells contribute unique features to Rett syndrome neuropathology. J Neurosci $\underline{33}$, 18764-18774

Nomura Y, Segawa M (2005): Natural history of Rett syndrome. J Child Neurol 20 , $764-768$

Ormazabal A, Artuch R, Vilaseca MA, Aracil A, Pineda M (2005): Cerebrospinal fluid concentrations of folate, biogenic amines and pterins in Rett syndrome: treatment with folinic acid. Neuropediatrics $\underline{36}, 380-385$

Percy AK, Glaze DG, Schultz RJ, Zoghbi HY, Williamson D, Frost JD, JR, Jankovic JJ, del Junco D, Skender M, Waring S (1994): Rett syndrome: controlled study of an oral opiate antagonist, naltrexone. Ann Neurol 35, 464-470

Perry SW, Norman JP, Barbieri J, Brown EB, Gelbard HA (2011): Mitochondrial membrane potential probes and the proton gradient: a practical usage guide.

Biotechniques $\underline{50}, 98-115$

Poot M, Zhang YZ, Kramer JA, Wells KS, Jones LJ, Hanzel DK, Lugade AG, Singer VL, Haugland RP (1996): Analysis of mitochondrial morphology and function with novel fixable fluorescent stains. J Histochem Cytochem 44, 1363-1372

Reers M, Smith TW, Chen LB (1991): J-aggregate formation of a carbocyanine as a quantitative fluorescent indicator of membrane potential. Biochemistry $\underline{30}$, 4480-4486

Reers M, Smiley ST, Mottola-Hartshorn C, Chen A, Lin M, Chen LB (1995):

Mitochondrial membrane potential monitored by JC-1 dye. Methods Enzymol 260, 406-417

Rett A (1966): Über ein eigenartiges hirnatrophisches Syndrom bei Hyperammonämie im Kindesalter. Wien Med Wochenschr 116, 723-726

Ruch A, Kurczynski TW, Velasco ME (1989): Mitochondrial alterations in Rett syndrome. Pediatr Neurol $\underline{5}, 320-323$

Salvioli S, Ardizzoni A, Franceschi C, Cossarizza A (1997): JC-1, but not DiOC6(3) or rhodamine 123 , is a reliable fluorescent probe to assess $\Delta \mathrm{Y}$ changes in intact cells: implications for studies on mitochondrial functionality during apoptosis. FEBS Lett $\underline{411}, 77-82$

Sanmann JN, Schaefer GB, Buehler BA, Sanger WG (2012): Algorithmic approach for methyl-CpG binding protein 2 (MECP2) gene testing in patients with neurodevelopmental disabilities. J Child Neurol 27, 346-354

Saywell V, Viola A, Confort-Gouny S, Le Fur Y, Villard L, Cozzone PJ (2006): Brain magnetic resonance study of Mecp2 deletion effects on anatomy and metabolism. Biochem Biophys Res Commun $\underline{340}$, 776-783

Shetty PK, Galeffi F, Turner DA (2012): Cellular Links between Neuronal Activity and Energy Homeostasis. Front Pharmacol $\underline{3}, 43$

Sierra C, Vilaseca MA, Brandi N, Artuch R, Mira A, Nieto M, Pineda M (2001):

Oxidative stress in Rett syndrome. Brain Dev 23 Suppl 1, S236-9

Signorini C, Felice C de, Leoncini S, Durand T, Galano J, Cortelazzo A, Zollo G,

Guerranti R, Gonnelli S, Caffarelli C et al. (2014): Altered erythrocyte membrane fatty 
acid profile in typical Rett syndrome: Effects of omega-3 polyunsaturated fatty acid supplementation. Prostaglandins Leukot Essent Fatty Acids 91, 183-193

Sims PJ, Waggoner AS, Wang CH, Hoffman JF (1974): Studies on the mechanism by which cyanine dyes measure membrane potential in red blood cells and phosphatidylcholine vesicles. Biochemistry $\underline{13}, 3315-3330$

Smiley ST, Reers M, Mottola-Hartshorn C, Lin M, Chen A, Smith TW, Steele GD, JR., Chen LB (1991): Intracellular heterogeneity in mitochondrial membrane potentials revealed by a J-aggregate-forming lipophilic cation JC-1. Proc Natl Acad Sci U S A $\underline{88}, 3671-3675$

Stettner GM, Huppke P, Brendel C, Richter DW, Gärtner J, Dutschmann M (2007):

Breathing dysfunctions associated with impaired control of postinspiratory activity in Mecp $2^{-/ y}$ knockout mice. J Physiol 579, 863-876

Suen D, Norris KL, Youle RJ (2008): Mitochondrial dynamics and apoptosis. Genes Dev 22, 1577-1590

Trappe R, Laccone F, Cobilanschi J, Meins M, Huppke P, Hanefeld F, Engel W (2001): MECP2 mutations in sporadic cases of Rett syndrome are almost exclusively of paternal origin. Am J Hum Genet $\underline{68}$, 1093-1101

Tropea D, Giacometti E, Wilson NR, Beard C, McCurry C, Fu DD, Flannery R, Jaenisch R, Sur M (2009): Partial reversal of Rett Syndrome-like symptoms in MeCP2 mutant mice. Proc Natl Acad Sci U S A 106, 2029-2034

Valenti D, Bari L de, Filippis B de, Henrion-Caude A, Vacca RA (2014):

Mitochondrial dysfunction as a central actor in intellectual disability-related diseases: an overview of Down syndrome, autism, Fragile X and Rett syndrome. Neurosci Biobehav Rev 46 Pt 2, 202-217

Villard L (2007): MECP2 mutations in males. J Med Genet 44

Weaving LS, Christodoulou J, Williamson SL, Friend KL, McKenzie OLD, Archer H, Evans J, Clarke A, Pelka GJ, Tam PPL et al. (2004): Mutations of CDKL5 cause a severe neurodevelopmental disorder with infantile spasms and mental retardation. Am J Hum Genet 75, 1079-1093

Weaving LS, Ellaway CJ, Gecz J, Christodoulou J (2005): Rett syndrome: clinical review and genetic update. J Med Genet $\underline{42}, 1-7$

Williamson SL, Christodoulou J (2006): Rett syndrome: new clinical and molecular insights. Eur J Hum Genet 14, 896-903

\section{Internetquellen}

http://edisonpharma.com/wpcontent/files_mf/1409757666RettSyndromepressrelease140903.pdf; Zugriff am 25.09.2015

http://www.abcam.com/jc-10-mitochondrial-membrane-potential-assay-kitmicroplate-ab112134.html; Zugriff am 05.11.2015 


\section{Danksagung}

Ich danke Herrn Prof. Dr. rer. nat. Michael Müller für die interessante Aufgabenstellung und kompetente Betreuung während meiner Promotionsphase. Er stand mir stets mit Rat und Tat zur Seite und war jederzeit bei Fragen und Problemen ein geduldiger Ansprechpartner.

Weiterhin danke ich meinen Kollegen aus der Arbeitsgruppe Müller für jeden weiteren unterstützenden Beitrag. Auch möchte ich Belinda Kempkes für ihre Einführung in Material und Methoden dieser Arbeit danken. 
